Portland State University

PDXScholar

Spring 1-1-2012

\title{
Making Education Accessible: A Dual Case Study of Instructional Practices, Management, and Equity in a Rural and an Urban NGO School in Pakistan
}

Zafreen Jaffery

Portland State University

Follow this and additional works at: https://pdxscholar.library.pdx.edu/open_access_etds

Part of the Educational Leadership Commons, Educational Sociology Commons, and the Education Policy Commons

Let us know how access to this document benefits you.

\section{Recommended Citation}

Jaffery, Zafreen, "Making Education Accessible: A Dual Case Study of Instructional Practices, Management, and Equity in a Rural and an Urban NGO School in Pakistan" (2012). Dissertations and Theses. Paper 409.

https://doi.org/10.15760/etd.409

This Dissertation is brought to you for free and open access. It has been accepted for inclusion in Dissertations and Theses by an authorized administrator of PDXScholar. Please contact us if we can make this document more accessible: pdxscholar@pdx.edu. 
Making Education Accessible: A Dual Case Study of Instructional Practices, Management, and Equity in a Rural and an Urban NGO School in Pakistan

\author{
by \\ Zafreen Jaffery
}

A dissertation submitted in partial fulfillment of the requirements for the degree of

Doctor of Education

in

Educational Leadership: Curriculum and Instruction

\author{
Dissertation Committee: \\ Emily de la Cruz, Chair \\ Christine Chaille \\ Samuel D. Henry \\ Yves Labissiere \\ Vivek Shandas
}

Portland State University

(C)2012 


\begin{abstract}
Two- thirds of Pakistan’s primary aged children are enrolled in school and less than one-third complete fifth grade. Decades after the inception of the goal of primary education for all of its children, the state is unable to fulfill its promise of providing access to universal primary education. The failure of the government to provide for a system that ensures equitable opportunities for all of its children has resulted in individuals, for-profit organizations, and non-governmental organizations (NGOs) intervening to fill the void. In particular, international donor agencies (IDAs) have come forward to provide financial aid and personnel support for primary education. There is currently a dearth of research on the work of NGO schools in Pakistan, which leaves many unanswered questions about the role of NGO schools.
\end{abstract}

Therefore, in this study, I examine the efficacy of not-for-profit, private schools managed by non-governmental organizations (NGOs) in providing quality education to primary school children in Pakistan. This study examined schools formed and supported by two NGOs in Pakistan and their impact on providing primary education. A dual case study approach involving a concentrated enquiry into two cases (a rural and an urban school) was used. The study focused on the following research question: How does an NGO school provide education to primary aged school children? Results corroborate previous key-findings that the NGO is the parent body which oversees management, provides training, mobilizes the community and generates the primary funds to run the schools. The study goes further to suggest that NGO leaders provide leverage and establish connections that are important for fund raising and creating opportunities for the 
schools to expand and work cost-efficiently. The rural NGO had created its own methodology for literacy instruction, which produced adult literate women who were then hired as primary teachers. In addition, it showed that the two schools use: (1) an eclectic approach to teaching which ranged from using public school's curriculum to local, contextually based materials to foreign British-based curriculum; (2) the shift in instructional strategies suggested movement from a behaviorist approach toward integrating constructivist methods of teaching; and (3) the flexibility in curriculum choices poses challenges as well as opportunities for growth for the teachers. These results help to frame future research by linking NGO school's instructional practices to those used in private and public school systems in Pakistan. 


\section{Dedication}

This work is dedicated to children all over the world

\& to Kaneez Sughra Haider and Professor Mirza Hussain Haider 


\section{Acknowledgements}

I am deeply grateful to Allah for the ability to work on this project.

Alhamdulillah.

I could not have been able to do this without the love, encouragement and support of my family. I want to offer deepest gratitude to my parents for providing the resources to make it happen. I want to thank my mother, Professor Zafar Hussain, for being who she is and for bringing me all the books that I could possibly read. I want to thank my father, Syed Bunyad Hussain, for setting high standards and for enabling me to pursue my dream. I want to thank my brother, Ali Hussain Syed, for being my biggest cheerleader and for visiting me. I want to thank my sister, Fatima Jaffery, for allowing me not to be there for the birth of her son as I defended my proposal. I also want to thank my nephew, Hassan Imam, for waiting patiently for eight months until I was able to see him. Thank you to my brother-in-law, Asad Imam, and sister-in-law, Mahjabeen Riaz, for being there for us. Thank you to my late paternal grandparents Rasheeda and Syed Amjad Hussain who happily bode farewell to me as I embarked on my journey and passed away as I was still working on it. I owe everything to my late maternal grandmother, Kaneez Sughra Haider, who taught me to persevere, to be resilient and to be self-reliant. Thank you. I miss you greatly.

I want to thank all the children, the teachers and administrators at the two NGO schools for so openly and honestly sharing their stories, for giving time, and for being patient with my questions. Thanks to Mudassar Sadia for transcribing data. 
I want to thank my advisor, and my committee members for listening, for helping me talk through things, for their belief in my abilities and for their consistent support. Emily de la Cruz is the most wonderful advisor a graduate student can ask for. She held me accountable, and was kind, and flexible. She has the patience of a saint and guided me carefully as I made complex decisions about my research. Thanks to Christine Chaille for setting high standards and for asking tough questions to steer this work in the right direction. I wish to express gratitude to Samuel Henry for allowing me to be two steps ahead in my thinking and for providing guidance and foresight. Thank you to Vivek Shandas for being my guru and for accepting and understanding of complexity. Thanks to Yves Labissiere for helping me to refine my understanding of key concepts.

I would like to acknowledge The Tokyo Foundation for a generous research grant offered through the Ryoichi Sasakawa Young Leaders Fellowship Fund (SYLFF) which enabled me to conduct my fieldwork in Pakistan. I want to thank Fulbright and the Institute for International Education (IIE) for the Foreign Language Teaching Assistantship that introduced me to Portland and Portland State. I want to acknowledge Anjuman Wazifa of North America for their generous support.

I remain tremendously grateful to Professor David Savage for listening to me, and for knowing me as a whole person long before I had started this journey. David and I copresented at the South Asia lecture series at PSU in 2006, where I started working on this project. I wish he had lived long enough to see how the initial idea grew to fruition. I want to thank Patricia Wetzel and Elizabeth Hengeveld for listening and for guiding me 
through every step of the way. I would not have been able to do anything without their consistent nurturing and support.

I am indebted to numerous professors in the Graduate School of Education, who helped me tremendously: Jackie Temple, Dannelle Stevens, Xiaochin Sun Irminger, Swapna Mukhopadhyay, and Andy Job. Dannelle Stevens recruited me to the program, wrote letters of support for me, and turned me into a life-long journal keeper and writer. I want to thank cohort 05 members: Dave Guile for editing my first papers, Deb Nelli, Amanda Smith Byron, Amy Juve, Jan Carpenter, Cindy Stadel, and Carol Campbell. I want to express profound gratitude to my writing partners for several years: Yoko Sakurauchi and Clare Wilkinson-Weber. Thank you for spending all those weekends writing. Other members from GSE: Anna Waters, Kathy Godfrey, Rosalyn Taylor, Serap Emil, Suad Al Azam Al Widyan, Chris Cartwright, Miki Yamashita, Ingrid Anderson , Maika Yeigh, Paulina Gutierrez and Jacqulyn Daniels provided valuable feedback. I want to thank other professors at PSU from whom I have learned so much: Linda Godson, Fred Nunn, Duncan Carter, Marcus Ingle, Kim Brown, Jean Campbell, Rosalyn McKeown Ice, Georgia Harris, Priya Kapoor, Steven Frenkel, Leopoldo Rodriguez, Martha Hickey, Keith Walters and Steven Reder. I want to thank my editors; Bryan Hull, Greg Steward, Laura Ann Burda and fellow colleagues who took the cohort research class and edited this work. Thanks to education librarian Sarah Beasly and lab assistants at the Instructional Development and Support Center lab. I am grateful to all of my teachers at Customs Public School, Lahore College for Women and Kinnaird College for Women: Amtul Hafeez Mirza, Farwa Shah, Nayyer Sultana, Durr-e- Shehwar Afzal, Shaheena Pervaiz, Gulrukh Khan Niazi, Sameena Hafeez, Era Hassan, Minnie Nathaniel, Isabel 
Williams. I am thankful to all of my students at Beaconhouse School System, Lahore and at Portland State University.

I want to thank the Office of International Affairs at Portland State University: Professor Gil Latz, Debra Clemans, Ron Witczak, Andrea Price, Todd Waddell, and Judy VanDyck for being a great team of supporters. Funding from OIA was one of the most important factors that determined my ability to work on this degree. Thank you to colleagues and advisers at OIA: Megan McLaughlin, Josh Davis, Rachel Goff, Alyse Collins, Blythe Knott, Katherine Morrow, Martha Ketcham, Sean Wilson, and Kristin Engelbretson.

I owe thanks to numerous people in Portland and in Oregon who opened the doors of their homes and hearts for me despite my short comings. I want to thank Karen F. Mundt for being the best host mom. I can never thank Carolyn Savage enough for being the best Grandma. She hosted me frequently at her house and held dinners to celebrate each of my milestones in the program. I want to thank Mohammad Saeed and Shahida of Corvallis for being my family away from home. Thank you to Saghir and Rasheeda Haider and members of my spiritual group in Portland who provided opportunity for spiritual growth and rejuvenation. This would not have been possible without the support I received from the numerous health care providers: Laila Noll, Cheryl Foster, Kacie Clawson, Nickolas Griffith, Douglas Rosario, Christine Borchert and Rene.

I want to thank each one of my numerous aunts, uncles and cousins all over the world who have continued to be the source of inspiration for me: Fizza Hussain and Abbas Hussain for visiting my parents in summers when I was unable to; a heartfelt thank you to Mohsin Haider for being there for my parents. I want to thank Fareena and 
Ali Shah, Zehra and Hassan Shah for being there for me. I want to thank Shaukat Hassan and Iftikhar Hussain for providing me with letters of support for my funding. I offer gratitude to my life-long friends: Kulsoom, Kamilah, Sadaf, Mehvish, Amina, Amna, Asma, and Yuki Kanai. My friends in Portland: Amel, Naveed, Vaqas, Hamza, Rehman, Shomaila, and Afeefah Marfani for helping me keep a sense of humor. Thank you also to my beloved nieces and nephews in town: Mano, Yusuf, Nauman, and Hassan. Thank you to friends: Mayumi Oka, Jill Scantlan, Erin Watters, Najia and Hadi Hyder, Neera Malhotra, Zahed Raza, Ayesha Wahedi, Jagdish and Allison Grewal. Thanks also to the city of Portland for the rain and the solitude that comes with it. 


\section{Table of Contents}

Abstract

Dedication

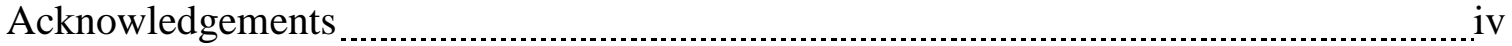

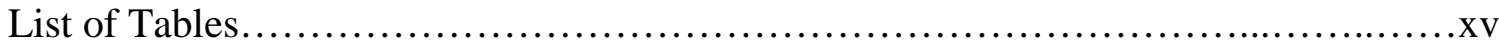

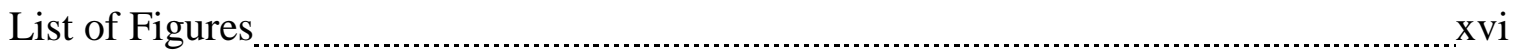

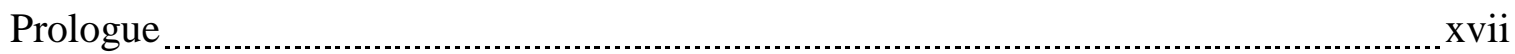

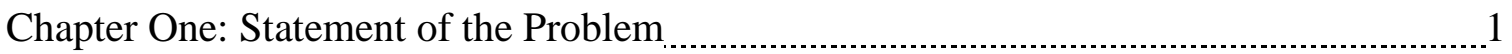

Definition of Key Terms

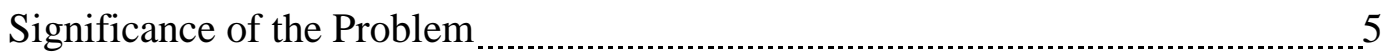

Personal Values and Identity

Theoretical Framework

Chapter Two: Literature Review

Exclusion based on economic factors: Children in poverty $\ldots 1 . \ldots$

Gender and schooling

Rural schools

Schooling in Pakistan: Types of schools $\ldots$

Learning in Public schools................................................15

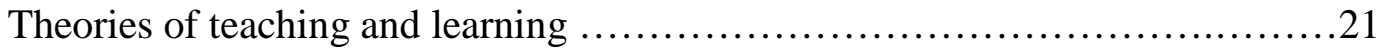

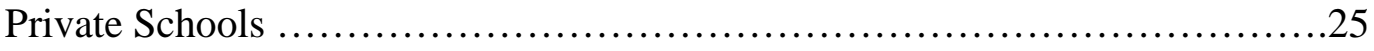

Analysis of the Studies $\ldots$

Non-Governmental Organizations $\ldots \ldots$

Types of NGOs 30

NGOs in education

NGOs for Education around the World $\ldots$

Partners in primary education: NGOs, state, and international donor agencies ..... 34

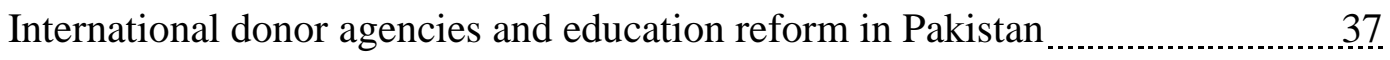


Non- Governmental Organizations for Education in Pakistan _................................ 40

Classification of NGOs for education in Pakistan _......................................... 40

NGOs' work in primary education in Pakistan _.................................................... 42

Community-based participatory approach for NGO schools: Community

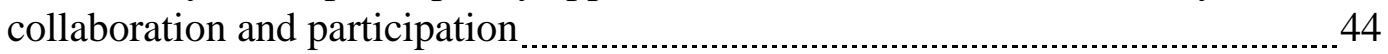

Synthesis of Literature

Chapter Three: Research Methodology

Site Selection _ 51

Site Description $\ldots$

Case study one

Case study two

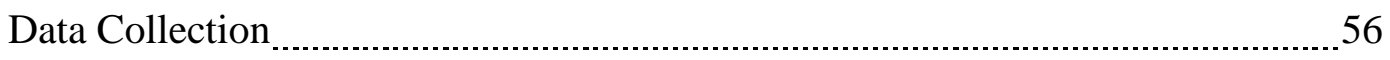

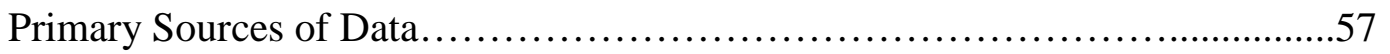

Data Collection Strategies

Analysis of Artifacts

Classroom observation

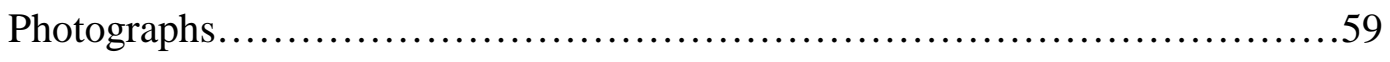

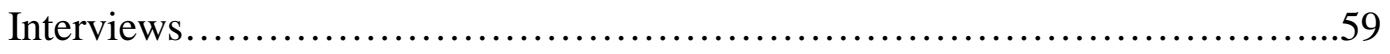

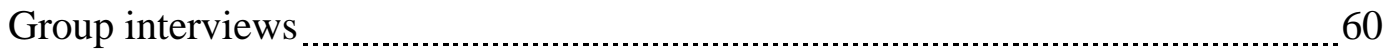

Individual Interviews

Research $\log \ldots \ldots$

Participant Recruitment $\quad 62$

Research Timeline

Data Analysis _ _ 64

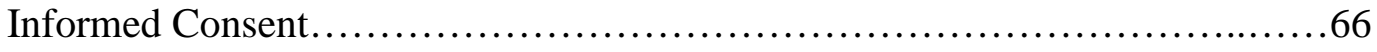

Validity

Ethical Issues 


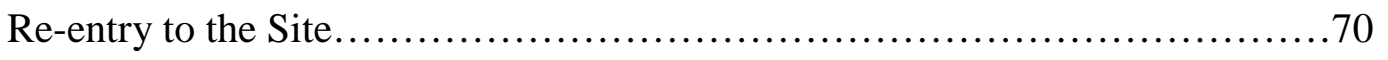

Follow-up Visit..................................................70

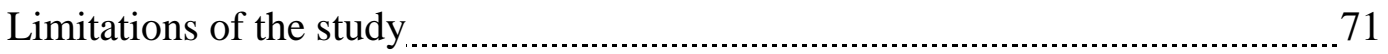

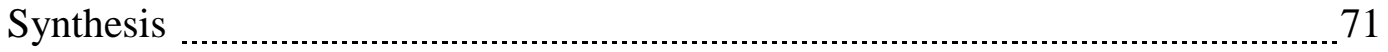

Chapter Four: Case Descriptions...........................................73

School Formation and the NGO: Kiran School and Inspire....................74

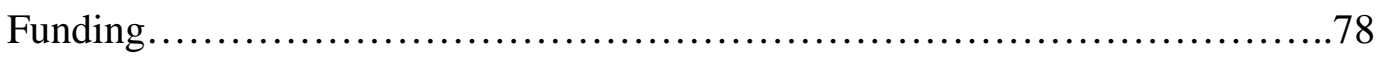

The Kiran School........................................................80

Community, occupation, geographical location...........................81

Building and facilities................................................ 82

The Participants....................................................83

The NGO founder...................................................83

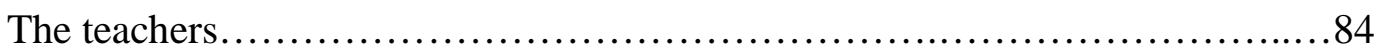

The students.......................................................... 87

The classes.......................................................... 89

Teachers’ Training: Teachers’ Literacy Manual..............................90

Teaching and Instructional Practices at Kiran School........................91

Children's Lives and Learning at Kiran School.............................96

Rice Festival at Kiran School...........................................100

School Formation and the NGO: Pathways and the Sunshine School...........102

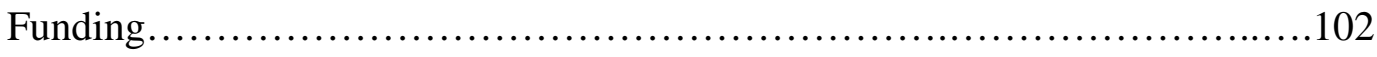

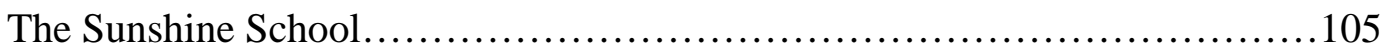

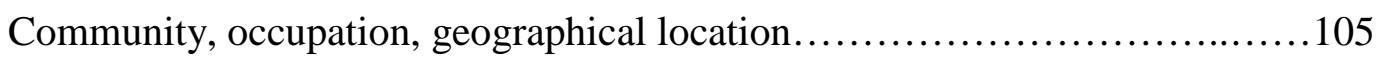

Building and facilities..............................................106

The Participants..................................................... 106

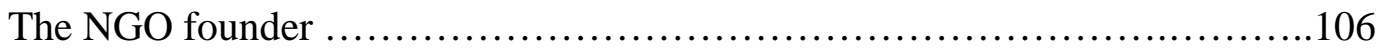




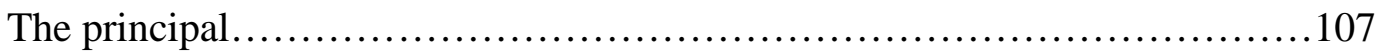

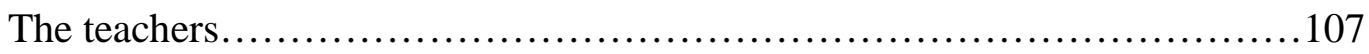

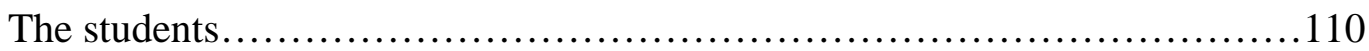

Teaching and Instructional Practices at Sunshine School......................112

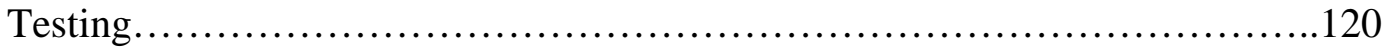

Children's Lives and Learning at Sunshine School............................122

Indian Peace Delegation at Sunshine........................................124

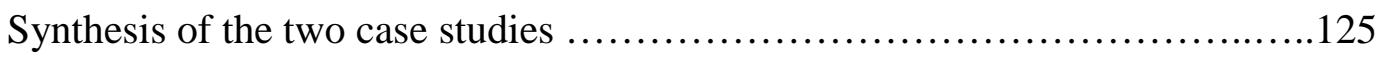

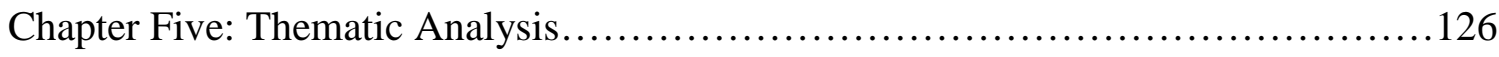

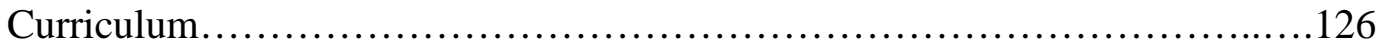

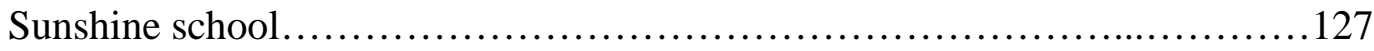

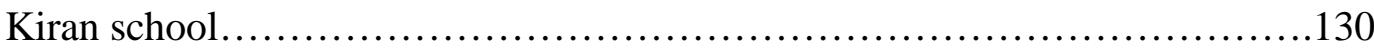

Cross Case Analysis of Curriculum.......................................130

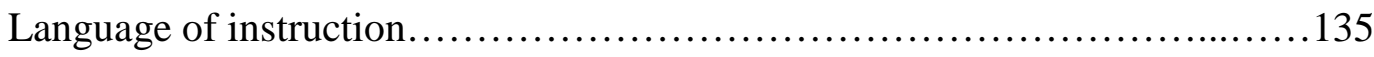

School Leadership........................................................138

NGO Pathways and Sunshine School.........................................138

NGO Inspire and Kiran School............................................142

Cross Case Analysis of School Leadership...................................147

Social class of the leaders...................................................148

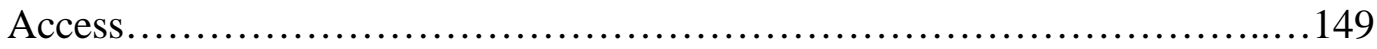

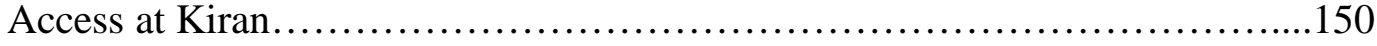

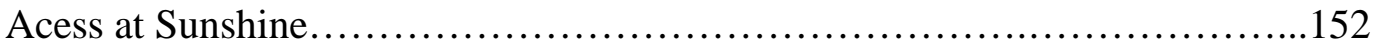

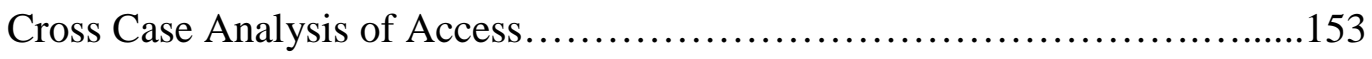

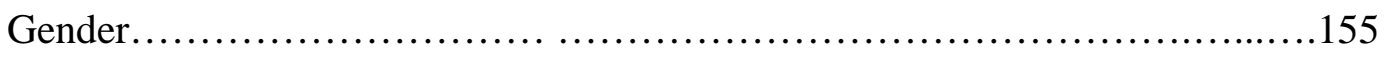

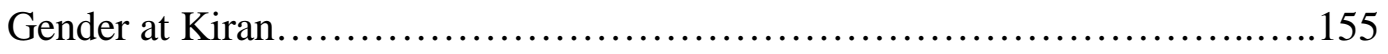

Gender at Sunshine..................................................... 157

Cross Case Analysis of Gender............................................158 
Chapter Six: Discussion....................................................... 160

Processes and Structures in Providing Quality Primary Education................160

Organizational Structures: NGOs and Leadership.............................161

Organizational structures at Kiran school...................................163

Organizational structures at Sunshine school................................164

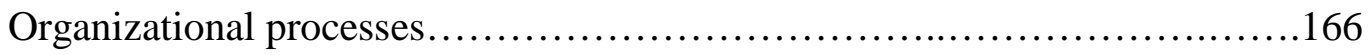

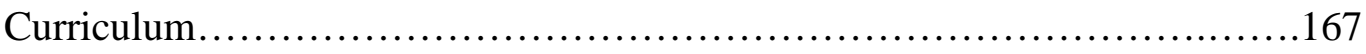

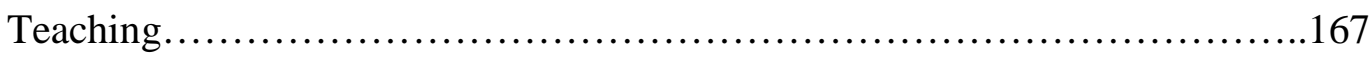

Factors and characteristics that contribute toward teaching and learning.........168

Monitoring and evaluation....................................................

Community mobilization and support for the school............................169

Staffing problems............................................................ 171

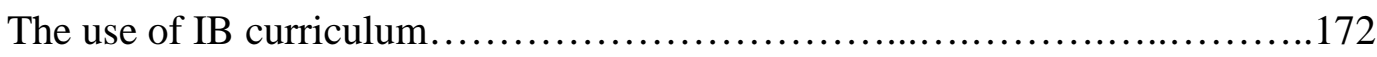

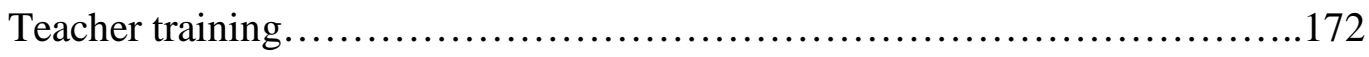

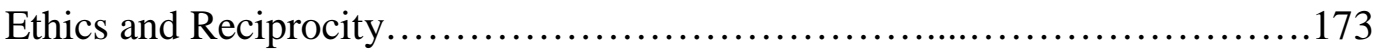

Beyond Data Collection: Epilogue..............................................175

Analysis through the lens of Critical theory ................................176

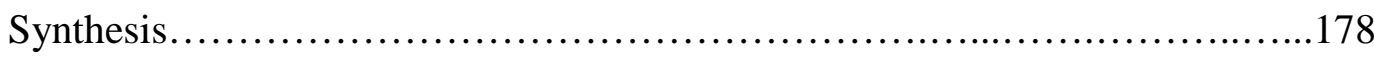

Chapter Seven: Recommendations and Implications...................................180

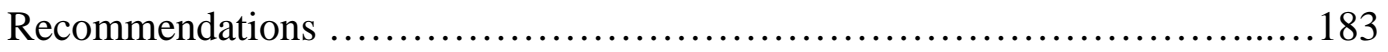

Implications for further research.........................................185

References $\ldots \ldots \ldots$

Appendices

A: Informed Consent for the NGO Administrator/ Principal _................... 198

B: Informed Consent for the Students _............................................... 200

C: Informed Consent for the Students’ Parent/Guardian _..._._._._......... 202

D: Informed Consent for the Teachers ………………………………... 204 
E: Interview Protocol \#1: Individual Interview Questions from the NGO Administrator/Principal

F: Interview Protocol \#2: Group Interview Questions from the Teachers

G: Interview Protocol \# 3: Individual Interview Questions from the Teachers

H: Interview Protocol \#4: Group Interview Questions from the Students

I: Interview Protocol \# 5: Individual Interview Questions from the Students

J: Classroom Observation Protocol

K: Research Log Protocol 


\section{List of Tables}

Table 1: Research Timeline...................................................63

Table 2: Kiran School’s Annual Operational Budget...............................79 


\section{List of Figures}

Figure 1: Types of schools in Pakistan 25

Figure 2: Partners in primary education: NGOs, State and the international donor agencies and their interaction with the communities to form schools

Figure 3: Case study one: NGO school A 54

Figure 4: Case study two: NGO school B 56

Figure 5: The dirt road that leads to Kiran school...............................81

Figure 6: Children playing in the school lawn at Kiran school......................83

Figure 7: Student work in Kiran school......................................96

Figure 8: Student work on display in Sunshine.................................117

Figure 9: Student work on display in Sunshine................................118 


\section{Prologue}

I remember my elementary school; situated in the heart of urban Lahore, it was an impressive building in an expensive commercial property area. Parents took pride in sending their children to this private, for-profit school where English was the medium of instruction. I remember riding in the school van with my friends, being on my favorite road in the world — the road that connected my house to my grandmother's. The road, named, Gulberg Main Boulevard, passed by my grandfather’s burial place, other elite schools, fancy bookstores, tempting ice cream parlors and wonderful shopping plazas. What fun and delight captured my heart whenever I rode along that road, either driven by a driver in a car or on the motorbike behind my father.

I can see in my mind's eye a huge courtyard on the left side of the school building where we gathered for the morning assembly, followed by a prayer and the national anthem. The front garden was decorated with all kinds of brightly colored (mostly red and blue) swings, monkey bars, and seesaws. There was a canteen at the left hand corner of the school where the children were served sandwiches and milk during recess. We sat on the marble chairs and tables eager for the lunch to be over so that we could go to the courtyard and play. For most, school was a happy place with colorful books, toys, friendly teachers, and playful, cheerful classmates; I was the only student who cried every morning all through kindergarten. At three, I was too young and scared to be in that place.

Almost three decades later, I am on my way to see another school, on a visit to Lahore from Portland. I have attended many schools, changed a few houses, achieved fluency in some languages, moved to a different country, and a new continent during the 
past decade. I am excited to be going to this school. It is located 65 kilometers away from my hometown, Lahore.

My mentor tells the driver to take a detour from the freeway. We pass through a noisy, crowded small city. Suddenly we are away from the hustle and bustle of the freeway and the city, and I am curious to see how the landscape has changed. It is a serene, beautiful, and picturesque morning and we are getting close to the villages of Risal Pind and Jalalpur. There is vast open space with rice and wheat fields stretching for miles on end. It seems a perfect rural heaven away from the smoke, the congestion, the pollution, and the jarring sounds of Lahore with its 10 million people. I have never seen the birds that I now see chirping gleefully in the trees. Suddenly the road disappears and the car skids on muddy pathways. We are no longer on a paved road. There are no paved roads that connect these villages to the city.

My mentor asks the driver to stop the car. She says (in Urdu), "I would like you to see this government school before you see the work of our NGO.” I am beginning to get a little uneasy with the scene in front of me but it is still perfectly serene and calm. I get out of the car. In front of me is an old brick building. It has four walls-not a remarkable fact in the U.S. but worthy of mention in this location. The windows are covered with some thickly packed fodder, perhaps to keep the inside warm. Cow dung, typically used as an alternative energy source in the villages, is plastered on the walls. A half legible sign on the wall reads in Urdu: Government Primary School Kaccha Pind. “This can not be a school,” I say to myself as my heart slowly sinks. I see a horse eating fodder in the open courtyard with no boundary walls. Two very old people, a couple, 
slightly lean and confused, who (I imagine) have been with each other through thick and thin, walk out looking at the strangers disturbing them early in the morning.

My mentor asks them, "Why are you living in a place which is government property?" She turns towards me and says, "Look! How they have turned this government school into a stable and a granary.” They mumble some words which are barely audible. I see signs that the place is inhabited by people. I think, "Maybe there are children registered at this school. Maybe there is a teacher who is drawing his monthly salary.” But there are no classes held in this building. It just bears the name of a school. It is what they call a "Ghost" school.

In the distance, I see people mounting the rooftops of their houses. Two women in a luxury car driven by a driver are quite a spectacle in this setting. We take some pictures with my digital camera and leave. We stop on our way to our destination at another school. It looks similar, animals stored inside, falling walls, and no signs of a teacher, chairs, desks, or students anywhere. "Have you not talked to anybody from the Ministry of Education about this?” I ask my mentor. "They tell us not to sensationalize it,” she replies. I am outraged.

The car slowly proceeds through narrow, mud-spattered village streets. It takes us to a building in the middle of some fields. The building is not surrounded by any houses. I am ready for anything and everything at this point. It is a school run by the NGO, Inspire, and the teachers are expecting their visitors. They are warm, friendly and pleasant as they greet us at the gate. The boundary wall is high enough that one can not see inside from the outside. After the introductions, a teacher takes me for a tour of the school. I am impressed by the computer labs, the Science labs, and the library. The 
toilets are on one side and are quite clean. Once I walk into the classrooms, the first thing I notice, is the eyes that are glued on me. Bright, sparkling, curious eyes fixed on me from all sides. The children are happy to see me: a stranger taking interest in their lives. I ask them to write my name in Urdu; delightfully they do. They are dressed in neat uniforms. I start asking questions about what they would like to become and how old they are. I am surprised to realize that they are seven or eight years old. They look small for their age, and younger than the four-year old nephew of my mentor who accompanies us this morning. "Malnourishment maybe,” I think to myself as my heart silently cries. In each of the four classrooms that I visit that day, children are engaged in what they are doing. A little girl in one class holds my interest. She raises her hand eagerly to answer all questions as though she is saying, "Listen to me; I am smart, too."

I am not unaware that, with a single stroke of luck, this could have been me. I could have been born in her place, 65 kilometers outside of Lahore. It is painful for me to think about what type of educational experience these children might have had if the NGO Inspire had not intervened in their lives.

Every time I reflect on this, I am burdened with the knowledge of access and opportunities that I received at the hands of a world class education, available in Lahore, which opened the doors of Western higher learning for me. I am reminded of the intelligent eyes of those children who are at the verge of being excluded from mainstream education, and I struggle with the questions of access, power, privilege and exclusion. Why is it so hard for governments, educational systems and educational bureaucracies to create conditions that respect the right of all children to have a quality education? The 
question is simple yet the answers are layered with profound complexities. I approach this study with a hope that I can make a contribution in this regard.

Reflections from field notes (Winter, 2009). 


\section{Chapter One: Statement of the Problem}

Historically, education has been viewed as a precondition for economic growth (Williams and Cummings, 2005). In recent years, in the changing global scene, education has assumed a greater role as a key factor in development strategies. Since the 1990 Education for All conference in Jomtien, Thailand, universal primary education became a formal international development goal. According to Birdsall, Levine, and Ibrahim, (2005), the target to achieve primary education for all is the second priority in the United Nations’ Millennium Development Goals (MDG). According to the MDG, it is important to ensure that, by 2015, children everywhere, boys and girls alike, will be able to complete a full course of primary schooling (Grown, Gupta and Kes, 2005). Pakistan is a country that is far behind in its struggle to reach this Millennium Development Goal of removing illiteracy and providing universal primary education. The Constitution of Pakistan in 1973 declared that the government shall provide universal primary education; this policy is yet to be fully implemented. (Haq and Haq, 1998; Hoodbhoy, 2004). Since the formation of this constitution, successive governments have consistently failed to fulfill this responsibility.

In a world where formal education is the major responsibility of the state, primary education in Pakistan presents a bleak picture. Pakistan, the nation state is weak and is unable to provide education for all of its children. Other factors such as inadequate resources, civil unrest, political and economic instability further contribute to the State's inability to concentrate on providing primary education for all of its children. (Shah, Bari, and Ejaz, 2005; Haq and Haq, 1998; Hoodbhoy, 2004; Akmal, 2003; Curtis, 2007). 
The net enrollment for children in primary schools is 52\% (Pakistan Household Survey Data, 2004). According to the U.S. Agency for International Development (Kronstadt, 2004) only two thirds of Pakistani children aged 5-9 are ever enrolled in school and only one third complete fifth grade. In addition, only 30\% of Pakistan’s highschool aged children receive schooling (The World Bank, 2008). And while the government of Pakistan has vowed to provide primary education to all of its children, this promise remains an elusive goal decades after its inception. Like many other developing nations, Pakistan has not had the management or resource capacity to provide education to all of its citizens. For example, Pakistan spends a very small portion of its budget on educating its children. From 2000-2005, public education spending was only 2.6 percent of GDP (The World Bank, 2008). In 2006, United States spent 22.2 percent of GDP on primary education, other countries such as India and Bangladesh spent 8.9 percent and 9.1 percent of GDP on primary education respectively (The World Bank, 2008). Pakistan's limited educational budget results in a lack of adequate school facilities, quality curricula and trained teachers—all in the midst of desperate poverty.

Warwick and Reimers (1995) state that "Pakistan has one of Asia's worst systems of government-sponsored education” (p.1). The heavily funded government programs to increase access to universal primary education failed to produce desirable results owing to: (a) political and bureaucratic interference (i.e., staff transfers, lack of merit- based appointments, corruption in contract awarding); (b) lack of accountability and sound management practices; (c) lack of internationally comparable learning outcome standards 
(curriculum) and mechanism to assess them in the classrooms and schools and (d) lack of cost- effective and high quality teacher and staff training (Hoodbhoy, 1998). Factors that compel parents to withdraw their children from government schools include absence of teachers or such low standards that parents feel the cost of sending the children to school is higher than the perceived benefits of schooling (Akmal, 2003).

The failure of Pakistan's government to provide for a system that ensures accessible opportunities for all of its children has resulted in individuals, for-profit organizations, and non-governmental organizations (NGOs) intervening to fill the void. In particular, international donor agencies (IDAs) have come forward to provide financial aid and personnel support to Pakistan’s primary aged children.

The research shows a proliferation of NGO schools in developing countries (Miller-Grandvaux, Welmond, and Wolf, 2002; Birdsall, Levine and Ibrahim, 2005). Increased collaboration between the government, not-for-profit, and private-for-profit sectors has proven an effective strategy to increase educational access in various parts of the world. Studies have shown that when NGOs along with IDAs collaborated with governments in Mali, Malawi, Ethiopia, Guinea, India, and Bangladesh, drastic steps were taken to increase educational access to marginalized children (Miller-Grandvaux, et al. 2002; Boukary, 2004; Stacki, 2004).

The actual impact of NGOs in education in Pakistan is neither documented nor studied extensively. A few studies indicate that NGOs have overcome barriers in service delivery of education to disadvantaged children (Anzar, 2002; Shah et al. 2005; Hoodbhoy, 2004; Khan, 2005; Khan, 2007). However, the research has not extensively documented the quality of education provided by NGO schools. Therefore, the purpose of 
the proposed research study is to describe the work of two schools run by NGOs in providing education to children in rural and in urban settings in Pakistan.

The following research questions will guide this research study:

- How does an NGO school provide education to primary aged school children?

- What processes and structures are evident in two NGO schools in providing quality primary education to children in Pakistan?

- What factors and characteristics are evident in two NGO schools which provide opportunities for teaching and learning?

\section{Definition of Key Terms}

For the purpose of this study the key terms, NGO, NGO schools, and international donor agencies are defined as follows:

The United States Association for International Development (USAID) defines non-governmental organization as a private, voluntary organization (Willetts, 2002). NGOs are independent associations of people acting together on a continuous basis, for some common purpose, other than achieving government office, making money or illegal activities (Willetts, 2002). NGOs are usually non-profit, private sector organizations located between the state and market institutions involved in providing educational, health, social, and economic services (Sutton and Arnove, 2004). In this research study, organizations identified as non-profit, private and/or trusts are also defined as NGOs. A school run by an NGO is defined as an NGO school for the purpose of this project.

International donor agencies are defined as international organizations that provide funding, loans, credits and assistance to developing countries for the provision of basic services. These agencies include but are not limited to the United Nations, The World Bank, and the USAID. 


\section{Significance of the Problem}

It is important to study the work of NGO schools in Pakistan because NGOs have achieved success in areas where government, with the lack of its infrastructure and resources, failed to mobilize the community to see the benefits of educating their children girls and boys alike (Khan, 2005). NGOs have reached far and wide in rural areas where there are no paved roads, hospitals, health services or other basic necessities of life (Anzar, 2002; Shah et.al. 2005).

\section{Personal Values and Identity}

My goals for conducting this study are rooted in my personal values and identity. I come from a family where education is highly valued. My parents always told us that ensuring their children's education was their first priority in life. As I grew up, the adults

in my family were a strong inspiration for me- four of my mother's sisters studied to become doctors and the remaining four received their Master's degrees and are teachers. My mother is a Professor of Botany and Department Chair at Lahore College for Women University. Her father was the principal of a college in Lahore and a Professor of Chemistry. He had received his education from Aligarh University in India before partition.

I went to a premiere women only college which was constructed during British times in Lahore, Pakistan. Throughout my educational career, I went to elite, private, forprofit, women only schools where English was the medium of instruction. It was not always easy for my parents to afford our education but it was their top priority. I have a Master's in English Literature and a Master's in English Language Teaching from Kinnaird College for Women. I was an English teacher at Beaconhouse School System 
(BSS) in Lahore, Pakistan for four years. (While teaching full-time at BSS I took Master's classes as a full-time student in the evening.) BSS is also an elite, private, forprofit school where English is the medium of instruction and I taught at the high school boys’ branch. In 2005, I applied for and was selected to receive a Fulbright scholarship to teach Urdu at Portland State University. After that Fulbright year of teaching, I started my doctoral program at PSU and received support in the form of a Graduate Assistantship in the Institute for Asian Studies. I have spent my entire adult life in school in one capacity or another.

My interest in this project is driven by a desire to do something for my country of origin. I believe that access to quality education is the right of all children regardless of their race, ethnicity, gender, or geographical location. I have strong personal reasons to study issues of educational access. As an individual born to educated, professional middle-class parents, I had access and opportunities to receive a world class education, available in Lahore, which opened the doors of Western higher learning for me. I know that there is a lack of research on the work of NGO schools in Pakistan. During the pilot project for this study, I witnessed that NGO schools provide education to those children who otherwise would not have access to education because of gender, class, and/or socioeconomic status based factors. I saw the intelligent eyes of those children who are at the verge of exclusion from mainstream education, and I struggle with the questions of access, power, privilege, and exclusion. Why is it so hard for governments, education systems, and educational bureaucracies to create conditions that respect the right of all children to have a quality education? The question is simple yet the answers are layered 
with profound complexities. I approach this study with a hope that I can make a contribution in this regard.

\section{Theoretical Framework}

My quest for understanding the problems of providing equitable and accessible means of education for all Pakistan's children takes guidance, shape and direction from critical theory. Critical theory aims to raise a voice against the existing status quo and to question the hegemony of the dominant forces that operate in the society. According to Brookfield (2005), thinking critically entails being able to identify, and then to challenge and change, the process by which a grossly inequitable society uses dominant ideology to convince people that this is a normal state of affairs. Critical theory also allows individuals and groups to understand and critique deeply held beliefs, practices, and ideologies (Petrovich and Wells, 2005).

The aim of critical research is to promote an egalitarian society and to make the public aware of social inequalities and injustices. A critical stance views reality as a product of particular exploitative social and political systems comprising competing interests where knowledge is controlled to serve those in power (Grbich, 2007). Critical research attempts to identify those who are powerless and who are (usually) exploited by those in powerful positions, to document their unequal situation and to bring about change through an active process of emancipation involving knowledge sharing or the transformation of the society (Grbich, 2007). Critical researchers enter into an investigation with their assumptions on the table, so no one is confused about the epistemological and political views they bring with them to the research site (McLaren and Giarelli, 1995). 
Among major characteristics of critical traditions in research is a documentation of clashes between those in power and those with limited power, be it economic or political (Grbich, 2007). Critical stances in research highlight the issues of race, poverty, gender, politics and culture. Data collection aims to document whether marginalization and exclusion are occurring. For example, exclusion of disadvantaged children from mainstream education in Pakistan (as elsewhere) occurs by omission, by failing to implement policies, and by failing to create opportunities for children who are at risk and to enable their participation in education.

Critical theory provides insights about developing a foundation for critical pedagogy (Giroux, 2009). Critical theorists view schools as cultural terrains that promote and facilitate learning opportunities for students. According to Kincheloe (2008), critical pedagogy is dedicated to understanding the context in which educational activity takes place. Critical educators understand that empowerment to all students takes place in an increasingly power-inscribed world where dominant modes of exclusion are continuously naturalized. Critical pedagogy issues a challenge to scholars and social activists to push the boundaries of knowledge, to gain insights from various cultures and knowledge producers, and to employ the insights gained for the larger social good. Kincheloe (2008) states that:

Critical pedagogy is grounded on a social and educational vision of justice and equality. It is concerned with the margins of the society, the experiences and needs of individuals faced with oppression. It is focused on understanding the profound impact of neo-colonial structures in shaping education and knowledge.

Critical theory applies to the inequities of the primary education system in Pakistan quite adequately. In Pakistan, those with power and privilege have an opportunity to achieve the ability to read and write, whereas marginalized groups; namely 
those living in poverty, in the rural areas, and females, are deprived of the right to acquire quality education. Too often the marginalized groups are pushed into ways of living that perpetuate economic and gender oppression. For example, in Pakistan, efforts to construct public schools in rural areas failed because the landowners converted those schools to stables and granaries (Haq and Haq, 1998). Some of these landowners view the masses gaining literacy and numeric skills as a threat to the status quo. To gather community support, it is vital to facilitate conscious raising groups that can create mass awareness about the long term benefits of being educated, as conscientization is necessary for social transformation (Freire, 1970). Critical theory and critical pedagogy forms the theoretical underpinnings of my research because the research design and the research questions are geared towards developing an understanding of teaching and learning in NGO schools which cater to historically underserved populations belonging to low income groups. The data analysis of the proposed research project also aims to disseminate information about the efficacy of such schools in reaching out and providing education for the children whom would otherwise be excluded from a mainstream education. 


\section{Chapter Two: Literature Review}

A review of the literature explores the types of schooling in Pakistan. It focuses on how exclusion from primary education occurs for children on the basis of three factors: economic status of family, geographic location and gender. Other factors that further perpetuate discrimination such as socio-cultural, political, and historic are of significance as well but the former three factors are discussed in depth. A broad understanding of the role of NGOs in education both at a global and local level is foundational for this study. The review then focuses on the global role of NGOs in education and shares the success stories of NGO schools in Bangladesh and Mali. A historical perspective on educational reform and agencies that fund primary education in Pakistan, and the concept of privatization adds further perspective on understanding the role of NGOs in education in Pakistan. The review attempts to highlight the complex partnership and interrelationships between NGOs, state and donor agencies to provide schooling for marginalized communities. The review is concluded by an in depth discussion of the current research on NGO schools in Pakistan.

\section{Exclusion Based on Economic Factors: Children in Poverty}

In Pakistan, children who do not have access to education are categorized according to economic, geographic, socio-cultural, and gender based factors. These children, without access to education, are the ones who live on the margins - in urban slums, urban peripheries, and rural areas. These children live in poverty and are mostly girls (Das et al. 2006). Whether schooling is an option for a child depends on multiple social, cultural, and economic factors. It depends on whether the child is living in the urban or rural areas, and the socio-economic status of the parents. The education of a girl 
child depends on whether the parents are inclined towards female education. A lack of primary education for all Pakistan's children raises profound questions about social justice and equity. It appears from the research studies carried out by several scholars that children born in poor households in Pakistan have the lowest possible chance of having an education or even having a healthy, secure, and stable childhood (Akmal, 2003; Haq and Haq, 1998; Warwick and Reimers, 1995).

Mansuri (2006) a World Bank researcher on Pakistan, has shown that there is a strong correlation between the level of income of a household and school enrollment rates. The decision on schooling is affected by a household's ability to invest in schooling, the perceived returns from such schooling, and the labor market activity of children. As wealth increases, enrollment rates rise and dropout rates decline across the board. At the household level, school enrollment and retention rates vary significantly with income and the gender gap declines as income increases (Mansuri, 2006; Alderman et al. 2001).

Gender and schooling. In Pakistan, as in many developing countries across the globe, fewer girls than boys are enrolled in primary schools. The World Bank (2006), reports that the average Pakistani boy receives five years of schooling, while the average girl receives just 2.5 years. Girls' access to educational resources remains inadequate and gender remains the major factor in children being left out and pushed out of school (Grown et al. 2005).

Research suggests that low participation in education is directly correlated with gender. Girls are less likely to go to school based on the distance from school and the wealth and educational attainment of the child's parents. (Holmes, 2003; Lloyd, Mete and 
Sathar, 2005; Alderman et al. 2001). The gender disparity exists in enrollment, retention and completion rates with regards to income levels and rural or urban status. In addition to the obstacles posed by poverty and demographic pressures, the tendency to devalue women remains a major threat to improved access to and participation of girls in education (Burnett, 2005).

The system of education established by the British colonial administrators perpetuated the gender ideologies such as Victorian norms of domesticity based on the duality of the breadwinner husband and the dependent house-bound wife (Swarna, 1997). A study conducted by Women Studies Center in the slums of Karachi (Aftab, 1994) showed distressing findings for learning achievement. A survey conducted in low income areas revealed that out of 500 girls, 76.5 percent never attended any school, the reasons given were poverty (28.6\%), against family norms (15.4\%), father’s opposition (14.2\%), respondents' own disinterest (14.2\%), distance to the school (3.6\%), household work (2.8\%), and several other reasons. Feudalism and patriarchy are the two main social impediments in the growth of female literacy (Aftab, 1994).

The rewards of educating girls are numerous. The benefits of educating girls are directly linked with reduced birth rates and improved uptake of immunizations (Aikman and Unterhalter, 2005). Education, particularly for girls, is related to lower death rates and longer life expectancies (The World Bank, 2006). Girls that are more educated would command greater autonomy and marry into higher socioeconomic groups (Das et al. 2006). Women with some schooling are employed twice as often as those who never attend school (Maletta, 2003). Maletta, in a study of women employment in rural Afghanistan, finds that even though female literacy boosts labor participation and reduces 
unemployment this relationship however is, affected by wealth (2003). In order for girls' education to bring about the positive outcomes, listed above, the quality of education available is extremely important. In addition, consistent and ongoing support to provide opportunities for higher education is also essential.

Rural schools. According to a study by United Nations Educational, Scientific and Cultural Organization (UNESCO) about 70 percent of the world's people live in rural areas (Grown et al. 2005). The data from Pakistan's population census indicate that almost 70 percent of Pakistan's 160 million people still reside in rural areas (World Bank, 2009). In Pakistan, fewer schools exist for rural than for urban students and the quality of instruction in urban schools, on average, is better than rural schools (Warwick and Reimers, 1995). Many rural schools do not offer the full number of primary grades and teach curricula that are not suited to rural circumstances. Demand for schooling in rural areas can be low, particularly because the cost of attending the schools is viewed locally in terms of lost income and/or labor — children could be working in the fields or working at home (Burnett, 2005).

Since the largest proportions of those receiving insufficient schooling live in rural areas, it is important to focus attention on the needs of rural children. The children in urban areas are by no means universally better off educationally than their rural counterparts. Rural areas can vary dramatically since the population densities, microeconomies and circumstances vary considerably. All of this has important cost implications for rural schools. In remote regions, access to villages (where the school might be located) is difficult. As a result, per student costs are high either because class 
sizes are small or because transport costs to consolidate children in rural schools are high (Burnett, 2005).

\section{Schooling in Pakistan: Types of schools}

Pakistan's children receive education in several ways. The system of education is complex and multifaceted with public schools, elite private schools, private schools catering to children from low socio-economic status and religious schools. Public schools at the primary and secondary level attract students from lower and middle income groups. However, prestigious institutes of higher education and professional colleges are almost always public and provide education in English.

There is a dual system of education present in Indo-Pak sub-continent that is the legacy of the colonial era. In order to produce a workforce that could be employed at the middle management level by the administrative and legislative institutions, the British rulers established English medium schools (Rehman, 2005). The same school system is still functional in Pakistan where these elitist schools are privately owned. In the public school system, at the high school level all subjects are taught in Urdu, the national language of Pakistan. English is also offered as a part of the curriculum in the public school system. Whereas in the private schools system, all subjects besides Urdu are taught in English language.

Schools that are of high quality and standard are English medium schools.

Students who study at these schools have a greater chance of entering professional colleges and institutes of higher education than the students studying at public schools. As a result, less prestige is associated with public schools at the elementary and secondary school level. Since English is the de-facto official language, all lucrative jobs 
are available to the ones who are proficient in English language. Parents aspire to send their children to expensive, private English medium schools rather than the public school where the medium of instruction is Urdu.

Linguists and educational researchers have argued for and against bilingualism for many years. However, it is not only a matter of using either Urdu or English as the medium of instruction. Since Urdu, which is the national language is spoken by only $8 \%$ of the total population as their mother tongue; parents argue that regional languages which are countless in number, should be the medium of instruction and consider instruction in English and Urdu as the hegemony of the dominant culture (Rehman, 2005). Textbooks are provided by four provincial government Textbook Boards of the provinces namely, Punjab, Sindh, Northwest Frontier Pakistan (NWFP), Balochistan (Rahman, 2004).

The dominant culture is that of mainstream English speaking elite. The elitist schools are available only for the children of military, bureaucratic, professional, and feudal elite. Whereas the underprivileged groups of the society do not have access to these schools and the public schools that are affordable for them do not provide the quality education with trained teachers, appropriate curricular materials, and adequate facilities.

Learning in Public Schools. In a rapidly globalized world, no nation can compete in the international community without quality education (Jacques, 2000). Education is not only concerned with qualification and good job, it has long term impacts on all sectors of development. Expanding access to primary education is a widely accepted priority in the fight against poverty. Basic education is universally seen as the 
only intervention that has a large scale impact on the quality of skill development (Hoodbhoy, 1998). According to Haq and Haq, (1998), a farmer with just four years of basic education is, on average, $8.7 \%$ more productive than a farmer with no education. A literate workforce in the labor market is an essential component to attract foreign investment for job creation and economic progress (Hoodbhoy, 1998).

As economic and social life becomes increasingly based on the written word and on recorded calculations, education at least in the minimal sense of basic numeracy and literacy has become increasingly perceived, even by the poor, as part of the necessary skills to survive in a changing world (Kabeer, 1998). Moreover, the future of Pakistan depends on enlightened and informed individuals (Rizvi and Elliot, 2005). Merriam and Caffarella (2004) describe education as a medium for economic growth and development, a medium for upward social and economic mobility, a basic human right, and it helps an individual in increased self - actualization and personal development.

Despite three decades of foreign donor support to Pakistan's public education system, the promise of universal elementary education remains an elusive goal (Hoodbhoy, 1998). Presence of and pressure from the international donors have been the driving factors in implementing education sector reform to provide progress toward the goal of Universal Primary Education (UPE). International donors have funded heavily to improve educational standards in Pakistan. Pakistan has incurred huge debts and loans from the World Bank, International Monetary Fund (IMF), UNESCO, and United States to increase literacy and standards of education (Hoodbhoy, 1998). As a result of universal primary education policy, numerous steps have been taken by the provincial governments to achieve the goal of childhood literacy. Initially many schools were established in rural 
areas without paying a lot of attention to buildings' location and accessibility (Haq and Haq, 1998). The system of transportation in rural Pakistan is not adequate. There is lack of proper roads and very few people have their own vehicles in the rural areas. As a result of children's inability to access the school, there was low enrollment across genders. In addition female children are not allowed to go unescorted; an action that increases the existing gender disparity between male and female literacy rates (Haq and Haq, 1998). Young girls' mobility is highly restricted as it is believed to cause dishonor to the family's name (Aftab, 1994).

Poverty and lack of basic services have deprived a large proportion of Pakistan’s children of educational opportunities (Akmal, 2003). The public primary schools, established in both rural and urban areas, lack facilities and resources such as clean drinking water, toilets, furniture, playgrounds, trained and qualified teachers, and curricular materials (Haq and Haq, 1998). In the rural areas, funds were spent on the construction of school buildings; inadequate resources and low efficiency resulted in low enrollment. The efforts to provide elementary education by creating more schools were not helpful in attracting more students, since low quality education was provided in these schools. In urban areas (Das, Andrabi, \& Khwaja, 2006), parents, even from the low income bracket, prefer to send their children to private schools which are comparatively better in providing functional education and facilities to the students.

Politicians at the national and provincial levels used the universal primary education policy as an opportunity to provide jobs to untrained, unqualified teachers in their constituencies (Haq and Haq, 1998, Hoodbhoy, 1998). In some rural areas, females who had completed education through $8^{\text {th }}$ grade and passed through a three month 
vigorous training program, were appointed as teachers. The school

administrator/principal was not involved in the hiring or firing of the staff; the provincial board of education appointments staff members. The remunerative package offered to them was very low; and was sometimes even less than the monthly salary of the chauffers' and cooks' salaries in the affluent households in the urban areas (Haq and Haq, 1998).

There was little accountability with the running of government schools. Unlike the system in United States, where a school board manages the budget and operation while holding schools accountable for their education outcome and actions, no such system were in place for these government schools. Parents and people from the local community were not involved in managing the affairs of the school, which were already functioning with a dearth of funds. The provincial board appointed a coordinator of education to advise and oversee the functioning of school. The role of the coordinator was not clearly articulated, the funds for transportation to travel to the schools in remote areas were meager and the coordinator position created jealousies amongst the members of the provincial board of education (Haq and Haq, 1998).

Since most of the school-going children are also involved in some form of work, the school timings clashed with their labor timings. Moreover, the cost of sending a child to school is much more when that child is contributing significantly to the annual family income. The additional costs of education such as school fees are expensive when the parents are using all resources for shelter and food for their family. A study by Sathar, Lloyd, and Haque (2000) revealed that a significant amount of money was spent on sending the child to the free elementary school in terms of expenditures on clean 
uniforms, textbooks, and other supplies. Since the education that the child receives in the elementary school is not vocational and does not make him more employable in the labor market, parents prefer not to send him to school. They would rather send the child to work as an apprentice at a local shop than send him to school. Student enrollment considerably increased in rural areas where care was taken to design a school calendar which does not coincide with harvest time for the farmer laborers (Haq and Haq, 1998).

Moreover, there was not enough support in the community to build consensus for the childhood literacy policy. Parents, who are not literate themselves, failed to see the long term benefits of education for their children (Aftab, 1990). Therefore most policy implementation initiatives failed to reach the goal of increasing literacy rates as they did not fully understand the realities, lives, experiences, needs, and aspirations of the targeted population.

The World Development Report by United Nations (2005) enlists factors that have restricted the provision of quality education throughout the under privileged areas in the world; unaffordable access, dysfunctional schools, low technical quality, low client responsiveness, and stagnant productivity. The language of instruction may be an obstacle to learning or teachers are untrained to teach a curriculum in a second language. Schools themselves may be dysfunctional due to teacher absenteeism, lack of teacher motivation, infrequent and low pay, poor welfare, but also lack of continued in-service teacher training (Achieving the Internationally Agreed Development Goals, p. 113). Pakistan's public school education system suffers from all the above- mentioned problems. Features that have contributed as a barrier towards universal primary education is the lack of trained teachers, inadequate curricular materials, outdated instructional 
methodology, inaccessibility, lack of supplies, and materials. Additionally, bad governance on the part of federal and provincial ministries of education, lack of planning and infrastructure, political instability played their part. Also, it is hard to create a literacy rich environment with lack of instructional tools and materials.

Several constraints in the implementation of the policy to achieve childhood literacy increase the difficulty to meet this goal. The first is scarcity of funds; public spending on education fell sharply over the years instead of increasing (Weiss, 2002). Pakistan, like its neighboring developing countries, faces a daunting task in its efforts to expand the delivery of educational service due to rapidly expanding population and tight government budgets (Alderman, Orazem \& Paterno, 2001). Pakistan is not a welfare state and subsidized or free of charge social services are not available to its residents. Pakistan's population that lives at or below the poverty line suffers most as a result of lack of provision of basic services.

A second major constraint in policy implementation is the lack of trained teachers, and adequate curricular materials. The low quality of education results in higher dropout rates and low enrollment rates. Pakistan's education minister quoted in the newspaper calling the country a, "Nation of Dropouts". The high dropout rate is also linked with outdated curricular materials that have no direct connection with student's life. Factors inciting parents to withdraw their children from school include absence of teachers from government schools or such low standards that the parents feel that the opportunity cost of sending the children to school is higher than the perceived benefits of schooling (Akmal, 2003). Lack of infrastructure and facilities like toilets and chalk boards also act as a major hindrance (Haq and Haq, 1998, Qaisar, 1998, Hoodbhoy, 
1998). Over 20,000 schools in the province of Punjab do not have clean drinking water, latrines, or proper classrooms (Haq and Haq, 1998).

Political commitment for a spirited campaign to universalize primary education in the shortest possible time is still lacking in the country (Haq and Haq, 1998, Hoodbhoy, 1998). One of the main goals of Social Action Program I was to involve the private sector and NGOs in the implementation of policy; on the other hand, no notable investment was made in the support structures so that there was little community participation. Participation of the private sector was considered to be inadequate.

Theories of teaching and learning. In this part of the dissertation, I describe behaviorist philosophy and demonstrate how Pakistan's public schools are influenced by this theory of learning. I describe the constructivist school of thought, which regards the process of knowledge construction directly in opposition to the behaviorist paradigm.

Behaviorism regards learning as a system of behavioral responses to physical stimuli. Researchers working within this paradigm are interested in the effect of reinforcement, practice, and external motivation on a network of associations and learned behaviors (Fosnot, 1996). Learning is believed to be carried out by observations, listening to explanations from teachers who communicate clearly, or engaging in experiences, activities, or practice sessions with feedback will result in learning and that proficient skills will quantify to produce the whole, or more compassing concept (Bloom, 1956; Gagne, 1965 as quoted in Fosnot, 1996). Further, learners are viewed as passive, in need of external motivation, and affected by environment (Skinner, 1953). Jackson (1986) views learning influenced by behaviorism as a "mimetic" activity, a process that involves students repeating, or miming newly presented information. According to Brooks and 
Brooks (1993), in schools influenced by behaviorist principles of learning, the curriculum is held as absolute, and teachers hesitate to tamper with it even when students do not understand the concepts. This model discourages cooperation and requires students to work in relative isolation on tasks that require low- level skills, rather than higher order reasoning. Behaviorist classroom are dominated by teacher talk and rely heavily on textbooks (Flanders, 1973, Goodland, 1984, Ben- Peretz, 1990 as quoted in Brooks and Brooks, 1993). Students frequently are unable to connect the information they receive in schools into interpretations of the world around them. Such an educational setting stresses students to believe that technique, rules, and memory matter more than context, authenticity, and wholeness (Brooks and Brooks, 1993).

In contrast to behaviorist philosophy, constructivist research focuses on how learning occurs in individuals and how internal cognitive structures are constructed (Philips and Soltis, 2004). Constructivism stands in direct opposition to behaviorism (Fosnot, 1993). According to Piaget, mental and cognitive structures make teaching and learning possible. He and his colleagues focused their research on the mechanisms of learning and the processes that enabled new construction of knowledge (Fosnot, 1996). Piaget, a developmental psychologist, describes a child' s learning process with the help of schemas and internalizing of various tasks the child performs as a result of interaction with its surroundings. Social constructivists regard learner as more than a mere lone investigator and places emphasis on the social surroundings, and communities in which the learners operate. Social constructivists regard individual subjects and the realm of the social as indissolubly interconnected. Human subjects are formed, are developed and they learn through their interactions with each other as well as by their individual processes 
(Ernest, 1993). The notion that knowledge is the result of a learner's activity rather than that of the passive reception information or instruction is the grounding principle of constructivist philosophers, theorists, educators and practitioners (Phillips, 1995).

Dewey's philosophy propagated that schools are a social medium where learners must engage with other learners by working on meaningful, purposeful activity hence the emphasis was on problem solving in social setting (Dewey, 1938). Children are active inquirers, they need adequate time to reflect, opportunities to test and evaluate the knowledge that they have constructed and reflect about constructions produced by other students and teachers. The goal of a constructivist curriculum is deep understanding and not mimetic behavior (Brooks and Brooks, 1993).

Learning theories prevalent in Pakistan’s public primary schools are influenced by a behaviorist philosophy. Critical thinking skills are not fostered as the examination system demands regurgitation of concepts learned through textbooks (Hoodbhoy, 1998). Rote memorization is the norm for memorizing difficult concepts in learners' second or third language (Hoodbhoy, 1998). The classroom is a teacher-centered environment with no attention to the contribution of learners' prior knowledge in the process of meaningful learning. One reasons for high dropout rates in primary schools in Pakistan is this out dated method of instruction (Haq and Haq, 1998). The low quality of education in the public primary schools is a strong reason why parents do not see any benefit in sending their children to public schools. School quality is an important factor in determining the returns to schooling (Mansuri, 2006). Since the opportunities for pre-service and inservice teacher training are non-existent, teachers have minimum knowledge of the subject matter assigned to teach in their second or sometimes third language. Reports 
indicated embarrassingly low levels of teacher attainment. A majority of teachers in rural Punjab province failed a test, which they intended to administer to their fourth grade students (Hoodbhoy, 1998). According to Ernest (1993), it is important to find out what are the objectives of the curriculum and how do the objectives of the curriculum align with teachers' knowledge of subject matter and diagnostic skills, with the teacher's beliefs, conceptions and personal theories about subject matter, as well as teaching and learning beliefs (Ernest, 1993, p.42). There is a dire need to recognize in Pakistan’s public school that knowing is active, that it is individual and personal, and based on previously constructed knowledge (Ernest, 1993, p 32).

Many public schools employ the rigid approach towards teaching where learners' are viewed as empty barrels waiting to be filled by knowledge by an outside, external source who possess absolute knowledge of all that is worth knowing. The learning process is viewed as being a linear, top-down approach, in which a teacher delivers information to a student who acquires and then applies that knowledge (Sfard, 1998, Palmer, 1998). Knowledge is often referred to as something that is acquired, gained and possessed. In an increasingly capital driven society, knowledge is also viewed as a bankable commodity. This figurative way of speaking about gaining knowledge indicates that wisdom, and therefore power, is a positive entity or acquisitions (Lakoff \& Johnson, 1980).

According to Rizvi and Elliot (2005), government -run primary schools in Karachi where reforms have been initiated by the government, teachers have a very strong sense of professionalism. These teachers perceived themselves as being professionals capable of leading students successfully and improving the teaching scenario in government primary run schools. However, these reforms were initiated at the 
district level in Karachi only. So the findings of this study are not applicable to rural schools where no such reforms have been initiated and where school retention and literacy rates are drastically low as compared to Urban Sindh.

Private schools. Private schools can be categorized as follows:

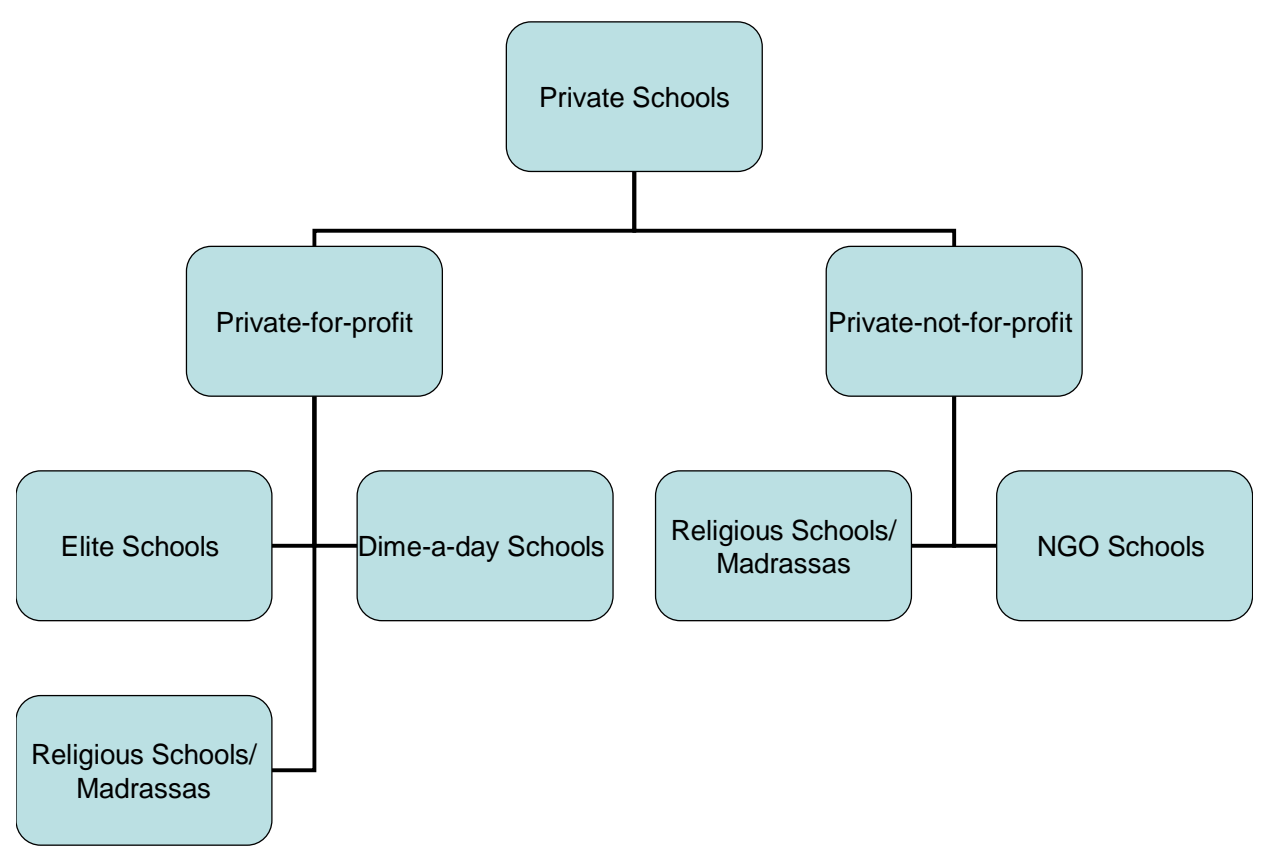

Figure One: Types of Schools in Pakistan

The focus of this dissertation is on private, not-for-profit schools managed by NGOs. The discussion of the private elite schools and religious schools is beyond the scope of this paper. However, it is important to understand the general picture of the forprofit private schools catering to children from low socio-economic status, because much of the research studies are focused on private, for-profit, non-elite schools and their 
comparison with government schools. In their studies of private, for-profit schools, catering to children in low socio-economic strata, Alderman, Orazem, and Paterno (2001) do not make a distinction between NGO schools and Das, Pandey, and Zajonc (2006) remove the NGO schools from their category of analysis. Andarabi, Das, and Khwaja (2006) do not mention the distinction they have used between private, for-profit, non-elite schools and private, not-for-profit, NGO schools, except for a single line in the footnotes in which it is mentioned that they have excluded NGO schools from their unit of analysis.

Even though their study focused on schools which are "overwhelmingly” for profit yet non-elite, the study makes important observations which are applicable to NGO schools as they also cater to children from low socio economic strata.

Andrabi et al. (2006), show that there has been a phenomenal rise in private schooling in Pakistan in recent years, especially among children from the rural areas in middle-class and poorer families. The growth in private schooling is higher in rural than in urban areas even among the poorest sections of the population. Their study revealed that private schools are better able to adapt to local conditions and use labor markets in a cost-effective manner. Their data showed a higher share of enrollment at the primary level in the private sector. In 2000, thirty-five percent of all children enrolled at the primary level in Pakistan were attending a private school. The tuition that these private schools charge is still very low. A typical private school in a rural village of Pakistan charged 1,000 Rupees per year which is approximately \$18 a year in United States dollars. According to Andarabi et al. (2006) the key element in the success of private schools in rural areas is the ability to keep fees to a minimum. 
Another key to success of private schools is the ability to adapt to local conditions—-for example, to use local resources by employing moderately educated females from the community. However, such schools are unlikely to cater to the secondary levels in rural areas, since there is no supply of potential teachers with required higher skills and education levels.

Das et al. (2006) use data from two tests conducted by Action Aid to make a claim that children in private schools performed significantly better than those in public schools in all subjects. Alderman et al. (2001) highlights that even in the presence of a government school; parents in Pakistan will send their children to the private school. These studies further strengthen the notion that public schools are neither sufficient nor the sole means of providing primary education in the rural areas or in the poorer sections of the society. However, it is important to mention, economists from the World Bank conducted these studies. Each paper contains a disclaimer that the studies do not represent the views of the World Bank; nevertheless the World Bank is well-known to promote policies which favor privatization (Bello, 2000).

Das and Zajonc (2006) in an independent survey of primary schools in rural Pakistan focus on the achievement of enrolled children, as measured through test scores. According to Das and Zajonc (2006), although it is known how many years children spend in school, and what determines the extent of their participation, little is known about how much they learn during this time. Household survey data conducted by government agencies reveal who start school attendance, and which children dropout and when, but say less about the basic competencies in language and numeracy that children have acquire in their school years. Data requirements partly drive the emphasis - it is 
easier to ask about school enrollment than to test children. Their study revealed that the quality school factors account for the difference in achievement rather than household factors such as literacy of parents. For example, the learning gap between a child in a high performing and a low performing government school is five times the gap between a child with a literate mother and a child with an illiterate mother (2006). However, the study does not mention what type of primary schools they had in their sample, government schools or private-for-profit schools or private-not-for profit schools.

\section{Analysis of the Studies}

Several researchers discuss the differences in public and private schooling in rural Pakistan. However, most of the research focuses on private, for-profit schools catering to children from low socio-economic strata with little documentation of the work of NGO schools. The research samples selected for these studies are quite large. For example, the Learning and Educational Achievement Project in Punjab (LEAPS), a study conducted by economists from the World Bank and Harvard Institute for International Development (HIID), collected data on 4,880- 4,890 teachers in 800 public and private schools in 112 villages of Punjab province (Andrabi et al. 2006). Similarly, the Basic Research and Implementation in Developing Education Systems (BRIDGES), a project which was carried out by Harvard School of Education, HIID and USAID, collected data with a field team a of 100 interviewers who contacted the heads of 500 rural and urban schools, 1000 teachers and 300 supervisors. The research team also gave achievement tests in Math ematics, Science and a short questionnaire to more than 11,000 grade 4 and 5 students in 500 schools (Warwick and Reimers, 1995). The study findings pointed out the abysmal conditions of public primary education in Pakistan. These studies, funded by outside 
sources, for example, the World Bank funded some grants for studies. The large data sets enabled the researchers to make generalized conclusions that increased the validity of their results. Such studies inform policy makers and funders in identifying trends in the current educational environment in public and private schools of Pakistan. However, none of these studies included NGO schools in their sample.

I will now focus on a discussion of NGOs and their role in education at a macrolevel, which entails the work of NGOs in education globally. I synthesize studies that highlight NGO success stories in Bangladesh, India, and Africa. Moreover, I highlight studies, which identify common failures and pitfalls in the NGO school model in different parts of the world. The focus then shifts to the micro-level, which comprises the work of NGOs in education in Pakistan. In this section, I will also discuss some of the key constructs such as NGOs, and IDAs, which is followed by a classification of these main constructs. I discuss the complex relationships between NGOs, state, IDA and the communities they claim to serve at both global as well as local (Pakistan) level.

\section{Non-Governmental Organizations}

According to Willetts, the term NGO came into being in 1945. A nongovernmental organization (NGO) is a legally constituted organization created by physical or legal persons with no participation or representation of any government. In the cases in which NGOs are funded totally or partially by governments, the NGO maintains its non-governmental status insofar as it excludes government representatives from membership in the organization (2002). An NGO is thus defined as an independent voluntary association of people acting together on a continuous basis, for some common purpose, other than achieving government office, making money or illegal activities 
(Willetts, 2002). NGOs are tools and instruments for change, consciousness raising, mobility, and advocacy. NGOs frequently depend upon, interact with, supplement, complement, and sometimes substitute for the state and the market in the meeting of basic societal needs (Sutton and Arnove, 2004). Large international NGOs work on developmental projects besides education such as provision of health services, birth control, HIV/AIDS prevention, and treatment.

Types of NGOs. Non-governmental organizations are of several types. Edwards and Hulme (2002) categorize NGOs involved in international development based on their size, location, and primary sponsorship. Their categories are

1. Big International NGOs (Care and Oxfam)

2. Donor sponsored NGOs (those who administer funds administered by USAID, for instance, Mercy Corps)

3. Government Oriented NGOs (Sarhad Rural Support Program)

4. Northern NGOs (Academy for Education Development)

5. Southern NGOs (BRAC)

The categories are not exclusive as an NGO, for example, Mercy Corps can fall under the category of both a Northern NGO and a Donor Sponsored NGO as for some of its projects it receives funding from the USAID. However, for most other projects its funds come from grassroots fundraising drives and also from the communities which it supports. Similarly, the Academy for Education Development, a Northern NGO, also administers funds by USAID.

NGOs in education. NGOs that work for education in the developing world either strengthen the existing government sector or fill the gaps where government system of education fails to reach marginalized populations (Miller-Grandvaux et al. 2002). To expand and to make basic education relevant, NGOs work in partnerships with 
the local communities (Boukary, 2004). Globally the NGOs have done considerable work to improve the service delivery of education in the developing world. NGOs that are concerned with education deserve particular attention because their proliferation in many parts of the world was a particularly striking development during the decade, which followed the 1990 Jomtien Conference. In some settings this change was the result of government encouragement as in Bangladesh, but elsewhere governments were neutral or or even discouraging as in Mali (Sutton and Arnove, 2004). The proliferation of NGOs has brought a major change in circumstances; it is among the elements triggering reassessment of approaches and strategies (Grown et al. 2005).

\section{NGOs for Education around the World}

The initiatives of NGOs for education in the developing world consist of highly regarded programs that specifically target unschooled or under-schooled children and offer a real alternative. For instance, Bangladesh Rural Advancement Committee (BRAC), an NGO in Bangladesh, states, that, "Our purpose is to help fill the remaining gaps in coverage, retention, and quality of compulsory primary basic education in Bangladesh” (BRAC, 2009). It is important to understand the model of BRAC schools because it is a pioneer in introducing an innovative model of non-formal primary education which is adapted and used all over the world (Williams and Cummings, 2008). BRAC started with the aim of developing a school model for poor rural children. BRAC took the following steps to improve government schools that were failing: hired and trained new teachers in the BRAC methodology; mobilized communities through the creation of school committees; provided training for head teachers and local committee members; put into place supervisory structures that strengthened the quality of 
management. In recent years, Bangladesh has made significant progress in the education sector, having achieved a primary enrollment rate of $92 \%$ and gender parity at both primary and secondary levels (BRAC, 2009). Primary education is free and compulsory in Bangladesh. 90\%of Bangladeshi children go to formal schools and 8.5\% attend nonformal schools. BRAC covers the non-formal sector. BRAC runs these schools based on three models: Non-Formal Primary Education (NFPE), Basic Education for Other Children (BEOC), Educational Support Program (ESP) for smaller NGOs who use NFPE. The BRAC school model consists of one-room schools with 33 children who attend for a cycle of three to four years. The curriculum used in these schools is similar to formal school curriculum. It caters to the children with illiterate parents or coming from economically disadvantaged families. In 1999, BRAC ran 34,000 schools, with 1.1 million children enrolled in their schools. Girls make up 66\% of enrolled students. At 97\%, the majority of teachers are female. In 1999, BRAC graduated 1.5 million children. Nath (2002) conducted a longitudinal survey of 1,109 graduates in 1995, 1997, and 1999 from these models and found that $36 \%$ of the children came from poor households, $33 \%$ percent from moderately poor households and 33\% came from non-poor households. At $42 \%$ more girls are enrolled in formal, private schools after completing the BRAC program owing to government policy of educational stipend specifically for girls, 33\% of which remained in school after four years. Five year graduation rates were higher for BRAC schools' students than the national average. Boys dropped out because of scarcity of money, dislike to continue schools, or being pulled into the labor market. Girls dropped out primarily because of marriage or scarcity of money. 
In a cross-country case study of NGOs providing education services in four African countries, Miller-Grandvaux et al. (2002), assert several reasons for the success of NGOs. First, NGOs work at the community level, thus affecting social change where others cannot. Secondly, NGOs can represent and catalyze civil society, an element that many consider critical for sustainability and democratization. Finally, NGOs are simply more efficient than other partner groups. Many NGOs however, run stand-alone, smallscale programs with limited outreach, taking a project rather than a systems approach. A study in Nairobi found limited outreach through the alternative education programs offered by NGOs. Sutton and Arnove (2004) in a sample of 250 to 300 NGOs with programs on the ground found that very few children were actually reached. Most programs had less than 100 children and estimates put the total number of children reached by the programs at about fifteen thousand. Their low impact is attributed to the fact that many NGOs are fragile, and resource poor; they have no support from the government and most are working in isolation (Sutton and Arnove, 2004).

In the following section of the dissertation, I will focus on NGO, State and IDA collaboration for developing strong and effective educational systems globally. The relationship between NGOs, the State, the community, and the IDAs is represented through a linear model in the figure below. However, this relationship is much more complex. Then, I will focus on NGOs and IDAs in education in Pakistan. 


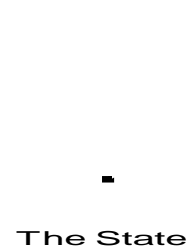

The Community

Figure 2: Partners in Primary Education: NGOs, State and the International Donor Agencies and their interaction with the communities to form schools.

\section{Partners in primary education: NGOs, State and the international donor agencies}

In this section of the dissertation, I describe the complex relationship and multifaceted partnerships between multiple stakeholders in providing education to children. These stakeholders are the NGOs, the state, the IDAs and the communities of teachers, parents, and children that they claim to serve. Institutionalization of alternative NGOs based education systems requires more reform work beyond the reach of the NGO and the local community; therefore, sometimes NGOs work in partnership with state agencies (Sutton and Arnove, 2004). The NGOs provide support and assistance with the help of public private partnerships. Some NGOs collaborate with international donor agencies and humanitarian aid agencies; while others operate solely on funds raised in the community or grants.

NGOs have collaborated with the state to good effect in the critical area of primary education. Based on their respective comparative advantages, and by urging from their donor communities, the NGOs are increasingly working with the state, 
forming partnerships geared towards supporting each other (Boukary, 2004). For instance, BRAC uses a strategy involving multiple-partnership scheme that involves the NGO BRAC, the rural communities, international donor agencies and the state educational agencies (Boukary, 2004). Similarly, Save the Children Foundation (SFC), working in rural schools in Southern Mali aimed at meeting the basic education needs of Mali's children via the expansion of partnerships at the community, local, regional national, and international level (SCF, 1995, as quoted in Boukary, 2004).

One of the ways NGOs influence education is by the host government adopting the NGOs innovations. Mali is a clear case in which the curriculum model developed by Save the Children for their community schools eventually led to a modification of the national curriculum (Miller-Grandvaux et al. 2002). A study conducted by Boukary (2004) points at the success story of the village schools of Save the Children/USA, an international NGO, in Mali. Save the Children's community school program in Mali was designed to resemble the BRAC school model. The village school curriculum and structure model was an inspiration for the government which later opened 20 centers following the village schools model. However, the partnership between the donor community and the government was initially fraught with problems. The study findings suggest that SCF/USA had overextended its organizational capacity in the creation of village schools in Mali. The lack of organizational resources to ensure quality education via community participation in the village schools compelled SCF/USA to involve the state educational agencies in the early stages of implementation and planning of the schools. There was not only misunderstanding and mistrust; but also the role of government agencies in the implementation of village schools was not officially spelled 
out in a memorandum of understanding between SCF/USA and the government. The state of Mali initially did not approve of SCF/USA's educational activities in the country. Their model of education deviated from the state norms in both the curriculum and their organizational structure. The qualification of the village school teachers was questioned as teachers did not have secondary education. One important lesson drawn from this study was that the international donor community had to rethink their communication strategies. The international donor community (SCF/USA) had to create and strengthen partnerships with the democratically elected governments and powerful civil society actors such as village school teachers and their communities. The major threat was the substantial aid money being diverted from the State to the NGOs (2004).

In her study of in-service teacher training programs for primary teachers in India, Stacki (2004), highlights the importance of mutually successful partner relationships based on trust such as that developed between UNICEF, Government of India, and the teachers' union. According to her findings, UNICEF played a mediating role through the Teacher Empowerment Program (TEP or the in-service training) by aiding communication and cooperation between the teacher union and government so that Universal Primary Education (UPE) is not merely seen as just another top-down mandated policy devised by the national government and a donor. The goal of the program was to create more empowered teachers and develop collective ownership for universal primary education. This study reveals that although UNICEF was a small contributor in terms of money, it had tremendous importance as a strong ally, an interested party, and an agency that provides considerable support to the government toward achieving UPE. 
In both studies, the international NGOs, such as UNICEF and SCF/USA, worked not only with the governments to achieve their goals but also with local NGOs who were instrumental in implementing their school reform strategies. The studies also highlight the importance of partnerships between the key stakeholders: the governments, the international donor community, the local NGOs, the teachers, and the local community. Tensions may build, and conflicts may result owing to miscommunication between the key partners. In order to make a collaborative arrangement work, partners need to continue to communicate, trust, and respond to each other’s needs (Boukary, 2004; Stacki, 2004).

International donor agencies and education reform in Pakistan. Several international donor agencies work for education in Pakistan. For instance, the World Bank, The United States Aid for International Development (USAID), and The United Nations (U.N.) The United Nations basically operates at the level of creating, formulating, and implementing educational policy. World Bank, on the other hand, has little to do with the creation of policies for promoting universal primary education in Pakistan. However, efforts directed by the World Bank for providing loans and credits to support government infrastructure and strengthen growth of rural universal primary education (World Bank, 2008). The USAID also gives credits, grants, and loans to improve the system of universal primary education and child literacy in Pakistan.

These international donor agencies have several reasons to support universal primary education in Pakistan. As humanitarian aid agencies, in accordance with their mission statements and stated objectives and goals, work in Pakistan with the help and support of local non-governmental organizations. They also work with government 
offices to support the programs and services offered in the humanitarian needs arena. USAID’s education programs in Pakistan focus on empowering the local community by fostering partnerships between parents and teachers that improve accountability for the children’s education (Curtis, 2007).

In past years, owing to the geo-political crisis which has created a civil war like condition in the North West Frontier of Pakistan (NWFP), aid from the United States increasingly directs financial aid towards promoting egalitarian educational opportunities for disadvantaged children. According to Curtis (2007) United States assistance to primary education and literacy in Pakistan has more than doubled from \$28 million in fiscal year 2004 to $\$ 66$ million in fiscal year 2005. Since 2004, the United States. has provided \$200 million annually to Pakistan in the form of direct budgetary support.

The World Bank assists the Government of Pakistan in education reforms at the national and provincial levels. The support provided comes from development policy operation with a strong focus on primary and secondary education. These programs target increasing participation of girls and children from poorer households through intervention such as student stipends and conditional grant systems. The World Bank also works in partnership with the private sector to provide access to low cost quality education. In 2007, the World Bank approved operations worth \$430 million U.S. dollars for the provinces of Punjab, Sindh, and NWFP to help improve irrigation, education, and human development indicators through improvements in public finance, governance, and financial regulatory support (World Bank, 2008). The state’s failure to provide the delivery of basic services such as education and health has promoted the policies of privatization. 
Privatization operates on the principles of neo-liberalism. According to Chang and Grabel (2004), neo-liberals promote the policy of privatization, a policy that involves moving resources and enterprises from public to private ownership. The neo-liberals hold the view that state-owned enterprises or government agencies suffer from chronic inefficiencies, waste, and mismanagement. As mere hired hands, government agencies’ managers have no incentive to run efficient enterprises and even less of an incentive to improve their efficiency. In private sector, shareholders monitor management performance checked by market incentives and competition. Underperforming firms can receive discipline sanctions such as of job loss. (Chang and Grabel, 2004). Therefore, the neo-liberals promote that greater and greater share of delivery of public services should be contracted out to private contractors so that the state is free to do other things.

In the past, international donor agencies directly funded the Pakistani government for the provision of social services such as education and health to under-developed groups in Pakistan's urban and rural areas. The government and international donor agencies' heavily funded Social Action Programs 1 and 2, yet failed to reach the desired goals of providing universal primary education and basic health services to the poor (Haq and Haq, 1998). The failure of these programs in meeting their desired goals resulted in a change of policy. Instead of directly funding highly centralized bureaucratic federal government infrastructures, IDAs started working with grassroots community organizations or NGOs. The World Bank and regional development banks as well as bilateral agencies such as USAID increasingly have preferred to circumvent national governments to promote programs through NGOs, which they view as more efficient and 
accountable than the state (Sutton and Arnove, 2004). In addition, NGOs demonstrate the capable of carrying out grassroots reform initiatives.

During the formation of World Bank in 1945, an American Senator Robert Taft, discussed the limitations of American aid in the following terms,

No people can make over another people. Every nation must solve its own problems, and whatever we do can only be of slight assistance to help it over its most severe problems....A nation that comes to rely on gifts and loans from others is too likely to postpone the essential, tough measures necessary for its own salvation. (Korten, 1995, p. 168)

The above-mentioned excerpt points at the Pakistani dilemma almost half a century later quite adequately. Dependence and reliance on foreign economic aid has reduced the country’s capacity to solve its problems from within using its own people.

\section{Non-Governmental Organizations for Education in Pakistan}

The term NGO is commonly used in Pakistan by government, donors, and the NGO community to describe the non-profit and volunteer sector as a whole. (GhausPasha, and Iqbal, 2003). NGOs have an important role to play in meeting challenges of quality, access and affordability of primary education in Pakistan (Shah et al. 2005). NGOs operate many low-cost schools in the poor and rural areas of Pakistan; they have been quite successful in establishing schools for girls. NGOs have also helped with the expansion of government schools and the provision of in-service training to rural teachers (Anzar, 2002).

Classification of NGOs for education in Pakistan. In 1990, the Planning and Development Division of the Government of Pakistan surveyed registered organizations and found 8,380 NGOs. The registration framework severely limits the availability of 
reliable data documenting the scope, size, history, and legal position of such organizations (Anzar, 2002).

The involvement and the rapid growth of NGOs in the past decade is a result of greater access to foreign and local funds. The NGOs operate on a small or large scale based on their sponsorship, funding, and other resources available for them. In the case of NGOs working for education in Pakistan, I have categorized the NGOs based on their scale of operate such as regional, national, or an international, and their management.

This division is significant in understanding and assessing the impact, scale, and nature of their work.The first type of NGOs operates at an international level in multiple countries_-for example, Mercy Corps and Care. According to the Edwards and Hulme (2002), classification, they are the Big International NGOs. The second type operate at the local, regional, or national level-for example, Khoj- Society for Alternate Education, and Idara-e-Taleem-oAgahi (ITA). According to Edwards and Hulme's classification (1995), these will be the Southern NGOs at the same time they can also fall under the category of Donor Sponsored NGO based on the source of their funding. The third type of NGOs includes the Government Oriented NGOs; they exist to support and administer an educational program that is funded by an international donor agency and who partner with other state agencies to provide education to underprivileged children. For example, the Sarhad Rural Support Project (SRSP) is a Government Oriented NGO that simultaneously falls under the category of Donor sponsored NGO. The fourth category is the international NGOs formed by expatriate Pakistanis residing in the United States, for example, the Association for the Development of Pakistan. Finally, the fifth types of NGOs are formed by citizens of either the United States or the United Kingdom, 
for example, Central Asia Institute and Learning for Life. I have categorized both of these NGOs as Northern NGOs since their founders belong to the United Kingdom and the United States and their headquarters are located in these countries.

NGOs' work in primary education in Pakistan. For the purpose of the literature review, I have drawn on the following studies that contribute significantly to understanding the concept of NGO schools in Pakistan.

Khan (2005) did a qualitative study of a comparative institutional analysis of government, private, and NGO schools in Pakistan. The study was based on field observations; he reports that NGO schools were in many ways most successful in providing "good" education. NGOs in his sample were classified as single school NGOs or part of a multi-school program with a support system. The multi-school NGOs were more successful than the single-school NGOs; however, there were both "good" and "bad" NGOs in each of the samples. Students from NGO schools performed better on tests; teacher and student absentee rates were lowest; in-service teacher training was higher than the private and government schools; there was high level of parent-teacher interaction; the incidence of cheating in the exams was lowest and the schools facilities were the best. The study also revealed that strong management is the key to good performance as demonstrated by the sample of multi-school NGOs. In cases where the multi-school NGOs were strong and effective, the organization was not reliant upon a principal or a key administrator to make a difference.

In the most recent and significant study of the role of NGOs of basic and primary education in Pakistan, Shah et al. (2005) highlighted that NGOs have made a difference in providing primary education in Pakistan. Important lessons and best practices have 
emerged from NGOs' intervention; adopted, duplicated and implemented by the public sector, they will promote continued success . Nevertheless their contribution is short of substantial, partially because of the scale and nature of their involvement and because their role is not to replace public education.

Shah et al. (2005) found donor dependency to be the biggest challenge in making the programs sustainable. According to their findings based on six case studies of NGOs in Pakistan, sustainability is hard to achieve when time-constrained funds by the donors are exhausted. The drawback of a donor-dependent NGO is that the focus of the NGO's activity is driven by the donor's agenda. The acronym "NGO" can then have negative connotations by community members, as the NGO is perceived to fulfill the hidden agenda of a Western, international donor agency. Shah et al. (2005) indicated that the sustainability of the NGO schools or the NGO's educational program are dependent upon community mobilization. Most NGOs in their sample, mobilized the community to acquire land, labor, and capital for building the schools. Communities also helped in hiring teachers and monitoring the overall performance of the school. This process facilitated trust building and ownership of the project by the community.

The Aga Khan Rural Support Program (a donor sponsored NGO), funded by the Aga Khan Foundation, a private, not-for-profit entity in Pakistan, works on several kinds of development projects. According to a study by the World Bank (1999 as quoted in Burnett, 2005), the Aga Khan Rural Support Program (AKRSP) developed a proposal for community schools in mutual partnership with village organizations. Public response to the program was overwhelmingly positive. Between January and October 1995, a first round of 250 community schools opened. By March 1996, enrollment in these schools 
had reached 12,088 students, about $16 \%$ of primary enrollment in the regular government system. Among newly enrolled pupils, almost $61 \%$ were girls and nearly half the teachers were female. The majority of parents seemed comfortable with co-education as long as the community chose the teacher. Another 250 community schools have since opened, with assistance from the directorate (Burnett, 2005).

What happens in a successful educational program such as this? Among other things, it includes capacity building to promote transparent, accountable, and inclusive system management by local citizens. Studies have shown that there are benefits in using a community-based participatory approach with emphasis on capacity building (Anzar, 1999; Samant, 2005; Khan, 2007). Local community involvement can take different forms, from recruiting teachers to designing curricula and discussing pedagogy.

\section{Community-based participatory approach for NGO schools: Community}

\section{collaboration and participation}

Research has shown that an instrumental component of NGO schools' success is the use of a community based participatory approach. (Anzar, 1999; Samant 2005; Khan, 2007; Mercy Corps, 2007). When an educational facility opened, community mobilization played a significant role (Dryfoos, 2003). The community might be able to provide land for school construction, operations, or other resources. The process of community mobilization involved building coalitions and bringing people together to give them a voice. Collaborating with the residents of a community to provide social services needed in the area, such as education and health services, create a deeper sense of responsibility and ownership of the schools by the community. Once a school is open, community involvement continues and is facilitated through site councils, parent-teacher 
associations (PTAs), and school management councils (Khan, 2007). The purpose of the school management councils and PTAs is to provide opportunities for parents and members of the community to participate in school management decisions. Parental participation in school activities allows ownership, especially if the school administration is responsive to their suggestions (Khan, 2003). PTAs, if not managed carefully, can result in a power struggle between the key stakeholders.

Milam (2009) in a comparison of NGOs in Pakistan and Bangladesh claims that NGOs are relatively weak and far less influential in Pakistan than in Bangladesh. NGOs such as Grameen and BRAC in Bangladesh fund themselves from local sources, but maintain their independence and control even when accepting donor funding. However, NGO's dependence on donor money helps to undermine NGO acceptability in Pakistan (Zaidi, 1999; Milam, 2009). Milam (2009) further asserts that the growth of NGOs specializing in social services delivery in Pakistan has been slow, and many have been unable to sustain successful programs which have helped to increase skepticism about them.

\section{Synthesis of Literature}

Shah et al. (2005) highlighted several constraints within the framework of the NGO school model. Many NGOs in their sample were limited in their outreach because of lack of resources. The study found a lack of coordination among NGOs which led to duplication of financial allocation. Other problems included a high turn over rate among NGO personnel.

There are several other limitations to the NGO school model. NGO schools drain resources from the other elements of mainstream education. Schools run by NGOs are 
akin to running a parallel system with the mainstream government schools, and if government agencies collaborate with local community organizations to support these schools, resources are shifted from public schools to these community schools. In NGO schools, resource allocation moves from an emphasis on pre-service training to more instructional support and regulation. Furthermore, in the NGO school model, students' progression to upper division classes poses a challenge. For instance, in this model the schools usually cater to the early grades because in advanced and upper level grades there is a need for highly trained teachers with advanced education. Student transition from NGO schools to mainstream public schools may not be smooth owing to language or cultural barriers (Williams and Cummings, 2005).

A review of literature on the workings of NGO schools in Pakistan further strengthened the notion that the phenomenon of NGO schools has not been clearly documented in development literature (Samant, 2005). According to Khan, to date there is little systematic sector-specific information comparing the performance of NGOs with the government and private sectors in education. Many assertions about the performance of NGOs are based on a handful of case studies, anecdotal response, and preconceived notions. There is a need to systematically assess the contribution of NGO-based community schools, their potential for growth, the lessons derived from their practice and the social implications of their practice (2004).

Researchers working for international donor agencies, including the World Bank, UNICEF, and UNESCO, have undertaken much of the work in public or private schools providing primary education. Mostly, these researchers are economists. Some of the statistical regressions and Math ematical models that they employ make the discussions 
inaccessible and very complex to understand for education policy makers, primary school teachers, and ordinary people. Perhaps the reports are intended for an audience that is familiar with the methods employed by the researchers.

International experts who employ local research assistants for fieldwork have very often led research teams, for instance, in the BRIDGES and the LEAPS projects huge data sets were generated with the help of fieldworkers. Hired field workers who collect data and transcribe it for the researchers to find themes and patterns mostly carry out fieldwork and surveys. The actual researchers may or may not have ever set foot in the worlds that they are investigating. This is a common practice in the development research work, and researchers who did not conduct the interviews or make the observations themselves analyze the field data. The inherent danger in this method is failing to report important information; the report writer was not present in the field collections. The other question is that of hired field workers' reliability and training. This approach pays little attention to the process of learning, the conditions in which women teachers work, the way their work is regarded by their societies, or the meaning that children make and take from what they learn in textbooks. Research with a large sample set is not as sensitive to the diversity and the potential heterogeneity of the individual case under analysis (Aikman and Unterhalter, 2005).

A great deal of empirical work is concentrated on counting the numbers of children in or out of school and measuring the breadth of gender gap between girls and boys enrollment and achievement. Government ministries, including census departments, have carried out this work. District household surveys have been a key instrument in collecting data on school attendance. Additional surveys have looked at how household 
relations affect decisions about sending girls to school and keeping them there. This quantitative work on gender, access, retention, and achievement tends not to deal with other dimensions of inequality, particularly race, ethnicity, caste, and disability. While some acknowledgement of these differences between rural and urban children exists, there is little engagement with the complexity of social division (Aikman and Unterhalter, 2005).

There have been very few third party evaluations of the working NGO schools in Pakistan. An in-depth understanding and exploration of NGO schools will help develop an understanding of the way these schools function. The research on the functioning of NGO schools is important because NGO schools in Pakistan provide education to the historically underserved low-income or minority families. There is little research available on the education of children at the elementary level in Pakistan's schools. Most of the research on learning achievement in Pakistan's public elementary schools has been sporadic and anecdotal (Hoodbhoy).Statistical data have been made available online recently, however, the data focuses on current school enrollment, drop-out rates, and numbers of schools in the rural and urban areas, including their facilities and infrastructures. Some of the information that is available about interventions for school reform consists of internal reports written by employees of IDAs in evaluating their own work.

The following section of the dissertation will include a detailed description of the methodology. 


\section{Chapter Three: Research Methodology}

The previous chapter concludes that NGO schools in Pakistan provide education to children historically underserved (Haq and Haq, 1998; Khan, 2005). For instance: children in poverty, girls, children living in the rural areas, children living in urban peripheries and urban slums. In contrast, the elite and the middle classes receive benefit from the private school systems. The difference in schooling between the social classes exacerbates and further perpetuates the already existing disparities and inequities. Therefore, given the importance of good schooling in bridging the disparity between social classes, it is important to study the role of NGO schools in providing quality education to children in Pakistan.

In so doing, the purpose of this research study is to examine the efficacy of notfor-profit, private schools managed by non-governmental organizations (NGOs) in providing quality education to primary school children in Pakistan. The intent is to develop an advanced understanding and to describe the work of two NGO schools in providing education to children in rural and urban Pakistan. This study's aim is documenting the work of NGO schools and generating an analysis of what is happening in the field. With a qualitative fieldwork approach using critical case study strategy, I will provide a platform for teachers to gain insights from their practice. In so doing, I highlight the children in these schools, and make the needs of these children and their schools visible. Key-constructs of critical theory such as power, privilege, class, and gender are used as lenses to investigate the socially produced nature of knowledge and school experience (Giroux, 2009). 
It is hoped that a critique of NGO schools will contribute towards the larger critical discourse of inequities in Pakistan's school system. Furthermore, an analysis of how NGO schools provide education in Pakistan can have an impact on policy making and policy implementation cycles. This study is not aimed at providing a single recipe for success, which can be utilized everywhere; rather it intends to show a model which is functioning in a particular setting. In so doing, the following research questions will guide this inquiry:

- How does an NGO school provide education to primary aged school children?

- What processes and structures are evident in two NGO schools in providing quality primary education to children in Pakistan?

- What factors and characteristics are evident in two NGO schools that provide opportunities for teaching and learning?

The method employed for this study is a dual case study — a concentrated inquiry into two cases, a rural, and an urban NGO school. Stake (2008) defines a dual case study as two cases studied jointly to describe a phenomenon, population or a general condition. Individual cases in such a collection may or may not be known in advance to manifest some common characteristics. According to Stake (2008), the cases may be similar or dissimilar with redundancy and variety, each of which is very important. They are chosen because it is believed that understanding them will lead to better understanding, and perhaps better theorizing, about a still larger collection of cases.

No detailed case studies of an NGO school in Pakistan exist and the NGO school model has not been described previously. Case study methods such as interviews and observations can provide accurate information about how NGO schools function successfully or unsuccessfully in a setting where the public schools are either nonexistent 
or dysfunctional. A dual case study is best suited to observing, describing and explaining the teaching and learning in an NGO school because the NGO school represents a specific, unique, bounded system (Stake, 2008). The advantage of the case study is that it can close in on real life situations and test views directly in relation to phenomena as they unfold in practice. For a qualitative research design, Denzin and Lincoln (2008) propose that case study concentrates on experiential knowledge of the case and pays close attention to the influence of its social, political, and other contexts. The proximity to reality that the case study entails, and the learning process that it generates for the researcher will often constitute a prerequisite for advanced understanding.

Case study with its multiple data collection methods provides an opportunity to describe the school model and to compare and contrast across a rural and an urban school. The two schools combined should generate a very interesting and rich data set. The urban school will give a contrasting example to the rural school. According to Denzin and Lincoln (2008), no individual or case is ever just an individual or a case. Any case necessarily bears the traces of the universal and must be studied as a single instance of more universal social experiences and social processes. That is, to study the particular is to study the general. A social scientist justifies the study of the particular only if it serves in understanding the grand issues or explanations (Denzin and Lincoln, 2008).

\section{Site Selection}

The process for site selection for this study started in 2007. I started email correspondence with Ujwala Sawant after reading her article (Sawant, 2005); she referred me to three NGOs: Learning for Life, Inspire, and an NGO that was working in Northwest Frontier Province of Pakistan. Learning for Life (LFL), based in London 
operated schools in Pakistan and Bangladesh. I visited LFL's office in the United Kingdom and interviewed NGO personnel there in December, 2007. At that time, they were no longer operating in Pakistan and they had changed priorities for regional focus. The NGO in Khyber Pakhtunkhwa Province of Pakistan had 250 community schools; however, the war-like environment in Khyber Pakhtunkhwa prevented me from conducting the study there.

I contacted the NGO Inspire, in December 2008 and I visited their office on my trip to Lahore. Since I had access to the NGO office and the NGO school, I conducted my pilot study there in 2008. At the time of pilot study, there were no paved roads that led to the research site. I faced some difficulty in physically accessing the site. However, I selected an NGO school in a low socio-economic rural setting because of the vulnerable population of the school: students are children who might be pulled out of school if education is not perceived to be relevant to their immediate lives or if they are required by circumstances to act as contributors to the family's meager income. During the pilot study, not only was I able to gain access to the site, I was also able to build a mutually respectful, congenial and trust-based relationship with the NGO founder and the school staff. According to Janesick (2000), access and entry are sensitive components in the research process and the researcher must establish trust, rapport, and authentic communication patterns with participants. Inspire managed the rural school and regards community participation as a central element of its operations. The rural school also employs its own unique methodology for the teaching of literacy skills. I felt that the pilot study left a lot of questions unanswered which motivated a return to the site. 
I selected the second NGO, Pathways based on a case study conducted on six NGOs. I contacted all the six NGOs and only one, NGO Pathways, responded. I visited the Pathways office in July of 2009. At that office visit, the NGO administrator referred me to Sunshine school. Sunshine is operated by The Trust for Children’s Education. I visited the school in 2009 as well. Pathways' administrator is also the managing trustee in the Board of Governors of the Trust for Children's Education. I decided to study the model schools of NGOs, Pathways and Inspire, as both are referenced to in academic literature (Sawant, 2005 and Khan 2008).

\section{Site Description}

The site for this study is an underdeveloped country on the other side of the world from the researcher's academic base. However, it is the home country of the researcher. I have selected the two NGO school sites based on purposeful sampling technique (Silverman, 2000). The first school that I have selected for this study is the rural NGO school. The school is in a village and is operated by the NGO Inspire. According to Stake (2008), a case to be studied is a complex entity located in a milieu or situation embedded in a number of contexts or backgrounds. There are sites within sites for this study which are illustrated in the visual below.

Case study one. Case study one refers to the NGO School Kiran which is the rural school. Within case study one, site one is the school building which is located in the village of Risal Pind and site two is the NGO office which is located in Lahore. 


\section{CASE STUDY ONE: NGO School A}

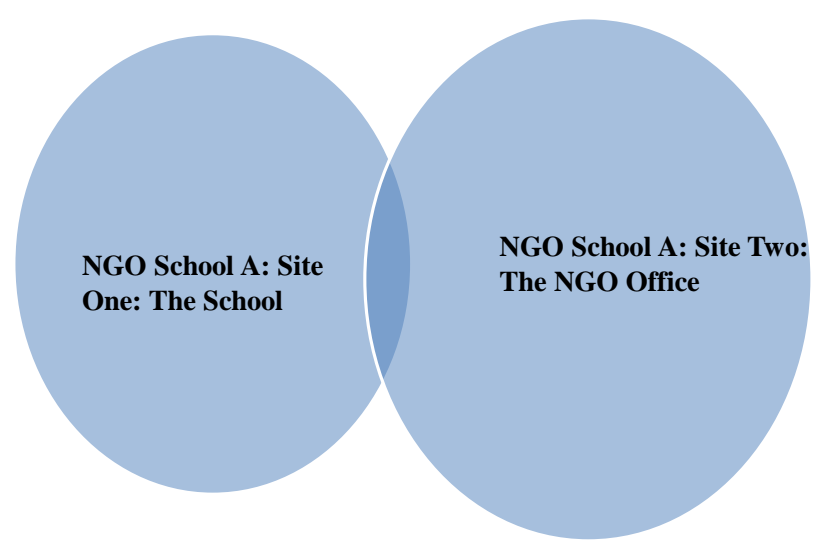

Figure 3: Case Study One: NGO School Kiran

According to the Inspire’s website, Kiran offers educational services to 175 children of more than six villages. These villages did not have access to a road or a health facility when the NGO started its operations there in 1994. The school is located in the village of Risal Pind which consists of 55 households. A local land owner donated one by fourth of an acre of agricultural land for the construction of the school. The original plan was to construct 14 rooms in the school. Upon the school visit conducted during the pilot study, I identified a total of four classrooms, a Science lab, and a computer lab. Three functional toilets were also present and a boundary wall surrounded the school. Six women are serving as teachers in school A. These teachers matriculated from the NGO's adult literacy program. Before these women matriculated, there was not even a single literate female who could be identified as a teacher in this school. Most of the students in the school are from low-income farming households (Habib, 2010). 
Case study two. The second school that was selected for this project is Sunshine school which is in an urban setting. The urban school is supervised by the Trust for Children's Education and the NGO Pathways supports its function and provides inservice training for its teachers. A trust is also an NGO since by the definition used in this study a trust is a private, not-for-profit, volunteer organization. The urban NGO school, Pathways, is more accessible in terms of its location. Trust for Children's Education was established in 1994. In 1995, the trust set up the Sunshine school which started as an English medium school for girls. Upon a school visit in 2009, I found out that the school caters primary to secondary school students. There are 517 students enrolled in the school and approximately 300 are enrolled in the primary grades. Sunshine is a co-educational facility. The school has 38 teachers, a community worker and 11 support staff members that are led by a school principal. Students are offered a bi-lingual curriculum in Urdu and English. Students attended the educational facilities free of cost including free textbooks, reference materials, and stationery. The Trust's original endowment provided all resources for the school including the land and building.

Figure 4 refers to case study two: the NGO Sunshine school. At Sunshine, site one is the building of the urban school located in an industrial area in Lahore. Site two is embedded in site one; it is the Principal's office which is located inside the school building. And site three is the NGO office which is located in an upscale residential area in Lahore. 


\title{
CASE STUDY TWO: NGO School B
}

\author{
NGO School B: Site one: \\ The School \\ NGO School B: \\ Site Two: The \\ Principal's Office \\ NGO School \\ B: Site Three: \\ The NGO \\ Office
}

Figure 4: Case Study Two: NGO School Sunshine

The urban and the rural schools are situated in different social, cultural, economic, and linguistic settings. The only two similarities between the two schools are; they are both managed by NGOs, and both cater to children belonging to lower socio-economic groups who, in the absence of these schools, would not have access to primary education.

\section{Data Collection}

Data collection occurred to answer the following overarching research questions:

- How does an NGO school provide education to primary aged school children?

- What processes and structures are evident in two NGO schools in providing quality primary education to children in Pakistan?

- What factors and characteristics are evident in two NGO schools which provide opportunities for teaching and learning?

The term processes refers to series of functions bringing about an outcome.

Processes specific to teaching and learning include methods of teaching, assessment, and curriculum and materials selection. Processes are also used in the management of the 
schools. This includes, for example, recruitment, hiring, firing, and training of teachers; and other management functions such as decision-making. Structures refer to the different groups of individuals that are involved in the daily management and operation of schools. This includes, for instance, teachers, students, principal/administrators, governing bodies or Trusts, and parent teacher associations. The term structure also refers to the hierarchical and social structures that overlap and help in management and governing of the school.

Primary sources of data. The primary sources of data are transcriptions by interviews, field notes produced through observations and documents. Photographs were used to create a visual landscape of the schools and the classes. Photographs further added to the field notes. Documents such as two teacher-training manuals written by the rural school's NGO administrator were used. Additional information used included lesson plans, teacher handouts, and brochures from the urban school.

Data collection strategies. The case study as a method relies on interviewing, observations, and document analysis (Denzin and Lincoln, 2008). The methodology involved an analysis of artifacts, participant observations, photographs, group interviews, interviews, and a research log. The following data collection strategies were used during the course of research.

Analysis of artifacts. The two NGOs have their own websites both of which are in English. The websites give the complete list of activities of the two NGOs, the different projects and the various schools that they are currently working on or have worked on in the past. The websites give information about the mission statement, the core philosophy, and the instructional methodology used in these schools. Moreover, 
numbers about the budget and the donors are also listed. The two NGO websites also provide details about the schools that are the focus of this study. Details include number of rooms, teachers, and students. By including the websites in the data collection strategy, demographic data about the numbers of students, teachers, and rooms was collected in the preliminary stages of data collection. This information was corroborated with the actual number of teachers, students, and facilities during school observations and interviews. The information on the website established the level of transparency evident in the working of the NGO and the school and the kinds of information readily available about a particular school. Other archival information collected included information about school policies, data on student retention, and student recruitment. An example of such data consists of brochures, pamphlets, and other policy documents. The data served as a prompt for further probing during interviews. Information from these sources constituted data that already exists in the public sphere (Silverman, 2000).

Classroom observation. Classroom observation is used to cover a mixture of observation and interviewing. A considerable amount of time was spent writing the field notes and systematically putting down initial insights into the setting. Participant observation does not mean doing what those being observed do, but interacting with them while they do it (Delamont, 2005). I observed early childhood classes and first through fifth grade to observe teaching and learning practices. I observed how children learn to read, write, and think critically. I took field notes on teacher-student interactions to do an analysis of what questions instill critical thinking skills in children. I took notes about the teaching of functional literacy skills. Permission was obtained from the classroom instructor to observe. A central problem of observation is that individuals, conscious of 
being observed are likely to behave differently than usual, often in a more socially accepted manner or in accordance with the observer's expectations (Krathwohl, 1997). I requested that the instructor inform students in advance about the presence of the researcher during the class sessions. It was also requested that the instructor introduce the researcher to the students so that they know the reason why someone is invading their space and privacy. If the students knew the purpose of the study, they felt less inhibited by the constant scrutiny of an outsider observing them and taking notes.

Photographs. I took photographs of the school buildings, facilities and teacher and students in interaction throughout the study to produce a visual landscape of the schools. The conditions and environment of the schools are different from each other. I focused on producing a detailed and authentic representation of the school facilities through digital photographs. Photographs allowed access to the activities where my presence would have otherwise caused some consternation. Since I took pictures of most of the things, I was visible on campus. It was assumed that generally my role was not restricted in talking to teachers and students but I took an active interest in student's work displayed on the school bulletin boards.

Interviews. The interviews were of two types: group and individual interviews. The following groups of individuals from both schools were interviewed for this study

- Children interviews $(\mathrm{n}=10)$

- Teacher interviews $(\mathrm{n}=10)$

- Administrator interviews $(\mathrm{n}=3)$

Informal conversations that occurred on the field were also a part of the data collection process. Informal conversations took place with several individuals: including 
principal of the urban school, NGO's board members, NGO's staff, donors, supporters, teachers, students, parents and community members besides the participants listed above. Group interviews. Group interviews were conducted with groups of teachers and students on-site at Kiran and Sunshine. Initially I had planned to conduct one group interview of teachers at school Sunshine. I had planned to interview 4-5 teachers for an hour. I had planned to conduct two group interviews with 4-5 teachers in each session at school B. Each group interview session was supposed to be an hour long. The purpose of the group interviews was to gather a group of teachers and then ask them some general preliminary questions. A group interview helps in funneling the questions. It also helps in determining which responses require further probing and/or clarification. With the help of the group interviews, participants were selected for the next phase of data collection: indepth interviews. The group interviews allowed for interaction between the participants which enabled the researcher to obtain more responses.

I conducted one group interview with teachers at Sunshine which was audio recorded. The interviews were conducted in one of the classrooms, with about 12 teachers. The teachers chose to be a part of the interview. The Principal introduced me to the group and then both of us asked the teachers present if they could volunteer their time for a group interview. The interview lasted about 30 minutes. At the rural site, I interviewed two teachers for approximately 30 minutes, I then conducted a second group interview with two teachers and three more teachers later joined us and the conversation lasted for 30 minutes. In both schools, I talked to several groups of teachers informally throughout the length of the fieldwork. Those conversations were not recorded. 
The group interviews at the rural school were interesting in the sense that the concept of privacy was different at the rural site. I would start a group interview with two teachers and several other teachers would join during the course of the interview. It made me uncomfortable in the beginning because I felt that teachers would be hesitant to speak freely in the presence of others who later joined the conversation. However, teachers were more comfortable in a group setting. It lessened their apprehensions and they were able to talk in a relaxed environment. I was also able to generate more thick descriptions in that way. The group interviews were tape-recorded and data was transcribed from the interviews.

Individual interviews. I interviewed the NGO directors of the two schools. I conducted interviews with the principal, teachers, and students from Sunshine and Kiran. All interviews were audio-taped primarily in Urdu since the teachers and administrators were comfortable communicating in their own (for some their only) language. There was code switching from Urdu to English as well. I took notes during the interview in Urdu and English; however, I transcribed all the notes into Urdu and I translated all notes into English. I looked for emerging themes in finding answers for the research questions. I interviewed the directors of the two NGOs at the NGO offices both of which are located in Lahore. I conducted multiple interviews with them for a minimum of three to five times. I interviewed five teachers from each school. The interviews were conducted onsite at the schools where they work. I interviewed at least five students from each school so that I was able to collect information about their experience in the school. The children were interviewed individually through open-ended questions. I took notes during the interview and reflected in a research log with the help of these notes after the interviews. 
I conducted more than 20 individual interviews with teachers, students, and NGO staff. All the interviews were audio recorded. Informal conversations with individuals were not recorded. All the interviews occurred face-to-face.

Research log. A research log was kept throughout the research process. The research $\log$ is a written account of all the research activities with dates (Silverman, 2000). It also served as a reflective tool on my status as an insider and outsider in the research setting. A reflexive approach to maintaining a log throughout the study involves a statement of positionality as well as a regular, ongoing, self-conscious description of research processes (Huberman \& Miles, 1994).

\section{Participant Recruitment}

There were twenty-three participants in all: two directors, one principal, ten children, and ten teachers. The directors of NGOs and the principal were approached via email whereas the teachers and the students were interviewed in face to face meeting conducted at the school. The teachers and students were recommended by the director of the NGO or the principal of the school. The participants' characteristics such as their age, ethnic or educational background did not determine the criteria for their selection.

Students were selected by referral from their teachers. Access to participants was through the directors of the NGOs and the principal of the school who are gate-keepers and informants in this setting. The key strategy was to interview a representative sample of teachers; teachers who are novices as well as experienced, and teachers who used a variety of practices in their classes. The group interviews were also used as an opportunity to recruit participants. 


\section{Research Timeline}

The study was conducted in Summer and Fall of 2010. I conducted group interviews, individual interviews and observations from July through December, 2010.

\begin{tabular}{|c|c|c|}
\hline Time-frame & Processes & Outcomes \\
\hline May 2010 & Defend the Proposal & - $\quad$ Proposal Defense \\
\hline June 2010 & Get the Human Subjects Review & - Human Subjects Approval \\
\hline July 2010 & $\begin{array}{l}\text { Arrive in Pakistan } \\
\text { Re-connect with the NGO } \\
\text { administrators and Principals }\end{array}$ & $\begin{array}{l}\text { - Re-establish connections on- } \\
\text { site }\end{array}$ \\
\hline $\begin{array}{l}\text { August } \\
2010\end{array}$ & $\begin{array}{l}\text { Begin on Site Data collection } \\
\text { Visit the rural school A Site } 1 \\
\text { Visit School A Site } 2\end{array}$ & $\begin{array}{ll}\text { - } & \text { Data Collection Phase } \\
\text { - } & \text { Conduct interviews } \\
\text { - } & \text { Observations } \\
\text { - } & \text { Document Analysis } \\
\end{array}$ \\
\hline $\begin{array}{l}\text { September } \\
2010\end{array}$ & $\begin{array}{l}\text { Visit the urban school B Site } 1 \\
\text { Visit school B site } 2 \\
\text { Visit school B site } 3\end{array}$ & $\begin{array}{ll}\text { - } & \text { Conduct interviews } \\
\text { - } & \text { Observations } \\
\text { - } & \text { Document Analysis }\end{array}$ \\
\hline $\begin{array}{l}\text { December } \\
2010\end{array}$ & $\begin{array}{l}\text { Return to US. } \\
\text { Transcribe all data }\end{array}$ & - Data Analysis Phase \\
\hline $\begin{array}{l}\text { January } \\
2011\end{array}$ & $\begin{array}{l}\text { Analyze the data } \\
\text { Write the findings and analysis }\end{array}$ & $\begin{array}{l}\text { - Data Analysis Phase } \\
\text { - Dissertation writing }\end{array}$ \\
\hline $\begin{array}{l}\text { September } \\
2011\end{array}$ & $\begin{array}{l}\text { Follow-up visit } \\
\text { Member-check }\end{array}$ & $\begin{array}{ll}\text { - Data Analysis Phase } \\
\text { - Dissertation writing }\end{array}$ \\
\hline $\begin{array}{l}\text { January- } \\
\text { June } 2012\end{array}$ & Final writing & - Dissertation Defense \\
\hline
\end{tabular}

Table 1: Research Timeline 


\section{Data Analysis}

Data analysis for this project was inductive and on-going. According to Maxwell (2005), it is important that qualitative researchers start analyzing the data with the first field observation and with the first interview.

The primary source of data analysis was textual analysis. The study produced copious amounts of thick descriptions in the form of textual and image data. For instance, data generated through interview translations and transcriptions, policy documents for archival analysis, and field notes produced textual information. Image data generated through photographs was used to further add to the visual landscape of the schools.

Data generated through transcripts was listened to, written in Urdu and translated into English. Tentative ideas about themes were determined while listening to the transcripts and writing them (Maxwell, 2005). The next step in data analysis was to read the textual information as narrative and further finding common themes. The data was coded for commonly recurring themes. The categories for coding were not predetermined but the goal of coding was to fracture the data and rearrange them into categories that facilitate comparison between things in the same category as well as aid in the development of theoretical concepts (Maxwell, 2005). Codes were inductively generated and emerged from participants' descriptions of teaching and learning in their schools.

Furthermore, data were analyzed under specific research questions as headings until a matrix of information was created under each question which enabled the researcher to answer the specific question and the broader research question (Stake, 2008). Matrices are constructed from the data and are used to identify patterns, comparisons, trends and paradoxes (Maxwell, 2005). For example, during the pilot study, 
my main research question was: how does the rural school provide education to children? I asked specific research questions about the type of curriculum and pedagogy that were being used in the school. The responses that were generated during the interviews and observations stressed the importance of conceptual clarity and understanding, roleplaying, student-centered teaching and a strong disdain for rote memorization. For an indepth understanding, further questions about these concepts were devised so that the participants were able to elaborate upon the information that is generated under these matrices.

Denzin and Lincoln (2000) identify some key steps for data analysis and suggest the following steps:

1. Locate within the personal experience, or self-story, key phrases and statements that speak directly to the phenomenon in question.

2. Interpret the meanings of these phrases as an informed reader.

3. Obtain the participants' interpretation of these findings

4. Inspect these meanings for what they reveal about the essential, recurring features of the phenomenon being studied (p. 390).

Data reduction was employed at this stage that referred to the process of selecting, focusing, simplifying and transforming raw data (Silverman, 2000). Constant comparative method was used to test initial hypothesis formed by primary data analysis (Silverman, 2000). Once I developed an understanding of School A (Rural: Kiran) and School B (Urban: Sunshine), I began cross-case analysis. Patterns and themes were sought by construction of cross-case displays and matrices.

Critical field-work is a collaborative endeavor (Carspecken and Apple, 1992) so participants' interpretation of the findings were obtained throughout the process and during data analysis. For example, while conducting individual interviews I verified with the participants if I had accurately understood the statements that they had made during 
the group interviews. I asked further probing questions so that they had an opportunity to explain and clarify their point-of-view. Furthermore, I discussed my preliminary analysis and conclusions with the research participants. Participants were asked for feedback on data collection, data analysis and conclusion throughout the process.

\section{Informed Consent}

The informed consent followed the 13 guidelines provided in the Portland State University’s Human Subjects Review form. I presented two copies of the informed consent for participants to sign. I kept one for my files and gave them one to keep for their record. The informed consent was translated into Urdu. I explained the contents of the document in Urdu to ensure that participants fully understand that there are no risks associated with participation in the research project. Their participation was voluntary and at any time they could refuse to answer any questions. The informed consent addressed issues of confidentiality and anonymity. The participants were not provided with any monetary benefits for taking part in the study. No compensation was offered.

\section{Validity}

Validity in qualitative research requires description and explanation and whether the explanation fits the description or not (Denzin and Lincoln, 2000). Validity in qualitative research is also concerned with truth telling and authenticity of descriptions (Silverman, 2000). Case study gains credibility by thoroughly triangulating the descriptions and interpretations, not just in a single step but continuously throughout the period of the study. In this project, data triangulation will be ensured by the use of a variety of data sources. Other ways of ensuring validity, as elucidated by Maxwell (2005) for instance, repeated observations, as well as sustained presence of the researcher in the 
field will be employed. Prolonged stay on the field site helped to rule out premature theories and helped to test out alternative theories. Further validation was achieved by discussing my analysis and conclusions with the research participants. The goal in data analysis was to build a logical chain of evidence and to construct a conceptually coherent description by checking for rival explanations and looking for negative evidence (Maxwell, 2005).

The researcher bias in interpretations of the findings can occur because of the researcher's multiple and intermingling identities. My identity on the field site was that of an academic researcher; however, I am also a native insider because of my Pakistani and Punjabi identity. Bias was reduced with the help of a researcher's log. The researcher reflected on the insider and outsider identities and perspectives with the help of a research log. Awareness that I am not merely an observer and a data gatherer but also a learner was helpful.

Ethical issues. Design decisions are made throughout qualitative research to address any issues that arise as a result of unforeseen circumstances (Janesick, 2000). Stake (2000) argues that in order to avoid ethical problems, a case study researcher needs constant input "from conscience, from stakeholders, and from the research community p.372." I had intended to be particularly careful of the ethical issues that might arise as a result of power imbalances between the participants and the principal investigator. The researcher is a privileged individual studying at a prestigious university in the United States. The researcher had higher status role. Distance through rank can bring certain protections but it is a delicate issue. The researcher has advanced degrees that might put the interviewees and those being observed at a disadvantage, as they might be 
uncomfortable with the researcher's prior knowledge and experience of working in school settings. I was careful in acknowledging the power differentials and made sure that the participants understand that my role was primarily that of an investigator wanting to add to the existing set of data on the working of NGO schools so that the participants felt at ease and were not focused on putting up a special performance for the researcher's presence. The participants were assured that the information that they provided about the school management and teaching would be kept confidential. It was made clear that the researcher is not involved in hiring, firing, promotion, compensation decisions in these schools and the information that the teachers provide would not be used to make such management decisions.

In a culture with a strong and traditional definition of masculinity, female researchers may also run the risk of unforeseen circumstances. In order to ensure safety and security, all field visits were carried out in the presence of a reliable and trusted accompanying person. Furthermore, I limited interactions with members of the opposite gender in the rural setting since such interactions are not viewed favorably and might reduce the researcher's credibility in that setting. However, no such limitations existed in the urban setting where the male and the female staff work together in the NGO office.

During the course of the interviews, teachers involved in the study had a voice and an opportunity to reflect on their condition. The researcher was ethically responsible for making sure that her interactions with the participants provided a safe space for teachers where they can address the issues, their doubts and their concerns. Building trustworthy relationships is important in qualitative research. Ethics also touch on the representation of data. In this stage of the research process, trust is associated with 
fidelity—defined by Thorne (1998) as "the obligation for truth telling”—and fidelity is especially vulnerable in secondary analyses. The final report should give adequate representation to the subjects' voices by quoting directly from the interviews whenever possible. Kvale (1996) claims that accurate written representation of the oral accounts given by the interviewee is an ethical aspect of qualitative research. The researcher can address the need for a platform or a mechanism to address the issues and concerns the study might raise for the teachers.

Reciprocity. Research participants not only give researchers time but share their private stories with them. Participation in research was not only voluntary, it was also without compensation. According to Eder and Fingerson, reciprocity is one response to power dynamics and can take place on several levels (2002). Conducting multiple interviews with the same interviewee promoted a deeper understanding of his/her life experiences and led to empowerment by encouraging self-reflection (Ryen, 2005). Reciprocity can also be materialized as taking something back to the community in which the study takes place or including some form of social action or change (Foley \& Valenzuela, 1999). Lack of reciprocity is definitely an ethical challenge. An ethical dilemma is not being able to contribute to improving the situation of the interviewees.

Reciprocity in South Asia culture can take many different forms that might be not be the norm or expected mode of behavior in a Western cultural paradigm. For instance, while doing the pilot of the study, the principal investigator was asked to volunteer for class-room decoration, for help in fund raising for the school and for assistance in providing a doctor and other resources for the health care project. This might be unusual to the Western eye. However, favors are expected to be returned by favors in South Asian 
culture, and not returning a favor is considered selfish, ungracious behavior. The principal investigator handled this delicate situation very carefully since when she is in the field she is wearing her researcher hat but she also identifies as a South Asian, having insider's knowledge of what is expected of her in this setting.

\section{Re-Entry to the Site}

I had mapped the two sites on my previous visits to Pakistan in 2008 and 2009. In 2008, I had conducted a pilot study at the rural school. I did not have difficulty in accessing the urban site but Kiran was difficult to access. I had to wait for two months to enter the rural school. Initially, at Sunshine, I found it difficult to explain multiple times that I was only interested in first through fifth grades for the purpose of this research study. Even though I had turned in paper work to explain my project and I had explained what I was researching, I constantly found myself being sent to upper division classes, senior school coordinators, and senior teachers. Once I connected with the junior school coordinator, the research objectives became clear to her. She sent me to nursery and prep classes but finally understood that my research drew its parameters around teaching and learning from first through fifth grade. I assumed that perhaps the teachers and the administrators viewed their school as an organic whole and it was hard for them to actually draw boundaries rigidly around primary, middle, and senior school. It could also mean that they were more interested that I talked to the older children who are more articulate and interview more qualified and experienced teachers who catered to the senior classes.

Follow-up visit . I returned from Pakistan in December 2011 and conducted data analysis from January through September, 2011. After preliminary data analysis, I 
conducted a follow-up visit of the two schools in Fall of 2011. I visited Kiran school twice and I visited Sunshine three times during my three months stay in Lahore. While I visited the schools I did the following: took extensive field notes; kept a reflection log; and met the teachers and the students and asked follow-up and clarification questions. I went to the NGOs' offices and I gave the administrators a two paged report about the schools. This allowed for an opportunity to initiate conversations about member check and participants’ feedback. The Principal at Sunshine asked me to make some minor adjustments to the narrative. Pathways founder, Meera, invited me to present the findings in front of a small audience of donors and participants. The resulting conversation and clarifications further enhanced my understanding of the key themes.

\section{Limitations of the Study}

A case is expected to generate context dependent knowledge and how the case is chosen is important in terms of whether it can be generalized. The study produced copious amounts of textual and image based data all of which is not reported in the findings. The study is not focused on the multiple roles and projects that NGOs perform in providing education to children rather the focus is only on the specific schools that are selected for the research.

\section{Synthesis}

The study will provide a much needed understanding and documentation of the work of NGO schools. A small body of literature exists that partially describes NGO schools that provide education in Pakistan. We want to know how the community is mobilized in the process, how the schools provide quality education to the student population, and how these schools are different from public schools and for-profit private 
schools that cater to the children belonging to low income groups. The study will provide an understanding of how NGO schools provide education to disadvantaged children. The participants in the study will benefit as well from reflecting on their practice and discussing the practice with the investigator. The research design, in part, will work towards empowering the teachers, and giving them an opportunity to have their voices heard. 


\section{Chapter Four: Case Descriptions}

\section{Case Descriptions}

The data analysis for this research project was carried out in three layers. The first layer of data analysis is the case descriptions. The second layer of data analysis is the thematic description and the discussion is an attempt at answering the research questions and connecting it back to the over-arching, broad arguments found in the literature. To that end, the case descriptions attempt to address how the two NGO schools provide education to children. The case descriptions and thematic analysis are written also in response to address the second research question regarding the structure and processes that are evident in these two schools as well as the third research question about factors and characteristics that support teaching and learning.

In the first part of the findings, I present case descriptions of the rural and the urban school. The purpose of these case descriptions is to answer the first research question: how does an NGO school provide education to primary-aged children? Case descriptions are also being used to situate the study into context. The descriptions emerge directly from the data collected. Through case descriptions, I narrate the stories of the children, teachers, and administrators and in so doing, make them visible.

The section on case descriptions is divided into two parts. The first part is a detailed description of the rural school's NGO (Inspire) and the school (Kiran). The second part is a description of the urban school's NGOs, (Pathways and The Trust for Children's Education) and the school (Sunshine). The description of the NGOs consists of how they started and how the two NGO schools were formed. In order to achieve clarity, it is important to make a distinction between the NGO and the school. In the two 
school descriptions that are being represented through these findings, it is imperative to distinguish that the school and the NGO are two separate and distinct organizations that even though intricately linked, operate and perform their own functions. Both the NGOs and the schools are inter-connected and inter-related as is the earth to its sun in the solar system. However, each has its different areas of operation, specific duties and specific functions that it performs. They constantly overlap but their circles of influence are different from the other. The narrative then focusses on a detailed description of the rural and the urban schools. In this section, I briefly describe the social context of the two schools, and the community that the schools served. Owing to issues of confidentiality and anonymity of the research participants, the geographical location of the setting is described in a way so that the schools cannot be identified. Then I describe the schools, the resources and the facilities that exist within the schools, followed by a brief profile of students, teachers and administrators. Next, I describe the choice of curriculum and teaching methodologies used in these two schools.

\section{School Formation and the NGO: Kiran School and Inspire}

This section presents a brief description of the origins of the NGO, Inspire, and Kiran School. The NGO Inspire's office is located in a modern, residential area in Lahore. The NGO is the parent body of the rural school, which oversees management, provides training, mobilizes community, and generates the primary funds. In the rural school, the NGO's operational person, the face of the NGO, is the founder who also performs multiple roles and functions. The rural school's NGO founder, Nargis, came across the rural site as she was working on a rural women's health services project, which was funded through Canadian International Development Agency (CIDA) in March 
1999. Once she saw the community and the dire circumstances in which they existed, she pulled all her resources together and decided to help them. The school started with contributions from individual donors. The NGO started working in 1995 and registered as an NGO in 2000. To create community ownership, this NGO developed the literacy of local women for three years. After the program with women, the NGO started working with children’s primary education in ten villages (Khoj, 2012). In 2003, a local landowner donated one-quarter acre of land for the current building. Rooms and boundary walls were built in 2004. The construction has been ongoing ever since.

The opening of the school in this small rural village is the story of an "unending struggle” (Khoj Facebook Page, 2011). Before the NGO started a school, the vicinity was served by a public school with only an occasional teacher. Initially the NGO director gathered a handful of adult women from the community with five years of instruction at that public school. She developed the phonics method of teaching literacy in Urdu that was interactive and increased the confidence and mastery of functional literacy skills of these women. The women acquired literacy through a curriculum designed specifically in conversations with the learners. The founder of the NGO developed the Inspire approach of adult literacy over a period of 18 years working with 20 local villages This program is, “A viable education program that is relevant, needs based and action oriented” (Khoj Facebook Page, 2011). The textbooks and materials published in the development phase were used to help these women learn basic literacy skills and functions. First the women learned to read and write phonetically, and the classes were held in the house of a village family. After acquiring literacy skills, they studied textbooks from the government's 
prescribed curriculum to appear in the matriculation exam, which is equivalent to getting a high school diploma.

Once these adult women began to develop self-confidence in their academic skills, they developed a desire to educate the children of the village. According to one participant, "It was then that they started feeling embarrassed that they were studying and their children were not” (Personal Communication with Aneela, 2010). This is when they first realized how important it is to read and write and solve every day-life math problems not only for themselves but also for their children. An awareness of the importance of education was instilled in these women. This is when they began to advocate for their children's education. These were the first women who matriculated in their villages and some of these villages have been inhabited since Mughal Rule which spans from 15261857. Once the women were literate they received regular training, monitoring, and oversight visits; then they provided education to the children from the same community. The Inspire team visited the school every other day to train the locally hired teachers. "This was something unprecedented in the history of the area; absolutely illiterate women working in the mud of agricultural fields emerging as educated women teaching in (the) schools” (Khoj, Facebook Page, 2011). The NGO founder not only developed a technique for literacy instruction in Urdu, she developed a sense of achievement and sense of ownership among these rural women. She possessed the drive and the passion to mobilize a community. She identified a few women who acted as agents of change and then gave them different tasks. She vowed to bring financial resources to the community if they agreed to do their part. The plan then materialized with the help of village folks, both men and women. She asked them to donate the land to the NGO; asked them for 
help raising funds for the laborers who will work at the building and will assist in school construction. To monitor and to provide some oversight for the planning process, a detailed needs analysis survey was conducted of the two villages and the surrounding villages. Once the land was donated at the name of the NGO, it became the property of the NGO. The NGO founder, Nargis, provided over-sight, management, guidance, and direction. She also enabled the villagers to build consensus and share information in committee meetings and community gatherings.

The NGO Inspire also provides education to the children by taking care of their basic health related needs. The health center was created after the school was formed. The community donated land to the NGO and provided labor, food, and shelter during the construction of health center. It is a modern building with modern equipment and access to first aid kits, medicines and tools for testing high blood pressure and diabetes. School staff, women who were educated from the school, were provided training in Lahore to act as health care providers at the rural health center. Two doctors were appointed who visited the health center from Lahore twice a week.

The NGO, the school and the health center are three separate entities but the same people manage their functions. Since the scope of the study was just the school and not the health center, the health center and its various operations and functions were not taken into consideration. The NGO, however, did arrange for training, building and supplies for the health center so that individuals could get treatment for minor health related illnesses and problems. 


\section{Funding.}

The school claims to have been built without international donor support.

However, the NGO founder, Nargis, came across the school site when she was working for a project for women empowerment with the Canadian International Development Agency (CIDA). The books for adult learners were published by the support and grant money that came from CIDA.

There are individual small private donors that support the functioning of the school. The annual expense of the school was not more than 300,000 Rupees $(3,750$ USD). The NGO founder mentioned that with almost 3 million Rupees (37,500 USD) they could run the school operations more conveniently. There are only six teachers that make a small amount of money, ranging from Rupees 3,000 (USD 37) to Rupees 10, 000 (USD 125) per month, and they are not spending much on teacher salaries. The utility bills, supplies and materials are the next biggest expense.

There is a health center associated with the school. Another expense would be supporting the functions of the health center. However, the donations for school and for the health center go into two separate accounts in the Royal Bank. The total amount of money that the NGO generates and the percentage of the total money it uses for its operations and management and the amount of money it spends on the two organizations, the school and the health center is not known. Much more information is needed to factor those costs, and that kind of data collection was beyond the scope of this project. 
School's Annual Operational Budget

PKR

Amount in USD

Human Resources

738,000

$\$ 9,225$

Stationary and Teaching Materials

48,000

$\$ 600$

Computer Lab

22,000

$\$ 275$

Science and Agriculture Lab

18,000

$\$ 225$

Library

20,000

$\$ 250$

Teacher Training

100,000

$\$ 1,250$

School Operational Cost

55,000

$\$ 687$

School van and travel

150,000

$\$ 1,875$

NGO’s monitoring and coordinating cost

366,000

$\$ 4,574$

Total Cost (1-9)

$1,517,000$

$\$ 18,962$

Money Requested for Construction of three additional

classes

1,170000

$\$ 14,625$

Total Requested

$2,687,000$

$\$ 33,587$

Total Cost per child

632

$\$ 8$

Table 2: Kiran School's Annual Operational Budget. (Email Correspondence with Nargis for fund raising purposes. 2009).

There is discrepancy in the numbers provided in the interview data versus numbers that are displayed in this table. The discrepancy stems from the fact that less money was spent on operational cost of the school than what is shown in the table. For the purpose of fund raising the ideal amount to be spent on various operations is shown in the budget.

The children do not pay any fee to attend the school. They have to buy their own uniform and stationery. However, the land for school building was donated by a 
community member and the land was then named after the NGO. The labor to build the school and the health center came through the support of the local village members; in kind support, in the form of hours, donated food, and shelter provided to the laborers, contributed toward offsetting the total cost of constructing the building.

\section{The Kiran school.}

The Kiran school is approximately an hour drive from Pakistan’s most recently built, modern highway, Motorway 2, which connects Lahore to Islamabad. The initial screening visit of the school and images available via digital maps through Google Maps revealed that it is not too far, approximately 12 kilometers off the main road, from a densely packed, small city. The road that leads from the highway through various small cities had productive rice fields on both sides. Several rice mills and brick producing kilns were visible along the road. Modern facilities and accommodations such as highways, roads, cars, buses, schools, colleges, hospitals, electricity, and running water exist not too far away from the school site.

After passing through the small city, and while entering the path that leads to the villages, the paved road ends. A dirt road leads closer to the villages that the school serves. Along the way, the dirt road leads to a field with wild grass growing as high as six feet tall. A turn in the pathway that is flanked by wild grass on both sides, opened into acres of fields. There are several turns on the narrow pathway that marked the boundaries of the fields. The only signposts were irrigation ditches, used to water the field, branching through a small canal. 


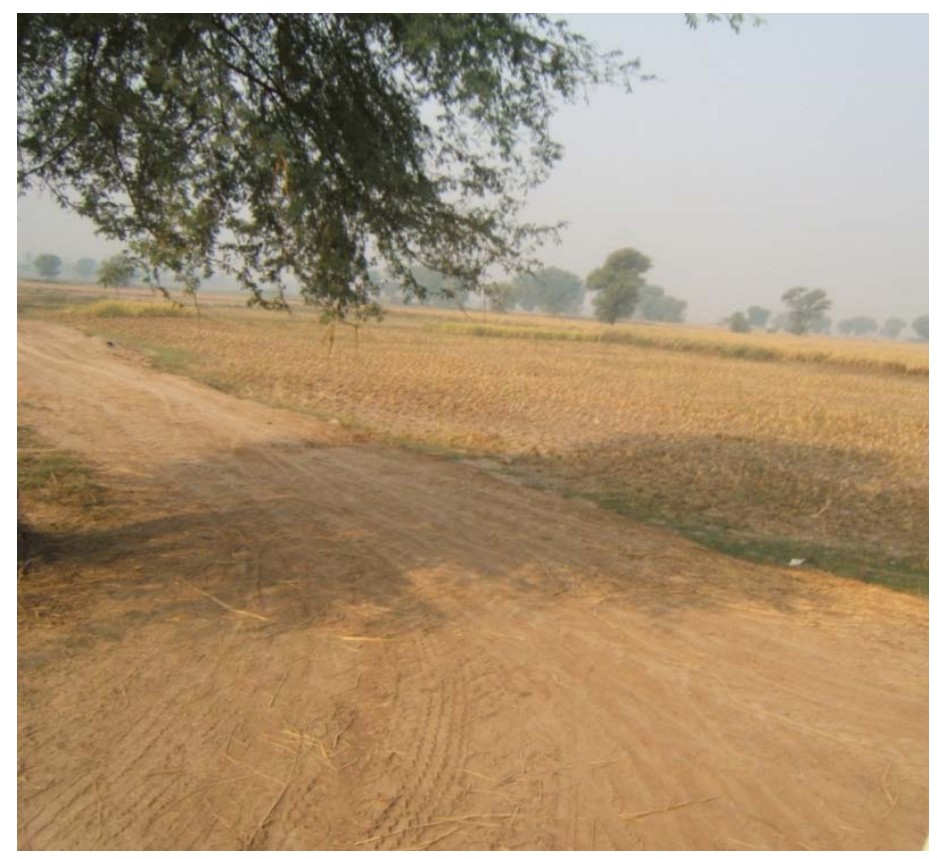

Figure Five: The dirt road that leads to Kiran school

Community, occupation, geographical location. Even though the website and the Facebook page for the NGO claimed that the school served ten villages in the area, at the time of data collection the school catered primarily to the population of two villages: Jalalpur and Risal Pind. Children attended the school from neighboring villages as well but their numbers were small. The community people that lived in these two villages were small land holders. The primary crops were wheat and rice. At the time of the research study in fall, 2010, they were harvesting the rice crop. As I traveled to the villages, there were acres and acres of rice fields being harvested by owners and hired laborers. After the harvest, there were also instances of fields being cleared by burning the stubble; this created the scene of a bon-fire in the middle of nowhere. Other occupations involved owning small convenience stores, selling milk and other dairy products to big, milk-packaging companies. Some male members in the two villages had 
migrated to the cities and their wives and children lived in the villages with their elderly parents.

Almost all houses in the villages were cemented, and only a few were uncemented. The villages had access to electricity. Upon one visit in Fall 2010, Risal Pind had no electricity because the transformer had malfunctioned. Occupants rode motorcycles and possessed tractors. Nobody owned a car in the villages and almost everyone had a television.

Building and facilities. The campus consisted of a small two-storied, brick building and two grassy lawns. There were four classrooms, two on the first floor and two on the second floor. Due to lack of rooms, some classes were conducted in the hallway. The classrooms had a long outer hallway in front, which was used for classes as well. The classrooms were airy, well-lit with windows and wall mounted blackboards. The Science lab had materials as well as pictures of human anatomy on the walls. The Science lab was also used for storing important school's administration-related documents. The library was also a classroom for pre-kindergarten students. The library was well stocked with books but I did not see any students there besides the pre-k students accessing the library. The computer lab had several computers which were functional and in use at the time of the pilot study. However, I did not see any signs of use upon subsequent visits. I also did not see any students in the two labs. The toilets were clean and on several occasions, the running water supply was dysfunctional so senior students carried water supplies from their homes to the school in big pitchers. 


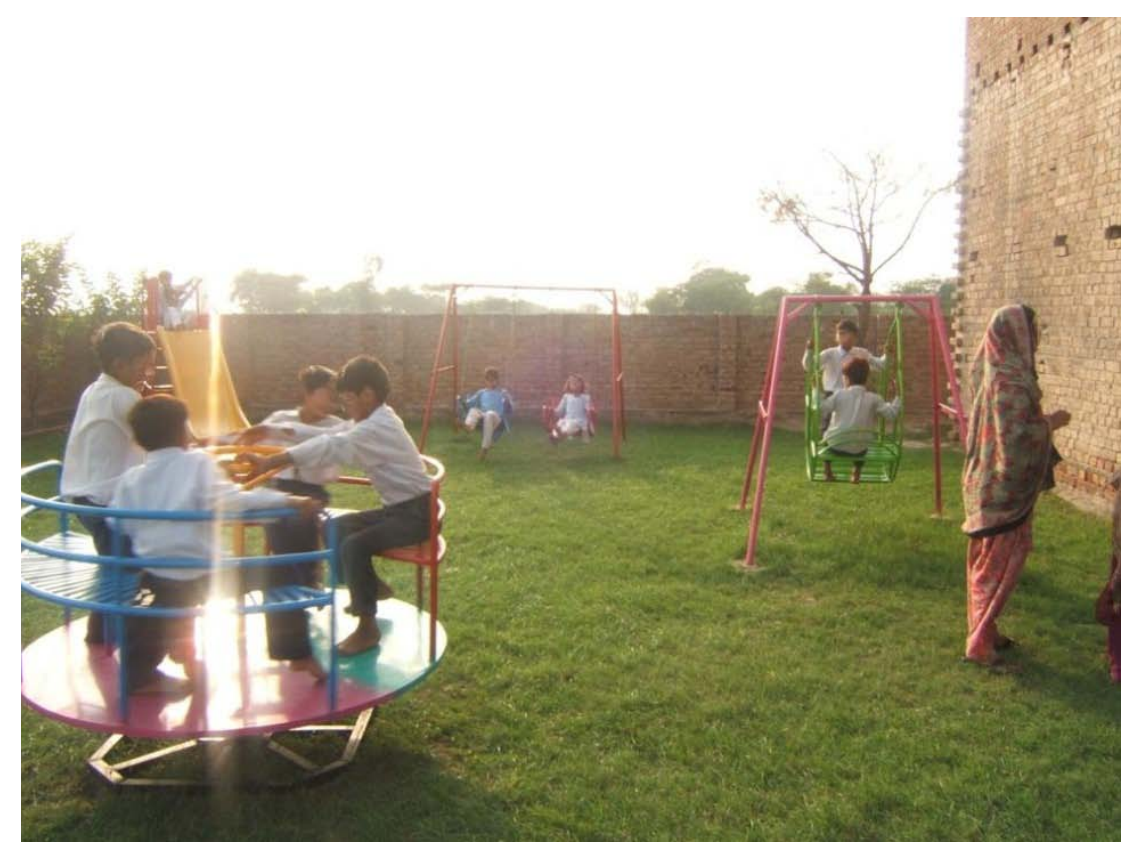

Figure Six: Children playing in the school lawn at Kiran school. There are also two teachers who are in conversation and watching over the children as they play. Boys and girls are on different swings.

The school did not have a cafeteria and some children brought lunch from their homes. Other children did not bring anything to eat. One of the lawns had colorful swings. The school hours were from 8 in the morning until 2 for senior school students and until 1 for junior school students.

\section{The participants.}

The NGO founder. Nargis was the founder of Inspire. She was born in a small village in Punjab and attended college in Lahore. She attended school in England for graduate studies. Her parents were land-holders. She started the NGO in January 2001 and worked on several projects which include the following areas: curriculum development; child-centered elementary education; use of pesticides and their impact on 
women; madrasa reform project; and rural women's indigenous knowledge in livestock keeping and human health. She had also conducted solo trainings all over Pakistan on community development through adult education and on empowering people through education with a focus on phonetic teaching of Urdu. She had worked in collaboration with UNICEF, UNESCO, Oxfam, Save the Children UK, Royal Netherlands Embassy, CIDA and Learning for Life. She had authored several books in English and Urdu on educational, gender and environmental issues that were published in Pakistan, India, Malaysia, Germany and England.

The teachers. All the teachers were residents of the two villages. They were hired from the local community and they had matriculated through a tenth grade exam offered by the Punjab Education Board after going through the NGO founder's technique for literacy instruction for adult women. In the previous years, teachers were hired from Lahore who taught Math, English and Science to senior classes. At the time of data collection, the school had employed only local teachers. There were six female teachers in the school. One teacher requested to be released of her duties as she had resigned. There was also a framework for the instruction of the teachers and their training. The teachers were trained in a way so that they were literate and hence they were capable of teaching literacy skills to primary grades.

Teacher Saira belonged to Risal Pind. She had appeared for the matriculation (equivalent to high school) exam but she had to reappear in one of the English papers to pass the matriculation exam. She appeared in the exam through Allama Iqbal Open University. She got married and moved to Malaysia and lived there for a year. She was now divorced and had returned to the village to teach at the school. She initially went to a 
public school and studied until fifth-grade; she then dropped out and stayed at home until, "Madam started this school." She explained that, "They did not teach English in government schools at that time.” Her teachers were Baji Aneela and Baji Amna who had learned reading and writing through the Inspire phonics method. She also studied from Baji Sidra who taught her Math and Science s and she came from Lahore. She said that, "We did not study Math at that time and now we regret it." She taught for two to three years before she got married and taught kindergarten. Then she taught the old core level and her students were in tenth grade at the time of data collection in 2010. All the girls in her cohort got married and only a few of them had taken the Matric exam. She talked about her motivation to teach and said that,

"I was not interested in teaching; I was smarter than all the girls of Risal Pind. And whatever I did not know I used to ask, that is why Miss Sidra thought that I should teach.” (Teacher Saira, 2010).

Sadia had matriculated by going through Inspire’s teaching methodology. She had also received training in Lahore to be a female health visitor. She was teaching the primary classes during 2010. Sadia was the second wife of a man who resided in the village. Her husband was considerably older than her. Of all the teachers I interviewed in the rural school in 2010, she was the only one who was teaching at the school upon the follow-up visit in 2011. Sadia organized a diabetes awareness walk in surrounding villages in 2011. During the follow-up visit, I observed that she was more involved with the health center and played an administrative role within the school.

Teacher Saima had also studied from this school. Saima started teaching in 2006 when she was in ninth grade. She would teach as a substitute when a teacher did not show up; this is how she was trained. She taught tenth-grade, Pakistan Studies; seventh-grade, 
English; third-grade, English and Urdu; and new core level, English. She was preparing to appear in the F.A. exam (equivalent to twelfth grade). Her subjects were Civics, Islamiat Elective, Punjabi, and Education. At first, she taught as a volunteer; she now receives a salary for her services. She had undergone teacher training from both Madam and teacher Aneela. She was single at the time of the interview.

Nasreen was a student of this school. She had taught for two and a half years. She started teaching when she was in Matric. At first, she taught grades second and third and now she was teaching senior classes. She started teaching because the school faced a scarcity of teachers. Teacher Nasreen taught tenth-grade, English and Islamiat Elective; ninth-grade, Urdu, English, Islamiat Elective, Islamiat Compulsory, and General Science ; and seventh-grade, Urdu. When I asked her about her motivation to teach, she responded by saying, "When someone used to ask me what will you become, I used to say I would not be a teacher and I could be anything else. But now I have to teach because I have studied from this school.” She was single at the time of the interview. Teacher Sara was married and had a daughter. She belonged to the family who had donated the land to the school. She started teaching in 2008 and she had completed Matric from the school. She was 25 years old. Sara resigned from the school. She participated because she was at the school for other business on the interview day. She taught ninth-grade, Math ; and seventh-grade, second-grade, and core level classes. She taught Math and English. She received teacher training from Ms. Aneela and Ms. Amna. She taught with Amna for a year and started by teaching sixth-grade. Teacher Sara left at a time when the teachers were scarce at the school. 
Teacher Qudsia had studied at this school. She was preparing to appear in the F.A. exam. She was twenty-one years old and was not married. She worked with the defacto Principal Ms. Aneela and taught classes with her and which is how she was trained. She said about her training, "I looked at her (Teacher Aneela.), observed her and learned how to teach.” She also received training from Ms. Amna and saw Madam training other teachers who taught her. She taught tenth-grade, Math , English and Punjabi; seventhgrade, Math ; ninth-grade, Math ; and core level, Urdu, Math .

The students. The school had approximately 125 students enrolled in all the classes. The classes were co-educational for the primary grades whereas from grades four and above only girls were enrolled in the school. Even though the website said that there were approximately one hundred and seventy-five students, I noticed approximately hundred students present in school during the visits. The NGO administrator said that the information on the website was out-dated and updates were planned. With these profiles, I present the children and describe who they are which makes them real for readers. This is a glimpse into the lives of these children in today's world.

Ahsan was a fourth-grade student at the rural school. He was ten years old. He was from Risal Pind and his mother tongue was Punjabi. His father was a farmer and sold milk. They did not have any cows but possessed two goats. He had two brothers and two sisters. His older sister was in tenth-grade and the younger sister was in core level at the same school. His older brother was in ninth-grade and went to a different school in Sialpur. They lived in an un-cemented house. At the time of the interview, he did not have access to electricity. 
Faisal was a fourth grade student at the rural school. He was nine years old. He was from Jalalpur and his mother tongue was Punjabi. He had four sisters and five brothers. Two of his sisters taught at the school and the youngest brother was in gradeone. His father was a farmer. His family owned ten cows, six buffaloes and two goats. They had a cemented house and had electricity, a television, a motorcycle and a tractor. His family house had a toilet with running water.

Farzana was a student in new core level at the rural school. She was nine years old. She was from Risal Pind and spoke Punjabi as her mother tongue. She had three sisters and two brothers. Her two older sisters were in seventh-grade at the school and the younger brother was in new core level. Her father was a farmer. Her family owned a cow and a goat. They owned a tractor, a television, a motorcycle and a fridge.

Hajra was eight years old and studied in new core level. She was from Jalalpur. She had two sisters and two brothers. Her older sister was in seventh-grade and the younger brother was in second-grade. They spoke Urdu and Punjabi at home. Her father was a farmer and owned cows, buffalos, and lambs. They had electricity and possessed a television and a motorcycle.

Asma was a student in new core level and she was eight years old. She had three sisters and two brothers. Her older sister dropped out of school from eighth-grade and her older brother was a student of seventh-grade in a school in Sialpur. Her older sister was in seventh-grade and she had a younger brother who was in kindergarten. Her father was a farmer. They had a cow, two goats, and a donkey. They had access to electricity and had a tractor and a television. They lived in a cemented house and had access to running water. 
The classes. The class configuration at the rural school was quite challenging to understand. There was a core level which learned basic literacy through the NGO's literacy teaching model. The core level was then promoted to fourth grade once they had acquired literacy. What made it more difficult to understand class configuration was the fact that each class did not have a specific room assigned to them. The students in some classes without a room had a specific spot that was allocated to them in the hallway. The fact that students were promoted to different grades while I was there during the course of the academic year did not make it easier to understand the class divisions.

In the primary section, during the first school visit, there was a kindergarten class with approximately thirty students; there were two classes that were identified as new core level and old core level. In my understanding, these classes were first and second grades and they were labeled as core levels as they mastered the NGO's basic literacy curriculum. Kindergarten had twenty-eight students and they sometimes sat in a room and sometimes in the hallway upstairs. Grade one (new core level) had twelve students and they sat in the hallway. Grade two (old core level) had fourteen students (six boys and eight girls) and they sat in a room on the second floor. There were chairs in their class and a blackboard was mounted on the wall. Grade three (old core level) had approximately sixteen students (five girls and eleven boys) and sometimes they were in a room but they mostly sat in the hallway. A blackboard was placed on a chair so that the teacher could write on it. Grade-four had about nine students (five boys and four girls), they sometimes sat in the hallway and sometimes had a room assigned to them. All classes had multi-age and multi-ability students. I noticed two classes, class seventh and class tenth in the senior section. The teachers mentioned a class ninth as well but since 
there was not a separate room assigned to class ninth, I assumed that classes ninth and tenth sat together. Upon future school visits, a new pre-K class was added to the school with approximately thirty new students. The teachers and the NGO founder seldom referred to classes as grades one, two, or three. They called them new core level and old core level. When the classes are promoted, they called them new core level one and new core level two. The division into primary grades is my own and is based on the age of children and the books that they were studying.

\section{Teachers’ training: Teachers’ literacy manual.}

There is a framework for the instruction of the teachers and their training. The teachers are trained in a way such that they are literate and hence they are capable of teaching literacy skills to small grades. The NGO had created its own methodology for literacy instruction, which produced adult literate women who were then hired as primary teachers.

The first teachers were instructed with the help of Moalim-e-Usatiza. I analyzed Moalim-e- Usatiza (Teacher of Teachers), a textbook that was written by the NGO administrator that is used for teacher literacy instruction. The two textbooks which form Moalim-e-Usatiza are written in Urdu. One book introduces codes which start the topic under discussion with a specific theme which is relevant to the lives of rural women. For example, Hum auratein or Us (we ) Women. Moalim-e-Usatiza is a book which is about teaching adult learners. It has good tips on what strategies to use while you are teaching but it is mostly for adult learners. Usatiza is created with the rural context in mind and also with lots of problem solving, activity based prompts on the topics under discussion that are of direct relevance to the lives of rural women. Some of the topics revolved 
around issues of dowry, property ownership, child bearing and women's health. It is very relevant to the immediate lives of the rural women for which it is written. The topics and themes that are presented in Usatiza are written with mutual collaboration and discussion with the adult women for whom it was written.

The Math textbook for literacy instruction for adult learners is written in a manner where abstract concepts of basic Mathematics are introduced with real-life examples of when an individual might apply the knowledge of ratio, percentages, division and multiplications to do problem solving in a rural context. For example, the Math book covers topics such as using measurements for cooking, division of property based on inheritance laws, paying bills, and buying and selling groceries. In the foreword of the book that she created to teach adult women basic literacy skills, Nargis highlights the importance of making use of "rural women’s indigenous knowledge."

\section{Teaching and instructional practices at Kiran School.}

In this section, I will briefly describe the choice of textbooks, teaching methodology, instructional practices and testing for the schoolchildren. The language of instruction in the rural school was Urdu. English was also taught at the school. However, no instruction took place in Punjabi, which is the mother tongue of all the children. The rural school is a busy place with several teaching and learning activities occurring simultaneously. In the rural school, they are preparing children for literacy instruction as well as they are preparing children to be important members of a democratic society as literacy would enable them to do so. The stress is also on problem solving in real life context. The children are memorizing and appearing in written exams. The children are 
role-playing and performing dramas with the focus on social consciousness and awareness.

For the first few years after the school formed, for children in first-grade through fifth-grade, the school provided free books. The free books offer was made possible through a donation by the Punjab government through a literacy scheme offered by the Governor of Punjab. When books were no longer provided, students had to purchase books and copies from stores nearby. The school sold books and copies as well to the students.

The rural school employed its own methodology for the teaching of literacy skills that is unique. Even though the school uses textbooks that are prescribed by the Punjab government's primary curriculum and students graduate from tenth-grade by taking the Punjab public board examination, the conversations with the NGO administrator revealed that their method of teaching is quite different than teaching in public schools,

"Students work on all four skills (listening, speaking, reading and writing) whereas comprehension and self-expression were some of the key constructs that are emphasized.” (Interview with Meera, 2009).

Since literacy is achieved through phonetic learning, learners are expected to tell what phonic sounds are involved in the pronunciation of a certain word. Gradual movement from simpler to complex skills and tasks is encouraged. Stress is on whether learners have achieved conceptual clarity or not,

"For children's education, at first we make them work with our method, and when they have a complete foundation, than we have a combination. We use some of the syllabus from the government (school's curriculum) and we do some of our own.” (Interview with Nasira, 2010). 
Teaching of literacy took many different forms. Teachers used a book called Rahbar (guide) to teach young learners and are written by the rural school's NGO founder keeping local contextual situations in mind. The teacher guidebook that helps in determining activities and topics around which they teach; Rahbar consisted of 25 codes that were used for literacy instruction for teaching young children. A code is essentially a story which is used to explain the words under study to the students. The words are then divided into phonemes to identify the relevant sounds. The word is then written on the board, the different phonemes are highlighted as representing a different letter which is written in a different way as they are combined with other letters to produce words.

The NGO founder demonstrated teaching phonetically. She started by teaching students about the word accident (Hadisa): she wrote it on the board and then asked if the students had experienced an accident, and what the word meant. The students talked to her at length about various accidents that they were involved in. She then broke the word into its letter parts and pronounced them separately for students, such as ha- $a$ - di- sa. Then she told students how to write the beginning form of $/ \mathrm{h} /$ and how to combine $/ \mathrm{h} /$ with /a/ and how it is written. She then explained to them how the $/ d /$ sound is an unconnected letter in the word. She then combined $/ \mathrm{s} /$ with $/ \mathrm{h} /$ which reads like $/ \mathrm{sa} /$. Both the letters $/ \mathrm{s} /$ and $/ h /$ when written in the combined form are written differently then when they are written in isolation. The letters are written differently based on their position in the word if they appear in the initial, middle or end position in a word. Writing Urdu in the Arabic or the Persian script is much more complicated then writing the English language. By breaking the word into the syllables and the corresponding letters was helpful for the students. They learned how different sounds combined and how they are 
written when combined. It was also helpful for the students to relate the newly learned

word to an incident that they had just narrated.

Teacher Saira explained teaching of literacy skills through phonics method to

young children in this way,

"This is code level. In this, the children learn from sounds, they learn sounds (of each letter in a word) and then they have to be instructed ... on how to say them and how to learn them, which sound will be spoken first, and which later and then how many sounds are produced which will then make a word and what is the meaning of the word .....and when they learn the sounds then they become smart, then they pay attention to the sounds of asking for water and asking for bread. And then afterwards we teach them the letters and when you teach kids about the sounds then it becomes easy for them to learn other things (letters) and that the only difference (in writing) is that of dots and then shapes are all (mostly) the same.” (Interview with Saira, 2010).

In the rural school, there was emphasis on memorization of poems and songs.

Children in pre-kindergarten and in core levels at the rural school demonstrated role-

playing. Teacher Saira explained why young children were learning poems in this way,

"For younger classes, ..... right now we are doing the story of Toot Batoot. Then we tell them Toot Batoot eats almonds (badaam) and walnuts (akhrot) and what is the nutritional value of that, and that they are good for your health and if you will eat it then your brain will be sharper and you would study well and then he drinks soda water and you should not drink it, because it is detrimental for children and this is how they start understanding as they progress further and then children learn with every story that what is detrimental.” (Interview with Saira, 2010).

The children performed role-plays and were instructed with the help of stories. Teacher

Sadia explained why children perform role plays in this way,

"They do really good dramas baji. Now there is a drama that what is a plant. Then the kids do a drama on it on their own. One child stands as plant in the shade, he neither gets water, nor is it dug, nor gets sunlight whereas the other plant is planted in the sun shine and it gets everything, it is watered on time as well and gets sunlight too then the plant that is planted in the shade dries up and then the other plant grows. And the kids play the role of the plant themselves. They are told about the parts of the plant with reference to that of human beings for example just as humans have legs and feet plants have root and stem. If humans 
do not have feet they cannot stand. Similarly the plant cannot stand without roots. And these arms that human have, plants have branches and the fingers are like leaves and the plants are alive like humans and they increase their progeny. There is everything in it.” (Interview with Saira, 2010).

Teaching for older students who were able to read and write took slightly different form. One day when I went to the fourth graders class, they were reading a chapter on the role of mayor (zilla-nazim) in a democratic society in the government prescribed textbook. Since the learning was self-directed and a teacher was not present, the children read the chapter out-loud and then answered questions in the exercise at the end of the chapter. In another class, that I had observed, the teacher instructed students about farming. She mentioned how plants made the environment healthy and they were pleasing to the eye. Another teacher mentioned the disadvantages pesticides and how their use pollutes the environment and water supply. The Math skills of the rural children were impressive in a lesson in which they demonstrated computation. Yet another teacher asked the fourth-grade students to draw posters to raise awareness about homes and habitat. I felt that this particular lesson was relevant to the immediate lives of the students and it was about a topic that they could easily relate to in that setting. The teacher was very creative as she constantly asked children questions to elicit responses about different materials used to build different types of homes and the source of such materials. She inquired how many rooms were present in students' houses and what they had in them. She mentioned a tent (jhonparee) also as a place to live and then asked students about the materials used to build it. On my way, to the school, I had noticed a tent colony with a few tents on the ground not too far away from the school. She asked students what was used to build an animal barn (chappar). In her lesson, teacher Sadia did not use any textbooks. The students in the rural school were given tests. They were asked to sit 
separately from each other in the outer hallway where they answered questions on the test. The children were then marked and a report was sent to the founder on their progress.

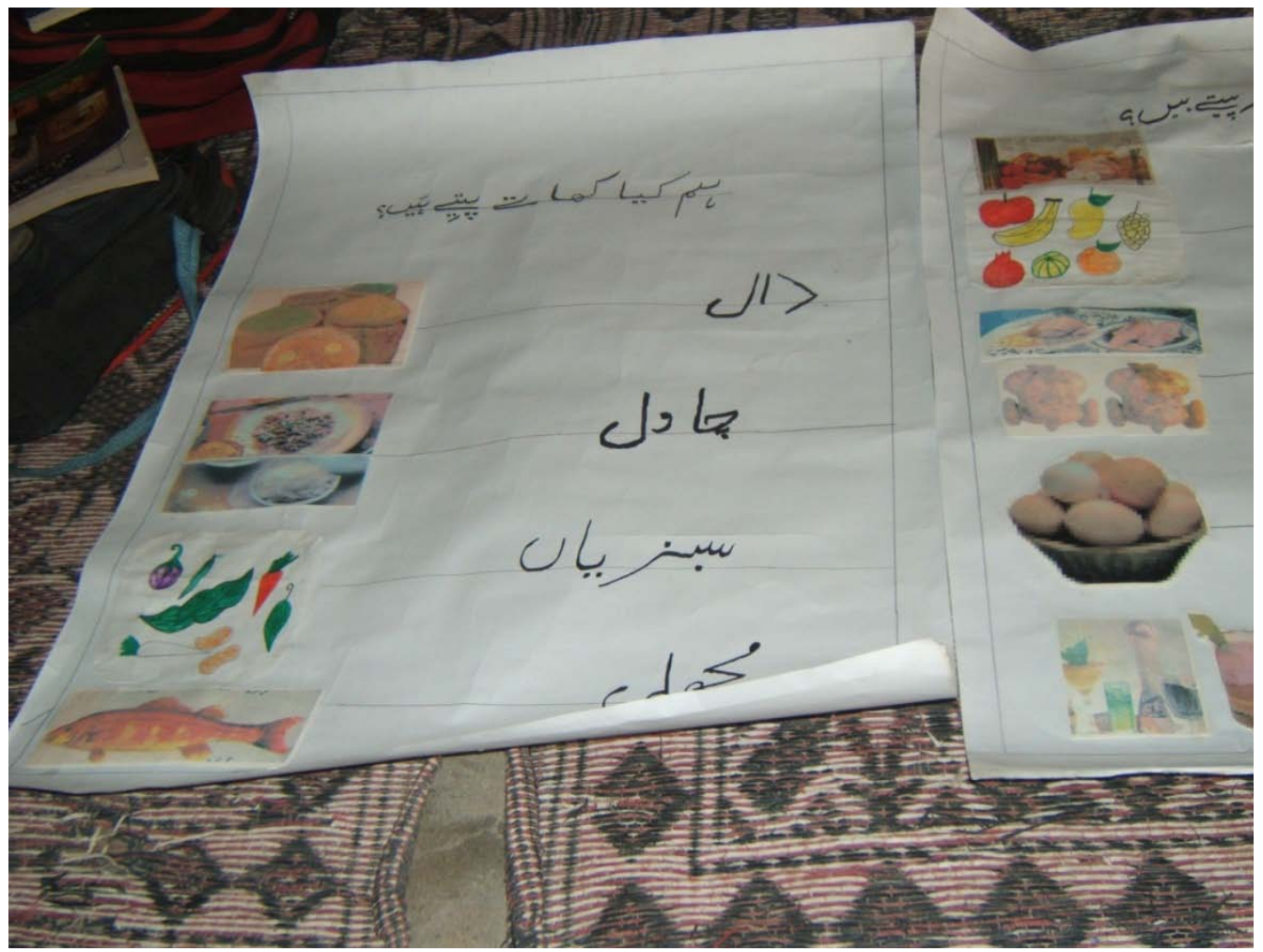

Figure Seven: Student work in Kiran school. The chart displays food pictures that are cut out of magazines. One figure is drawn by the teacher. Students have labeled the items.

\section{Children's Lives and Learning at Kiran School}

Students at Kiran school had a well-rounded curriculum that offered traditional subjects such as Urdu, English, Math, Science, Islamic Studies as well as non-traditional subjects for primary grades such as Agriculture, and Health Education. Student Faisal responded about his learning at school in the following excerpt,

"Zafreen: What is your favorite subject?

Faisal: Urdu. 
Zafreen: Who teaches that?

Faisal: Miss. Saira.

Zafreen: Why do you like it?

Faisal: We learn Urdu and then we can read about health education and that is how we learn about health. We learn how disease is spread and what do you have to do for prevention.” (Interview with Faisal, 2010).

Besides the learning of functional literacy skills, children at Kiran school were involved in a variety of learning activities such as role plays, speeches, and singing. Student Asma at Kiran described her learning process in the school in the following way,

"Zafreen: What do you do in school?

Asma: Miss, I study in school. I write stories. I do math problems of addition and subtraction........

Zafreen: Do you think you are doing the right work at school?

Asma: Yes, Miss.

What do you like best doing in school; talking, doing speeches, conversations, singing songs, or performing in plays?

Asma: (I like) to sing songs and to do speeches.

Zafreen: So what was your speech all about?

Asma: Miss, teacher asked me to do a speech when I did not know how (another girl) did it.

Zafreen: What was the topic?

Asma: To make Pakistan better.”

(Interview with Asma, 2010).

Children were fined a hundred Rupees per day if they were absent from the rural school. This policy is enforced to ensure that parents and children take their school seriously and attend it regularly. If the child is absent for a valid reason such as sickness, 
they have to show a letter from the health center they had visited. The presence of the health center nearby also facilitated in improving children's overall well-being.

Children at Kiran were strictly disciplined and required to obey the school rules and dress code. At one observation, when the uniform of the children were torn or not clean, they were chastised and slapped. Their parents were required to meet with the NGO founder to offer explanation for the shabby dress. During observations, children were slapped for not knowing an answer to a question. Some younger kids were scared to ask the teachers if they could use the bathroom. I was told to not spoil the children by asking their permission to interview them. Some of these factors were interpreted as barriers to an efficient learning environment.

During the first few visits, the NGO founder bought colorful swings from a store in Lahore and brought them over to the school in a hired van. This caused quite an excitement and thrill among the student body. The NGO founder's driver and senior school students dug and helped to firmly place the swings in the school's yard.

At Kiran, the children were aware of the assets that were available to them. Children responded that they liked their school because it had swings, flowers, grass and shrubs.

“Zafreen: Do you like your school?

Asma: Yes.

Zafreen: Why?

Asma: Because it has plants and very nice flowers.

Zafreen: They are everywhere in the village.

Asma: No Miss, they are not all over in the village.

Zafreen: What is in the fields?

Asma: Those are trees.

Zafreen: And you do not have grass in the village?

Asma: No Miss.....

Zafreen: And the school would not look good without plants and grass. 
Asma: Miss, the swings look nice in the school.

Zafreen: What do you not like in the school?

Asma: I like everything."

(Interview with Asma, 2010).

This statement baffled me because of my outsider identity as I did not recognize the plants and grass as an asset. The NGO administrator helped to clarify their statements and said that the children pointed these things out as they are a rare commodity in their immediate setting. In a rural area where the primary occupation of the residents is farming, fields and associated greenery is food, and a means of sustenance that is necessary for survival. It does not necessarily have the same aesthetic or ornamental value that it has for an outsider. The grass, the flowering plants, and the swings had a price tag and an ornamental value attached to them in that setting. Children knew that this was precious and rare and hence, they recognized them as assets that made their school worthy of attendance. The environment within the school, friendly teachers, garden, swings and plants were some of the factors that were identified by students as supportive of their learning.

During the group interview, children reported that they did not need anything else in the school. However, one student responded in the following way.

“Zafreen: Do you need anything in school?

Asma: Miss, (I) need books.

Zafreen: Okay, anything else?

Asma: Yes Miss, a room and chairs.

Zafreen: Do you need an English teacher?

Asma: Yes, Miss.”

(Interview with Asma, 2010).

When I asked them how they could improve their school, they responded by saying, "we need to protect the swings, and the school from outsiders.” Another child 
responded, "We need to take care of the grass and the plants, make sure that they are watered and are protected.” (Group interview with students, 2010). Student Asma responded to that question in the following way, "If we go home and study and if we go to the teacher's house and study and if we study from our sisters, then the learning can improve.” (Interview with Asma, 2010)

\section{Rice Festival at Kiran School}

Extra-curricular activities supported teaching and learning at the rural school. Kiran's community took great pride in celebrating their culture. The teachers had organized a rice festival (mela) to celebrate the harvest of the rice crop. The festival lasted for an entire day. The event was held outside the school premises very close by, in a field which was partly cleared by the senior school students and school alumni. A tent surrounded the premises and a small stage was constructed for the performances. A music system and a microphone were present. There was a toy stall which was placed outside the arena where the event was held so that children could purchase toys. Toys were bought to be used in school as well.

The festival was supported by the school staff and members of the community. The NGO did not offer any monetary support for this event. In that festival, the teachers combined with the other members of the community and presented more than 20 dishes that were made out of rice. The parents of the school children were quite involved in the festivity. Almost everyone was assigned a food dish and some families provided the main course. One of the NGO donors (who volunteered at a low-income government school in Lahore) brought a group of 30 middle-school girls to attend the festival. Other participants included founder and staff-members of another non-profit organization that 
supports the school. Family members of NGO administrator, educators at higher educational institutions in Lahore, were also present. No men were present in the festival accept a few alumni of the school who also helped in organizing the festival.

The interaction between the village and the city children was quite fascinating. The students had put on their best clothes whereas the city students were clad in uniform. The teachers gave the visitors a tour of the school. The visitors were greeted by a loud beating of a traditional drum: the dhool. This was followed by a dance performance by a school teacher and several school alumni. The children performed dances and role-plays. The community took great pride in showcasing their culture to us. There was a small ground fire where the women made rice crepes which were sweet and savory, vegetable fritters and fried fish. The villagers showed model hospitality and the food was plentiful and in abundance. Some village women sold home-made food, bangles and jewelry to the participants. There was a henna stall as well.

The rice festival provided me with an opportunity to observe the community's role, participation and involvement in school's activities. The rice festival was an important window to view how the community, teachers, students and parents took ownership of the school and how learning in the school was viewed as culturally relevant to the setting. It also gave me an opportunity to broadly interact with the community that the school served. Some of the key ideas that emerged as I attended that event were: selfhelp, plenty and abundance within the Kiran's community. The rural rice festival also highlighted celebrating the local. 


\section{School Formation and the NGO: Pathways and the Sunshine School}

A philanthropist of Lahore established the Sunshine School in 1994 . The

philanthropist believed in bringing about a social change, he founded a Trust for

Children's Education, and appointed a board of trustees to oversee school management.

The board of trustees invited the founder's daughter, Meera, a renowned educator, to assist with academic aspects of management. "The third year of Sunshine, the board started feeling that they needed academic support, . . . I came on the board in 1997-1998 and in 2000 Pathways was formed” (Interview with Meera, 2010). Meera joined the board and later opened the NGO Pathways to assist with school monitoring, oversight, and teacher training. Pathways started its operation in the year 2002. The NGO Pathways did not mobilize the community to start the school. It began to work with the school while it was already functioning.

Funding. Funding to support Sunshine comes from an endowment that is given by the school and board founder, a well-known philanthropist in Lahore. The school began operation in 1994 with the original seed-money of 40 million Rupees (500,000 USD). Several other individual donors support the school financially as well. Sometimes philanthropist and donors support and pay towards that original seed money and sometimes they send monthly contributions. Support also comes from other partner and non-profit organizations such as Pathways and Pathways-UK.

The principal endowment amount is invested and the profit generated on the endowment fund is used to run the school. The total monthly cost of running the school is 1 million Rupees (7,500 USD). Approximately 60 percent of the monthly school expense goes to teacher salaries. The remaining amount is spent on other functions; such as the 
salaries of the administrative staff and school support staff, for instance, the cleaning maids, and paying the utility bills. The school is housed in a building on land, which is owned by the Trust.

Sometimes Sunshine pays Pathways to conduct staff trainings, however, at other times the money for providing training and staff development for school staff comes from Pathways.

"There is training at Melbourne which is very important for Primary Years Program (PYP), suppose it costs about 200,000 Rupees ...send a proposal to Pathways UK saying can you help us maybe we need a 1000 pounds of support, it is important so that the person who will go such as Tahira will bring back all the knowledge in taking the institution forward.” (Interview with Meera, 2010).

The function of Pathways is to provide training, oversight and management of the school's life. Pathways UK, which is the sister branch of the NGO, assists in providing funding and opportunities for grant money for the training of the administrators and teacher training abroad. The sister NGO conducted a fund raising drive in the United Kingdom to help raise money and funds for Sunshine.

Pathways conducted two fund-raising drives to support the school and added money to the original seed money. A campaign, Indus Inspirations, was launched which show cased the artwork of renowned artists from Pakistan who donated their artwork to raise funds for the school. The art-work was then auctioned and a book was created to promote the sale of the donated art work of renowned and established artists.

From the original opening of the school to 2010, the children did not pay a fee to attend the school. However, during 2009-2010, the school started charging a 10,000 Rupees (125 USD) registration fee per child as they entered nursery grade. This policy was implemented on my follow-up visit in 2011, where everyone paid approximately 
eight hundred Rupees (10 USD) per month to attend the school except in some cases of extreme hardship. Students are expected to pay a fee to the transportation committee that is run by parent volunteers. Students are also expected to pay for books, copies, stationery, extracurricular expenses, field trips, and their uniform. Some of these things were provided to the students without a charge when the school first opened. As the price of the utilities increased and the school continued to grow, the cost of running the school increased; this necessitated charging students and their families for many of the supplies and services that were previously included with enrollment.

The school management structure at Sunshine includes concentric layers of leadership circles. The outer layer of management consists of theTrust for Children's Education that oversees the management function of the school. The trust determines and enables financial resource allocation to the school. The NGO Pathways determines additional resource generation and flow to the school as well as provides support for training, professional development, networking and school leadership oversight and access to other resources. The second inner layer of management consists of the school management team. The management team consists of the Principal, the senior-school coordinator, and the junior-school coordinator. A team of accountants and personnel staff handle daily financial operations. Several employees help and support the interaction of Pathways with the school management team. For instance, a liaison to Pathways who is termed the Project coordinator works closely with school staff and the NGO to facilitate training and supports the functions with several partner organizations. The third layer of managers is the teaching staff. At the inner most ring of command and control circles are 
the children. The community and the parents are outside these rings of management and leadership.

The Sunshine School. The Sunshine School is easily accessible as a paved road led to the school. It is in an industrial suburb of Lahore. Due to heavy industrialization in the neighboring areas, the main road that leads to the school is a newly built double highway in Lahore. There are sign-posts on the road indicating various suburban neighborhoods on its either sides. There is also a green belt which is well-kept with shrubs and flowering plants throughout the length of the road. The traffic ranges from cars, buses, rickshaws, and other motor vehicles, to donkey carts and horse carts.

Community, occupation and geographical location. Sunshine was located in a residential area and the area surrounding the school comprised of small households. The main road led to a side road, and small shops flanked the two sides of the small road which passed through a residential area and led to the school. A gate-keeper was always present near the gate which was mostly locked. The community that the school served composed of low-income households. Mostly the male member was the bread winner and women were either stay-at-home mothers or mothers who were engaged in home-based small businesses or worked as teachers or support staff at the school. The children's parents worked as drivers and rickshaw wallas.

Sunshine School caters to the Christian as well as the Muslim community. However, it is set in a neighborhood that is predominantly Christian. Even though there are no exact numbers as to how many Christian children and teachers are present in the community, there is a significant Christian population within the school staff and the students. 
Building and facilities. Sunshine is housed in a modern, cemented two-storied building with access to facilities such as running water, electricity, library, computer lab, two small cafeterias, a huge playing field with swings and an inner playground. There are seven classrooms on the first floor, two on the second floor, a library, a computer lab, a resource lab, and two Science labs on the second floor as well. As I interviewed teachers, teacher Khalid responded about the school's facilities in the following way,

" The infrastructure of this school is quite good. This is a school that provides computer labs, (and) Science labs that are well-furnished and elaborate.” (Group Interview with Teachers, 2010).

The participants. Sunshine is an all girls' school in the morning. However, the teachers are both males and females. Sunshine has approximately 650 students and 38 teachers, a community worker and 11 support staff members. The school comprises of four sections a primary section (Pre-Kindergarten through fifth grade), a middle section (sixth through eighth grade), a senior section (ninth and tenth grades) and a college section (eleventh and twelfth grades). The college block is a separate building on the same campus and is the newest addition to the campus.

Sunshine ran an evening shift which was co-educational. In drawing parameters around the case study site, I excluded data collection from the urban school when classes took place in the evening.

The NGO founder. Meera was born and raised in Lahore and Karachi. Her father was a lawyer and a social, political activist. She had studied in England and in the United States for college. She had worked as an education advisor for UNICEF among other organizations. In 1995, she joined a task force on education in Punjab. Two years later she joined the Sindh Education Foundation. In 2000, she opened the NGO Pathways 
which started with a project based on adopt a malfunctioning public school policy in Sindh. In 2000-2004, she served as the Technical Advisor to the Federal Education Minister and worked on reforming curricular and funding structures within the educational bureaucracy. The NGO founder served as the Managing Trustee of the trust that oversaw the operations of the school. In addition, Meera led three professional organizations: a South Asian forum for economic development, an institute for professional learning for teachers, and Pathways. She started the professional development institute for teachers out of the NGO office. She was also the de facto head of all operations at Sunshine.

The principal. Tahira was the principal at Sunshine. She had fifteen years of teaching experience at a prestigious elite, private school. She obtained a certificate in Professional Studies in Education from Bradford University, in the United Kingdom in 1999. She received a Master’s in School Administration from an elite, private University in Lahore in 2005. In 2007, she completed a training course at The Plymouth State University, New Hampshire and was given a certificate as a qualified master trainer and an evaluator. Her major areas of specialization were mentoring and institutional strengthening. She could communicate well with local donors and international donor organizations. She was also able to receive trainings on leadership and instructional strategies through international workshops and conferences and then she conducted training sessions for teachers.

The teachers. Of the six teachers interviewed individually, four had a college degree at the bachelor's level and two had a Master's degree. The teacher qualifications 
were further enhanced by consistent and on-going support from the school staff and NGO staff which arranged for teacher professional development sessions. One teacher had visited a professional development course held at Plymouth State University in the United States for a month. Teachers have the liberty to use in classes what they deem appropriate and they enjoy this freedom.

"Sunshine has got 99 percent of the teachers coming from the local context. They are the most ordinary people who have suffered the normal education system." (Interview with Meera, 2010).

Teacher Sabira taught at Sunshine since 2003. She came from a low socioeconomic background and had studied at government schools. She said, "My educational background is such that I have not studied from a very good school.” ( Interview with Sabira, 2010). She had a B.Ed. in Education and a Master's in Urdu. Sabira had been working as the coordinator of the junior school for four years. Not only has she bought into the philosophy of the IB curriculum she was the real driving force behind implementing it. "I am interested to find out more about it, so I have been doing it on my own.” (Interview with Sabira, 2010).

Teacher Khalid graduated from Peshawar University in Education and English Literature. He then received a B.Ed. He wanted to work for the Army or the Air Force but joined the teaching profession because his parents and grandfather were teachers. He said, "My parents (were) teachers and grandfather (was a) teacher and (I belong to a ) teachers' family, it is inherited.” His primary schooling occurred in a missionary school in a village in Punjab. He also received vocational training in wood work and electrical repairs. He continued to attend Mardan college but appeared in the B.A. exam as a private candidate. He was thirty years old, married and had children. He had started his 
teaching career by teaching at a convent school. When he first joined the school in 2005, he taught $3^{\text {rd }}$ grade but in 2010 he was teaching first grade. He was motivated to teach because he said,

"I was brought up in a church compound and (I felt that) we must do something for our nation and our country and critical thinking was developed (in a youth group in the church) and that showed me a path......”(Interview with Khalid, 2010).

Teacher Hina had twenty-five years of teaching experience. Her motivation to teach stems from the following,

"My mother was a teacher at St. Mary's Convent in Multan....everybody is a teacher in our family....it is my passion.” (Interview with Hina, 2010).

She was born in Lahore and raised in Multan where she attended primary school. She graduated from Allama Iqbal Open University in Education and Sociology. She started her professional career as a radio artist in 1979 and worked in theatre productions. She worked on stage, radio and television before she joined the teaching profession. She was married and had two children. She was hired as a teacher and a community worker for the school but was only teaching in 2010. She had helped the students prepare two annual English plays for the school. She was teaching second grade at the time of the interview in 2010. Teacher Hina said that she was happy to be a teacher in this school, "here students are given more opportunity and they are not subdued.” She also emphasized how she liked the teaching methodology employed in the school,

"I like the way how teachers are using new methodologies and as a teacher we have been given more opportunities to attend workshops and use latest technologies and methodologies....”" (Interview with Hina, 2010).

Teacher Khadija had a Master’s in Education from University of Education in Lahore. She was born and raised in Sargodha. She had eight years of teaching experience 
and started teaching at Sunshine seven years ago. She started teaching because her parents were teachers and she further elaborated by saying, "I was born a teacher and I have not done anything else. Maybe I cannot do anything else” (Interview with Khadija, 2010). She was teaching in this school because she had migrated from Sargodha and knew a teacher who worked in this school. She was married and had a daughter.

Teacher Sobia had a B.A. in Education, Persian and Punjabi. She had studied privately and was preparing to appear through Allama Iqbal Open University (a distance learning based University) for her B.Ed. She had completed a computer application course from a local college. She received her primary education at a government school in Lahore and matriculated from there. She had six years of teaching experience and had been teaching at Sunshine for a year. She taught grades second and third. She was twenty- three years old and was single. Her parents were not educated and they motivated her to get an education,

"My parents wanted that their daughters to study a lot, they are not educated themselves that is why they wanted their children would study...." (Interview with Sobia, 2010).

The students. There were five fourth graders whom I interviewed at Sunshine. They were nine, ten or eleven years old. Each of them studied Math, Science, English, Urdu, Islamic Studies, Social Studies, Computer and Art as compulsory subjects. They also had time allotted for library and games in the weekly schedule. They went on yearly field trips as well to places such as the Zoo and Mitchells' sweets factory.

Anita was in grade four. It took her half an hour to get to the school. She came to school on a motor-rickshaw. She had access to electricity and television at home. Her two sisters studied in the same school with her. They were in grades two and five. 
Her older sister and older brother studied at different schools in the vicinity. They were both in eighth grade. She did not pay a fee to attend the school but had to pay a transportation fee every month for about five hundred Rupees (6 USD). She wanted to continue studying further and wanted to do research, "I want, just like you have come here, I want to do the same,” (Interview with Anita, 2012).

Sitara was nine years old and studied in fourth grade. She spoke Urdu and English at home. She had an older brother who was nineteen years old and studied at a college. She lived in a two- bedroom house with access to electricity and television. She had a computer at home but did not have access to the internet anymore. Her mother was a teacher at Sunshine. She wanted to be a solider when she grew up,

"I would really want to save the world, I wanted to save Pakistan but now I think I do not want to save Pakistan because it hurts us so much, sometimes there is a bomb-blast and sometimes if you give donations for flood victims, they do not get it.” (Interview with Sitara, 2012).

Rafia was ten years old and she studied in fourth grade. She spoke Urdu at home and spoke Punjbai only when she was angry. It took her half an hour to get to the school. She came to school on a school bus. She did not pay any money for transportation. Her father was a motor-rickshaw driver. She had four sisters and one brother. Her brother was in ninth grade. Her older sister was in seventh grade and studied in the same school and her two younger sisters were in Kindergarten in a different school. The youngest stayed at home. Her father wanted her to become a teacher and she wanted to become a doctor. She was also considering being a pilot.

Savila was in fourth grade and she was eleven years old. She spoke Urdu at home. She had access to electricity, television and cable at home. Her father was an electrician. 
She had four sisters and one brother. Her older sister was in fifth grade and studied in the same school and her brother was in Pre-K in a different school. Her brother would be admitted to this school but they were not able to afford the ten thousand Rupees (120 USD) admission fee. Her three younger sisters were too young to attend school. Her grandparents and an uncle lived with them. She came to school on a school bus and paid six hundred Rupees (10 USD) monthly for the transportation fee. She wanted to become a teacher and wanted to teach in the same school because "they are doing really good work.” (Interview with Savila, 2010).

Anisa was nine years old and studied in grade four. She spoke Urdu at home and did not speak any Punjbai at home. She had two brothers, one of whom studied at a college and the other one studied at a madrassa. Her father was a driver. She had access to electricity and television at home. She came to school on a school bus and gave five hundred Rupees (6 USD) as the monthly transportation fee.

\section{Teaching and instructional practices at Sunshine.}

In this section, I will discuss the approaches to curriculum, teaching and learning practices and strategies that are used in Sunshine. In this section, I make a description of how the teachers are teaching. The use of activities and textbooks is discussed. This description is followed by how the teachers are assessing what is being taught. Third is a discussion of teacher education, teacher qualification and teacher training which helps to put in perspective the choices that they make in their teaching.

There are different approaches to curriculum that are in place in Sunshine. The approach that is used largely by the teachers is a topic-based approach where the teachers teach a certain topic and then use supplemental books, or additional worksheets to 
complement what they are teaching. Teachers used supplementary materials such as work sheets downloaded from the internet. The students at Sunshine are taught through a combination of government prescribed curriculum, children's primary grades textbooks on Science, and Social Studies, and English published by the Oxford University Press and the International Baccalaureate (I.B.) curriculum. However, during the teacher observations, I seldom observed teachers teaching through the government textbooks. The textbooks were selected by a consensus of subject teachers, principal and school's coordinators. The textbooks comprised of books prescribed by Punjab Education Board as well as books published by Oxford University Press. The teachers at Sunshine pointed out that they had liberty to teach at Sunshine. They were not required to teach the government school curriculum. They taught a curriculum where they had freedom to choose their own teaching material from different textbooks and worksheets. According to Khalid,

"(Teachers) are not just bound to government curriculum only. Teachers have full liberty to do anything in the class and authorities have given opportunities to students and people with more experience to come and share with us." (Group Interview with teachers, 2010).

The school administration was also in the process of implementing a curriculum to prepare students to appear for the International Baccalaureate (I.B.) exam. In Fall of 2010, Sunshine had just begun to use an International Baccalaureate curriculum. The international baccalaureate curriculum requires student-centered learning, environmental consciousness and an approach towards developing certain desired competencies in the learners through creating a learner profile system. The assessment is also based on more continuous forms of assessment rather than more summative forms of assessment. Teacher reflection and creating of rubrics is strongly promoted through such an approach. 
Decision-making is achieved through consensus and requires a lot of collaboration on the part of teachers, coordinators and the administration. Hina mentioned the collaborative environment in the following way,

"I like the management/administration, there is natural understanding between the management, administrators and teachers and they really provide the atmosphere which is very friendly and when someone wants to do something creative, here will be a very friendly environment, so I like it, that's great!” (Group Interview with teachers, 2010).

The use of theme of the month was being implemented as part of the IB curriculum. For instance, when I was present there, they used empathy and compassion as the themes of the months. Bulletin boards displayed students' art work around the themes. The IB also requires students to be fluent and competent in the English language. At Sunshine, the primary language of instruction was English and Urdu. Most of the children spoke Urdu at home and some claimed to speak English or Punjabi at home with their parents and grandparents.

The environment at Sunshine was also literacy rich. The bulletin boards in the schools were colorful and presented students' work on the topics that they were studying in classes. Each classroom had several boards which represented the work of the students from art displays to different units under study to students' writing about their class work projects. The atmosphere at Sunshine was quite relaxed. Most of the teachers had a very friendly attitude toward students and an excellent rapport with them. Students asked questions and voiced concerns. The student teacher interactions were positive. During her lesson, Teacher Hina stressed the importance of friendly behavior with young kids. She also used students' first name when she interacted with them. She said that she believed 
in creating a friendly environment in the classroom. Seating arrangement in the class was also something she paid special attention to. She said that by making students sit in small groups it added to the spirit of healthy competition and collaboration among young learners. Moreover, during an Urdu lesson, teacher Sobia involved students of second grade in small group work where the students made a chain of words with a single letter. The teacher was friendly, students were engaged and wrote and matched words with a lot of enthusiasm. The whole class was divided into small groups and they had a friendly competition. The class was loud and the students had fun as they were able to come up with words which started with the letter assigned to their group. Teacher Khalid taught Social Studies to first graders and taught them about People. He instructed them about what was similar and different amongst people of different races and nationalities. He also discussed skin color as a difference in people. He used small group work to help students identify difference in people’ pictures cut out of Western magazines. Students constantly responded to his questions, added new information and were asking questions eagerly. In teacher Hina's class, second graders learned about their family tree. She explained the concept of a family tree, had them fill in information about their families on a worksheet with a tree and bubbles drawn on it. Students sang a song and were involved. The lesson was taken from a textbook.

During class observation of Social Studies to fourth graders, teacher Khadija used role playing techniques and asked students to speak to the group as though they were teaching them. She taught fourth graders concepts such as equator, northern and southern hemisphere in English. In teacher Khadija's class, students asked lots of questions. Teacher and student interaction was on-going which involved clarification of concepts. 
She brought a globe to the class to be used as realia. She said that she had a hard time explaining to students what an imaginary line was.

Teacher Khadija talked about how she studied at the government school system where the stress was on rote memorization without an understanding of the key ideas. She understood geographical terms better now that she was teaching them to her students because when she went to primary school she was instructed to learn concepts without having a thorough understanding of them. She said that she worked really hard to change that for her students. She required students to learn their lessons and to memorize their spelling and important concepts, however, she also liked them to have a complete grasp of a topic. She contended that it increased students' confidence as well as understanding.

Teacher Khalid discussed the use of rubrics for assessment. Rubrics are being used in the school to assess student learning as part of implementing the IB curriculum. And he contended that using profile of the learner and rubrics explaining different learners’ profiles helps a teacher in assessing what a learner is best capable of. He mentioned,

"You have to make these children into enquirers and you also have to make them independent and not dependent," (Interview with Khalid, 2010), something that he has learned by implementing the goals of the IB curriculum.

He used an example of a classroom practice to describe how he allows the learners to be independent thinkers, he brainstorms with children the answers to the questions that are presented at the end of a chapter that they have read and discussed in class. He allows the children to come up with their own answers and write them after he has discussed the bullet points with them in the class. He also discussed that he was better able to understand scientific concepts as he taught them to the students. 
"We actually took plants from a nursery and I taught them about different parts of the flower-what is anther, what is pollen and fertilization process that I was never able to understand. I was able to understand that as I taught them, fertilization occurs and then the pollination precedes that and when you do such things and make kids do them and then you learn yourself from the students." (Interview with Khalid, 2010).

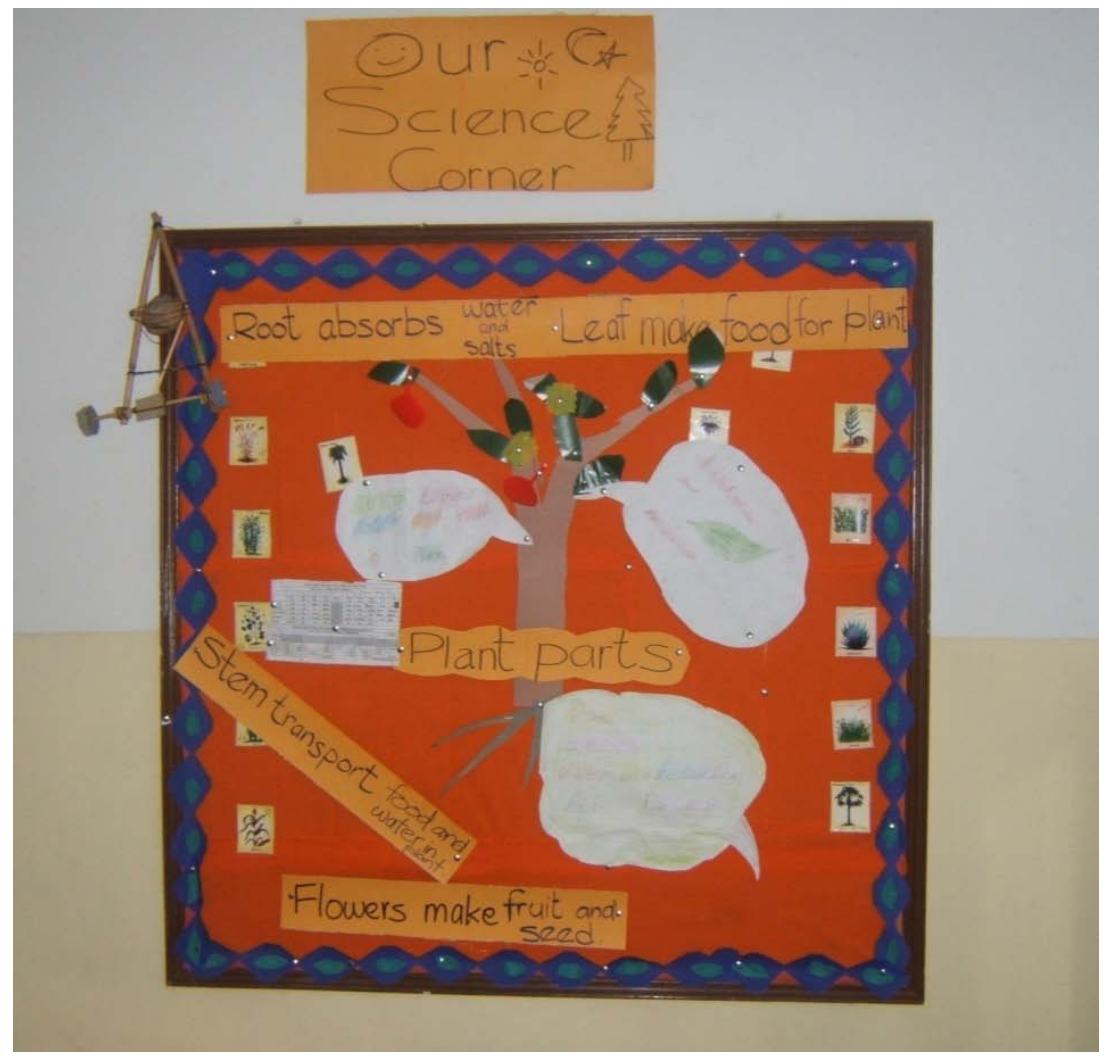

Figure Eight: Student work on display in Sunshine. The chart is mounted in an area allocated as the Science Corner in the classroom. It shows plant parts and students have drawn pictures and written about leaves and flowers. The bulletin board was present in a fourth grade classroom. 


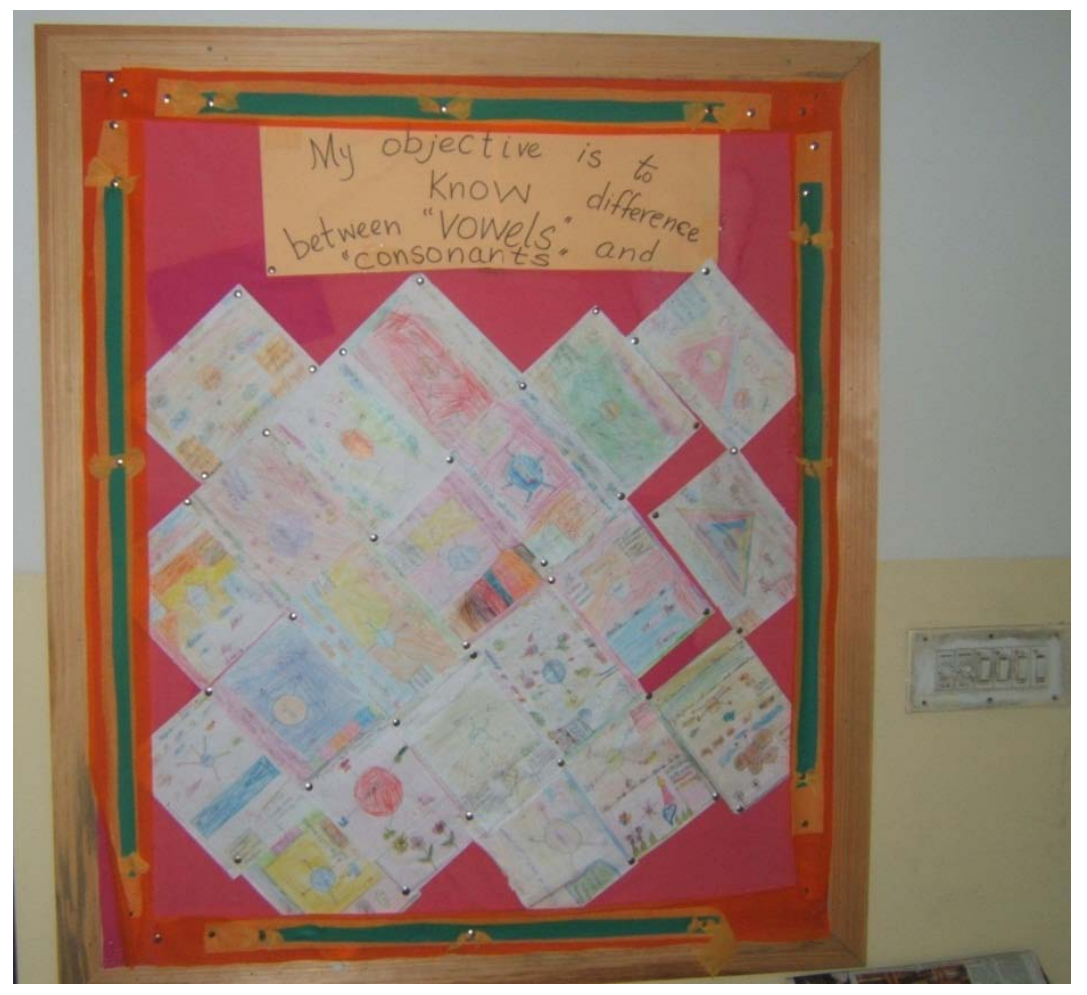

Figure Nine: Student work on display in Sunshine. This bulletin board showed students' drawings and labeling of various words as they started with a vowel or a consonant. The bulletin board was mounted in a first grade classroom.

Khalid mentioned the flexibility in teaching in the following excerpt,

"I like this school, teacher has the liberty to teach on their own and the best part I like, really like in this school is that I can teach activities according to my desire according to my plan and make my own syllabus and incorporate methodologies.” (Interview with Khalid, 2010).

Khalid further discussed how he made his lesson plans in the following excerpt,

"I use pictures from somewhere, download worksheets, and change them according to the level of students. My lesson plans are also flexible.” (Interview with Khadija, 2010).

Even though this liberty can be considered as something that empowered the teachers, it posed problems for the students. In the urban school, students were tested on an assessment that tests students' mastery of a government prescribed curriculum. For instance, the tests that were administered by the Punjab Education Foundation (PEF) 
tested students on their master of government prescribed textbooks. Students complained about the burden they had to face as a result of preparing for two different approaches to the curriculum.

Not all the teachers have seamlessly woven the two approaches in their teaching. There are instances of observation when teachers taught in a style which reflected more of a direct instructional approach. For instance, in an observation of a fourth grade English classroom, the teacher focused on error correction and simple sentence filling techniques to teach the students the difference between nouns, adjectives and verbs. The students' mastery of the concepts was a source of great delight for the students as well as the teachers. The teacher had used small group work to enable them to create sentences around a noun using adjectives. However, the small group strategy does not necessarily reflect work here that is contextually situated. Moreover, during a class room observation of post kindergarteners, I observed a teacher using a technique where she held the students' hand as they painted an apple. This technique does not necessarily reflect the student-centered approach that the junior school coordinator claimed that they were using rather it showed a rather teacher controlled approach. The students in that class, however, were incredibly independent, confident and self-reliant for their age. Using two different and sometimes apparently contradictory approaches toward teaching also created great burden and responsibility for teachers. They were constantly trying to create more materials and fulfill the desired language competency requirement for students. For the junior classes there is not much that a teacher needs to follow with regards to a government prescribed curriculum as the textbooks have minimal information restricted only to the alphabets in English and Urdu. Teachers used a lot of playful activities in pre- 
$k$ to engage young learners. Once the students transitioned to first grade, the burden substantially increased on the students as well as the teachers in an effort to seamlessly integrate different approaches to teaching in the curriculum.

Testing. Even though teachers were not required to teach the government school curriculum, students were tested on it. The school received a Punjab Education Foundation Fund for Rupees 300 per child. The PEF tested the students to see whether they were learning the mastery of certain concepts in English, Science, Math and Urdu. So the teachers are under an obligation to teach through books from the government prescribed curriculum because they receive a Punjab Education Foundation award for 300 Rupees per child. Students complained during the student interviews, that through the PEF tests they were tested on concepts and themes that they have not necessarily studied in class. The students were tested through PEF because the school received a PEF grant which was discontinued on the follow-up visit in 2011 since the school had decided to be a fee-based school.

Children were tested through work sheets. Passing the test required for them to memorize concepts and reproduce them. At Sunshine, the children were tested on activity based worksheets for Urdu. They were mostly being tested on things that they had learned in the class. All teaching stopped when tests were being taken and the students were expected to learn, to memorize and to reproduce the information to answer test questions. Students were generally satisfied by their performance on the tests and the assessment. In the requirement by the IB curriculum, students were assessed on their projects as well, and continuous assessment enabled the teachers to mark their classroom performance and their overall performance through several tests taken during a term. This 
was a new development at Sunshine, and I was asked to help in this process where I helped them to develop a rubric for continuous assessment of presentations, and projects. These were innovative ways in which assessment was being changed.

However, while Sunshine was going through the curriculum transition students were still being tested in the traditional way. Students mentioned that through tests, they were asked to answer questions that they may not necessarily have discussed in classes which then required them to get tutoring in the evening to cover the syllabus on their own. Students at Sunshine viewed the process of their learning as a privilege and talked about how hard they had to work in terms of memorizing and producing materials that they were required to produce on the tests. Student Savila said,

" At first I write, then I put my fingers in my ears and memorize it out loud, that is how I memorize information. Sir Kalid taught us this method. When we were in third grade, we could not memorize tables and when Sir taught us this method we were able to learn everything." (Interview with Savila, 2012).

Rafia scored highest marks in Urdu, English and Computer and had an A grade in

Art,

"Teacher when I am preparing for the test, whatever I do not understand I rote learn it. Then when I have memorized it completely, I write it down on a notebook.” (Interview with Rafia, 2012).

Anita said,

"Teacher the way Sir Khalid teaches us, I can understand things but I am not able to memorize them, now he is revising all that we have studied before (for the exams)." (Interview with Anita, 2012).

Anisa talked about how she received help from her brother when she was unable to engage with the material on her own, 
“ At first, I write it down and I memorize it. Then I write it down again and show it to my brother. Then I write it down once again and then I memorize it completely.” (Interview with Anisa, 2012).

The students mentioned getting help from their older siblings and they mentioned that they were getting tutored. Two of them mentioned that they were being helped by their parents in completing their homework assignments or while they prepared for the tests.

\section{Children's Lives and Learning at Sunshine School}

Students at Sunshine School studied a well-rounded curriculum that offered traditional subjects such as Urdu, English, Math, Science, Islamic Studies as well as Social Studies and Computer Studies. There was one Christian student whom I interviewed who expressed her difficulty in memorizing Arabic texts required for Islamic Studies. No exceptions were made for her to study another subject besides Islamic Studies. Students at Sunshine were articulate and vocal about their learning experience. They gave elaborate responses to each of my questions during the group and individual interviews. Student Anita explained her learning at Sunshine in the following way,

"Zafreen: Who is your favorite teacher?

Anita: My favorite teacher is teacher Khalid because he is our class teacher, and he has given us a very good experience, so that we can become doctors, and so that we can come to such a big school and he has taught us very good things. He works very hard (day and night) and takes our notebooks (home) and checks them diligently and he makes us work quickly and I understand what he says as though someone has cast a spell on me.”

(Interview with Anita, 2012)

Students expressed their appreciation for Khalid and other teachers who facilitated their understanding of difficult concepts in Science, Social Studies and English in a friendly environment. Children also expressed their pride in learning all subjects in 
English in the school. Students at Sunshine informed me that they received occasional slaps from the teachers despite the zero-tolerance policy of beatings. Student Anita mentioned her apprehension about punishment in the following excerpt,

"Zafreen: Do you think you are learning well in this school?

Anita: Yes, teacher. Now see, there is an alarm system in this building. I want to touch the alarm system but I think that the teacher will beat me that is why I am very scared.

Zafreen: Which teacher will beat you?

Anita: Teacher nobody beats (us) a lot, they beat us only a little.”

(Interview with Anita, 2012)

Student Sitara was concerned about the Rupees 10,000 (109 USD) donation

policy for every newly admitted child. She expressed her concern in the following way,

"Teacher, those people who do not have money cannot afford this (school) now, at first, children could get admitted to (this school) in pre-kindergarten, now they are admitting the children of rich people. They are saying that give us Rupees 10,000 and you can admit the child in any grade."

Girls in the urban school aspired to study further. They did not necessarily know what professions they wanted to acquire besides teaching, medicine, and air hostess. The five girls I interviewed unanimously agreed to complete all the classes. They mentioned that their parents had high expectations of them,

"Zafreen: You told me that you want to study a lot.

Rafia: Yes, teacher.

Zafreen: And what do you want to become?

Rafia: Teacher my father says that I have to become a teacher.

Zafreen: What does your heart desire? 
Rafia: Teacher I really like to be a doctor. My father says that in order for you to become a pilot you need to be tall and I am scared as well, so I will become a doctor."

(Interview with Rafia, 2010).

Another student discussed her future plans in the following excerpt,

"Zafreen: Tell me would you study further? What would you become?

Savila: I will become a teacher.

Zafreen: Okay, where would you teach when you become a teacher?

Savila: I will teach at this school. I like it and they do really good work.

Zafreen: What is good about this school?

Savila: Teacher all the teachers here make you work and they give you easy work and then you score good grades in the tests. And if there are any children who do not learn, they get zero marks (in the tests)."

(Interview with Savila, 2010).

Students openly expressed their likes and dislikes about things that worked in their school, their favorite teachers and favorite subjects.

\section{Indian Peace Delegation at Sunshine School}

The urban school participated with a peace delegation from India. There were three students, two boys and a girl and two teachers (a male and a female). The visitors mentioned their apprehensions about coming to Pakistan owing to the news about violence in Pakistan. The delegation arrived at the Wahga border and they were greeted warmly by the school management. Sunshine School had also sent their delegation to India a few months ago. Students and teachers collaborated on drawing and painting posters on friendship. A puppet workshop was held in the evening where a puppeteer came from a very renowned puppet family in Lahore. I was introduced to the group and the entire day I had informal conversations with teachers, guest lecturers, students and 
administrators. The school received a lot of publicity from the national and local media, news outlets as well as print media. Pictures were published and stories were strewn on air about the successful visits.

\section{Synthesis of the two case studies.}

The case descriptions of the two case studies help the readers to understand the context in which the two schools operate. The descriptions further highlight the differences between the two schools, the teachers, the funding structures and the instructional practices. The narrative helps shape the understanding of how the two schools are providing education to children from low-socio economic backgrounds. 


\section{Chapter Five: Thematic Analysis}

In this section, I examine four themes that emerge out of data which is dialogic, digital and observational in nature: curriculum, school leadership, access and gender. The aim of this chapter is to provide empirical evidence about the processes of teaching, learning and management in Kiran School and Sunshine School and frame the larger discussions regarding the relationship between curriculum and leadership practice in developing policies for just and equitable educational access.

\section{Curriculum}

There are two important decisions about a framework for instruction: first is the decision about curriculum choice and the overarching philosophy and second is the actual implementation of the curriculum. There is an overarching broad philosophy and a theory that guides educators as multiple stakeholders make decisions or policies about what to teach in the school and how to teach in a school. The curricular framework or the overarching theory helps to determine how important decisions are made about some of these aspects: what is the role of the teacher? What is the role of the learner? Is learning student-centered or teacher-centered? Whose voice is heard in what is being taught at school? The choice of theory or guiding principles that direct the curriculum is important in determining how it is implemented. Educators make decisions about the guiding theory behind how children are taught, the choice of methodology and the textbooks, how teachers are trained to teach that curriculum and how children will be assessed. In an ideal situation there is a clear and an explicit connection between a curriculum theory, a teaching philosophy, the method of teaching, the choice of textbooks, classroom 
activities, the use of projects, topics and themes and the way learners are assessed.

However, that connection is missing in these two schools.

Sunshine School. In the Sunshine School, the decision to implement the International Baccalaureate (IB) curriculum came from the top management. The management bought into the philosophy of the IB curriculum. The teachers were then told that those unable to teach according to the IB curriculum would have to find other employment,

"Madam (an administrator) said that (only those teachers) will stay here who know how to implement the IB curriculum.” (Interview with Sabira, October 2011).

Training was organized to instruct teachers in the IB way, however, those were not sufficient and some teachers took the initiative to learn about it on their own.

"Ever since I came here, I have developed an interest for research,..... and I have a curiosity.... I do not apply anything until I see all the evidence.....And unless I see things how things are done globally on the internet, I cannot apply them.... (Interview with Sabira, December, 2010).

The teachers and coordinator were aware of the IB concept, but it would take some time to see it implemented across the board. The senior teacher organized collaborative sessions to instruct teachers about the curriculum,

“For teachers' understanding (of IB curriculum) it is imperative that they agree that they are self-learners... and any teacher, even if they are trained, you can not make them do it, unless they are committed to it....(the IB philosophy).”

(Interview with Sabira, December, 2010).

The stress on the implementation of the IB curriculum was more on childcentered learning and global competence

"I believe the world, it is now (a) global village and then (in the past) there were standards that the child has to be prepared for survival in the country ....and now 
only when you are bringing the child at an international level then you are giving them a real education so you must work hard.” (Interview with Khalid, 2010).

At Sunshine, the IB curriculum, allows the teachers to experiment with subjects that would not be discussed in traditional classrooms such as variation in skin color. It also allows teachers to teach creatively and think intuitively about creative problemsolving.

"The teachers are the most ordinary people taken from any system and then upgraded gradually .......how do you take ordinary teachers from a very traditional system and make them into agents of transformation and lifelong learners and I think it is their acknowledgement, finally, to say we do not know it all, we will also be learners in this journey and those by the way acquiesce to that, are the most successful teachers of Sunshine (Interview with Meera, 2010).

However, teaching at Susnhine was practiced by some in more teacher-centered ways. In Math , English, Computer or Art classes, singing nursery rhymes, or in painting, activities that would not necessarily require so much teacher control, the teachers were the center. The teachers provided a lot of opportunities where the students could interact with them and provide responses to what they were asking.

In the discussion of the teaching and learning in the classrooms, a central issue has been the use of methods. Teachers in the Sunshine school, showed a disdain toward how they were taught in the government schools.

"I never understood technical terms in geography when I was a student, I wanted to change that for my students" (Interview with Khadija, December 2010).

They indicated a disconnection with a style of teaching where students had no real understanding of the concepts that were being taught. A student later responded about this teacher's teaching style and said,

"Teacher Samreen and Teacher Khalid are my favorite teachers. They teach well. They explain and make you understand. Other teachers do not do that (Interview with Anita, December 2010).” 
A teacher's teaching philosophy also shapes their methods of teaching, the choice of textbooks, the classroom activities, the use of projects, topics and themes and the way children are assessed. The teachers employed more learner friendly strategies whereby learners developed understanding and engaged with the materials that they were presented with.

'It is a teachers' job to look at students' interest and then design the activities. Whenever I get a new class I spend one week on orientations. I identify their strengths and weaknesses and then it helps me in making the curriculum and in making it flexible. I do modifications in the curriculum" (Interview with Khalid, December, 2010).

On the other hand, other teachers maintained a stricter classroom environment and

activities were controlled and supervised by the classroom teacher. For instance, in a kindergarten art classroom the teacher only allowed learners to color an apple as she held her hand so that color would not be spilled outside the apple's boundaries. Another teacher taught a lesson on changing fonts on a word document with a single computer and the learners took turns as they practiced changing fonts on the desktop even though a well-equipped computer lab was present on campus. Literacy skills were being taught in the Sunshine school as well, for instance, there was a lesson on grammar rules in English for fourth graders. One teacher used drilling and repetition to hone concepts such as parts of speech. Most of the academics would readily agree that there is some benefit in learning English as a Second language where students are instructed in drilling to master the concepts of adjectives, nouns and verbs. However, others contend that learning a language in a constructivist paradigm would result in a movement away from drilling, repetition, and rote memorization. 
Kiran School. In the Kiran School, the curriculum focuses on the teaching of functional literacy skills to young learners. Children are taught subjects such as agriculture, health and nutrition (besides the regular core subjects) through a topics-based approach. The children performed role play and dramas with a focus on social consciousness and awareness. In one of the core classes, when the NGO founder taught how the word accident was written, she used a technique whereby she elicited students' response first by asking them to narrate incidents where they were involved with accidents. The connection of the new vocabulary with life stories of children was helpful for students in connecting learning in school to their own lives. Teaching in the Kiran school was also teacher-centered. The children were memorizing and appearing in written exams.

\section{Cross-Case Analysis of Curriculum}

The use and choice of textbooks is an important part of the curriculum. In both schools, the curriculum is devised in consultation with the Punjab government textbooks, both schools then significantly converge and employ their own methods. Where Kiran uses more rural and more indigenous local based systems, Sunshine is more global in its outlook and approach. Sunshine uses implants from outside, Oxford University Press, as well as other curriculum such as the International Baccalaureate (IB),

"To use the books published by Punjab textbook boards is our necessity, we take funding from them (Punjab Educational Foundation Fund) and then they take a quality assurance test so in order for the learners to pass that test, we have to teach with the help of their books.” (Interview with Sabira, December 2010).

The management of Sunshine School also sees the values in using books published through the Oxford University Press, 
"The books from Oxford have very good activities, we take activities from there and we collect (teaching) materials from other sources as well.” (Interview with Sabira, December, 2010).

In both schools, a theory that guides teaching and learning is not mentioned in the interviews and the school information materials. Rather I observed different approaches were being used to teach and assess the students. Both schools emphasized a movement away from traditional methods, characterized mostly by a behaviorist approach to teaching and learning where the stress is on rote memorization, reward and punishment. Teachers from both schools associated these traditional methods with government schools, and they wished to distinguish their practices from those of government school pedagogy.

In the two schools, movement away from traditional modes of teaching required scaffolding. In the absence of scaffolding, teachers used approaches drawing from the traditional paradigm. At Sunshine, in the painting class the creative elements were not allowed to develop as the hand-held painting denied that opportunity to the students. However, when the Indian delegation came and a workshop was arranged with older children with an artist from a renowned college, the atmosphere was different. The children were given instructions and a lot was left for their creativity, imagination, interaction and dialogue with each other and with their teachers as they were all equally involved in presenting the posters.

At Kiran, when Pre-K children engaged in coloring the stress was on children's creativity and joy in coloring but language use was being strictly corrected. Children were informed to refer to the vegetable they were coloring with only the Urdu name and they were told to not use the Punjabi name. Children at Kiran demonstrated role playing 
which focused on memorization and reproduction of dialogues which provided an opportunity to understand social inequities, and gender roles. Children at Sunshine also performed plays and were involved in puppet plays.

The teaching and assessment practices in both schools suggest that teaching is happening from a behaviorist perspective. The behaviorist perspective regards teaching as teacher-centered, and operates on the principles of reward and punishment. Children relied heavily on memorization, drilling, and repetition to pass their tests. This is different than rote memorization. In Pakistan, the term rote memorization refers to memorizing without understanding what is being memorized. The teachers' primary insistence was to demonstrate that children had sufficient knowledge and understanding of what they were memorizing. In the section on testing, I make a case that the assessment followed a traditional model.

In summarizing then, as I suggested earlier, teachers who claim to favor an instructional approach that focuses on developing a real understanding of the subject matter being taught cannot test learners in ways which requires them to learn by rote to achieve good scores on tests. Their assertion that their efforts are directed at producing learners who can develop a sense of real engagement and enquiry with the subject matter is contradicted by their test taking strategies.

The use of punishment to reprimand children and to make them behave in an appropriate manner was also quite evident in the two schools. Even though, physical punishment was not allowed in Sunshine, the consequences of not behaving appropriately in a classroom could be quite detrimental. At Sunshine, children made contradictory statements about how they were disciplined through physical punishment. They 
mentioned that they were slapped occasionally by some of their teachers but were quick to assure that they were confident that the teachers loved them and only disciplined them for their own good. I argue here that the stimulus-reward approach of the behaviorist paradigm is reflected in withholding praise when children make a mistake and punishing them to make them aware of the consequences. The reward and punishment paradigm goes from apparently benign options of withholding praise and affection to physical beatings. In any case, I contend that slapping children to discipline them is not helpful in creating a conducive learning environment. The use of reward and punishment approach which stems directly from the behaviorist philosophy disqualifies the claim that movement away from traditional approach is influenced by the constructivist paradigm. A constructivist approach to teaching does not use reward and punishment.

The use of poems, performances and songs was quite apparent in both schools. However, in the two settings, play was viewed as something that was neither desirable nor recommended. Even though most learning happened in a fun, friendly way, in an interactive environment, play was viewed differently. Play was monitored in a different fashion where younger children were expected to come up with their own activities to facilitate play. At Sunshine school, a games period was assigned to the students. Even though a teacher was assigned for games, the teacher did little to initiate games and activities for students. The students were also required to not play on the playground since the grass was being preserved for the annual sports day. The fact that the swings were available and not accessible created a definite strain for the students. They were upset that the swings were not accessible to them but only in special circumstances. The fact that children were asked to come up their own activities was something they were 
not used to and they expected that some of the activities for play would be teacher facilitated and guided. At Kiran school, even though, a games period was not assigned during the regular day, swings were installed in one of the gardens. Initially, the teachers chained the swings but they were later informed by the management to allow children to use the swings when school was over.

The paradox here is, that even though there was no emphasis on children's play in either school, extra-curricular and co-curricular activities such as sports day, Pakistan day, puppet performances, debates etc, were frequently organized and encouraged.

Experimentation is the key principle behind a constructivist curriculum and a framework. However, at Kiran, I saw that the labs were not in real use. There is clear experimentation and observation and reflection at very early stages in the life of a learner within the constructivist paradigm and there was only one teacher who was doing it at Sunshine. However, as Khalid, a teacher at Sunshine, mentioned that while he was teaching his students about different parts of the flower he was better able to understand the process of fertilization and that too for the first time. Khalid's teaching showed use of constructivist strategies. Also in order to be able to teach a constructivist curriculum, two things must happen. The teachers must have a very advanced level of knowledge about what they are teaching. For example, in order to teach the phenomenon of light with experimentation with shadows and reflection, they must have an understanding of concepts related to light, such as speed of light, shadows, reflection and refraction. In order to experiment with light, they must have materials such as plexi-glass, prisms, and flashlights. The teachers at Kiran school are not able to teach English, Science and Math 
well to senior classes. More advanced knowledge will be needed in order to teach Science, Math and English to senior level classes.

There are several things that are happening in the two schools which indicated that learning as a process is quite complex, dynamic and interactive. An eclectic approach to teaching involves a combination of constructivist and behaviorist paradigms. In the two schools, we see an evidence of using a combination approach. This is what I proposed in the initial literature review where I contend that the use of the two approaches in combination can work effectively in schools in Pakistan as each has its merits. An eclectic approach that involves two apparently contradictory approaches and philosophies produces a lot of tension for learners and teachers. A gradual movement away from the traditional approach would require the slow integration of practices that give students autonomy and whereby more creative elements can be encouraged. I argue that the classification is not to disparage one method teaching over the other, learning can occur at any significant level from all the methods. Within the constructivist paradigm though there are opportunities that creativity can be fostered and critical thinking encouraged.

Language of instruction. The medium of instruction is an important factor in determining the teaching approach and methodology. Both schools employed a bi-lingual curriculum. At Sunshine, the language of instruction is Urdu which is not the learners' mother tongue but is the primary language of communication at home. Children also learned most subjects in English including Science, Math and Social Studies.

At Kiran, the children were being taught in Urdu which for almost all is a second language and not the mother tongue or the primary language of communication at home. 
The children learned in a language other than their mother tongue, Urdu, and they also learned English. However, the use of Punjabi, which is the mother tongue for all children and teachers in the school was strictly discouraged. English was being taught in the school in a grammar translation method whereby words were translated directly from English to Urdu and students memorized essays such as Raheem's Farm.

"Zafreen: Okay Ahsan, now tell me what language do you speak at home?

Ahsan: At home, Punjabi.

Zafreen: And in school?

Ahsan: Urdu.

Zafreen: Do you know Urdu? Is it difficult?

Ahsan: I know Urdu, it is not difficult..............

Zafreen: So what subjects do you like in school?

Ahsan: I like all subjects but Urdu is my favorite.

Zafreen: And then which is the most difficult?

Ahsan: Miss, the most difficult is English.

Zafreen: Who teaches that?

Ahsan: Teacher Saima and then the difficult words I am unable to say them.” (Interview with Ahsan, 2010).

At Kiran, teachers made a specific effort to instruct young learners to avoid using Punjabi in class or at school. Teachers took pride in the fact that since the students knew how to converse in Urdu their parents realized that they were receiving a quality education in school. One teacher said,

"It is important for me to be able to speak in Urdu. Now I can speak like one of the city girls. I am no longer embarrassed.” (Interview with Sadia, 2010). 
In this context, the ability to communicate in Urdu language bestowed prestige as it identified the literate from the non-literate, the educated from the non-educated, and the elite from the common people. As an outsider, I tend to be judgmental and I am inclined to be extremely critical of forcing children to learn in languages other than their mothertongue, namely English and Urdu, and to discourage the use of their mother-tongue, Punjabi, in school. However, as an insider, I am aware of the realities of social divisions in my home-culture. I am aware that by learning only in Punjabi from first through tenth grade, it would severely restrict employment opportunities for these children in the real world when they would compete with students graduating out of the private, for-profit English as the only medium of instruction schools. But the question is would these children continue further education and compete with students who have graduated from English-medium, private schools? Would they even consider Engineering and Medical schools where the medium of instruction is English only? Is it even practical or fair to suggest that they study only in Punjabi because eventually they would end up farming anyways? This needs further interpretation from an outsider perspective since it is related to the hegemony of the dominant culture, who thinks, believes and practices that English is the key to opportunities for upward social and economic mobility in the present world, and I am an insider as the member of the ethnically Punjabi, yet English speaking, dominant culture.

Children can learn effectively in their native languages and they would then have to be simultaneously proficient in English to receive professional internationally comparable higher education. Moreover, in case of Punjabi, advanced textbooks are not available to teach sciences for senior classes. The children in the urban school are 
learning an internationally renowned British style curriculum that would give them better opportunities for upward progression to college level classes once they graduate. The phenomenon that rural children are learning basic literacy and critical thinking skills whereas their urban counterparts are studying an advanced British style, English medium education raises concerns for equity and social justice.

\section{School Leadership}

In this section, I first define leadership and I discuss how the two schools handle management. Finally, I make a case of how the NGOs support and provide leverage to the schools that they serve. Leadership is the driving force within an organization. Leaders provide a vision and make things happen. In the case of the two schools, leadership resided with the personalities of the two NGO founders. The two NGO founders employed teachers as managers to operate the two schools. Teachers and administrators were the middle managers and provided a second tier of leadership within these schools. The NGO founders were primarily involved in: creating and establishing the schools; creating a vision for the schools; figuring out costs; finalizing budgets; and generating and allocating funds.

NGO Pathways and Sunshine school. The management model at the Pathways NGO for the Sunshine school took many shapes and forms. It ranged from school leverage, to community mobilization, to garnering support, to making global connections. School leverage took shape in a very intricate and extensive network of connections. The personal connections that the NGO leaders have with individuals from their own social class are important in terms of fundraising and creating other opportunities for the school to expand and work cost-efficiently. The NGO founder at Sunshine used her personal and 
professional networks for supporting the school. The support ranged from wealthy, wellconnected, powerful individual donors who were also board members, to government agencies, to other NGOs, to private educational institutions both national and international, to multinational corporations.

The NGO, Pathways, which is based in Lahore provides opportunities for training and development of the teachers. Pathways partnered with other international agencies such as commonwealth to garner greater support for the students of the school and to offer professional development opportunities for its teachers. The NGO founder provided more visibility for the school through her connections. For instance, the partnership experience with the Indian school children and the visit of the Indian delegation was a result of her work with the Indian counterparts. The IB initiative is also a result of her acquaintance with an IB board member.

"Everybody on the board is passionately involved, some more than others, who have got time also, but also because of my involvement in education at multiple levels including the IB initiative because the IB team globally is part of my own connection from U.S. (Interview with Meera, 2010).

By introducing the IB curriculum the school is getting ready for global competition. This kind of global competition provided them with more visibility and uplift which would enable expansion and more flow of resources. Meera's involvement in different organizations helped her in establishing these networks and also provided her with a very effective way of cost reducing for management operations for Sunshine.

"I am now working with four organizations for me all four are organically linked, I cannot separate one from another,” (Interview with Meera, 2010).

One of the primary purposes of the partnerships is the leverage that is provided to the school which helped to reduce the costs of teacher training and student learning 
through strategic alliances. Leverage comes through the financial support through

partnerships that the NGO has formed with other institutions of higher education and

learning. For instance, Plymouth State University offered a leadership and training

program for the school teachers where selected urban school teachers participated.

"We send teachers to U.S. through Pathways.... for these past several years Sunshine has always been the recipient of that. In sending these people to U.S. every year, so many people have benefitted in Sunshine from that so these are I think the great advantages of these scholarships, which I mean I have to admit are embedded within me and I am the sort of the portal which is emerged in that way.” (Interview with Meera, 2010).

Support also comes in the form of scholarships that are offered by private, for-

profit institutions such as Fair and Lovely and the Commonwealth.

"Some of these networks do help and in many ways we also meant that Sunshine has been able to get away with very, what should I say, very effective funding because of these links." (Interview with Meera, 2010).

Sunshine is coming up with its own brand and the school leaders would like to see

this model reaching out to other children as well. This would enable them to increase their impact. However, the expansion of the school model is related to the availability of sufficient funds. Money would also be needed for further expansion. For instance, buying land for new school development and school construction. Partnerships and leveraging can help to reduce these costs.

"Our goal is to reach up to 100,000 students in ten years ....we will be seeking support of lots of partners ...those who want to give us technical support and those who want to give us financial support......we are partnering with the Social Enterprise Initiative and the Acumen fund and the agreements are in very advanced stages of negotiations.” (Interview with Meera, 2010).

It is evident that the sounder the NGO and the better it is in its management and operation, the more active it would be then in providing for the services that are needed in the school. With solid strategic partnerships in place, the NGO can concentrate on 
expanding the school model, and reaching out to larger number of students. In case of Pathways, a powerful trust, Trust for Children' Education, oversees operations and functions of the school. The board members of the trust are from all spheres of life: artists, educationists, and businessmen. An all-volunteer trust where members are willing to donate their time and money to support the cause of the school also helps to reduce costs and allows the development of strategic partnerships based on trustees' individual connections. For income generation, the sister NGO in the U.K. helped to create numerous fund raising drives for the school. They provided money for conferences and outside travel and that is how the donations from the sister NGO in U.K. were being channeled. For the expansion purposes, an individual donor bought the land on which a new school was built for children from low socio-economic backgrounds. The school leaders have been able to tap into the right resources in that way.

At Sunshine, leadership was manifested in a top down and hierarchical way. In 2010 Sunshine started to charge Rupees ten thousand (USD 120) as a donation for entrance to pre- school from all students. On the follow-up visit in 2012, they had also started charging Rupees 800 (USD 10) as school fee per child per month. The ten thousand Rupees donation for school entrance per child is a way of community contribution toward school management but it also then becomes a very powerful gatekeeper in terms of who is able to enter the school for the next twelve years or so. The decision making for these important changes happened within the Trust and the school management team with little significant input from parents. During the follow-up visits, I observed parents arguing with the staff about their inability to pay for the fee, and some policies were instituted to offset cost for siblings of students attending the school. 
However, a significant amount of parents were resistant to paying a monthly fee. As a result of dwindling individual donations, Sunshine needs to be able to generate some funding from student fee to offset the cost of running the school. The school administration also blamed the exponential rise in the cost of utility bills in Lahore and their inability to pay for them through their own funds.

At Sunshine, the approach towards school management slowly moved towards collaborative decision making, which involved getting voices of teachers to make a decision. The IB system was somewhat effective in terms of moving teachers and coordinators towards collaboration, and reflection. For instance, the junior school coordinator started organizing Saturday morning collaborative sessions with the teachers to discuss the IB initiative. At Sunshine, collaboration and collaborative decision making was seen as a result of the IB curriculum which demanded for a buy-in on the part of the teachers. An administrator at Pathways suggested that collaboration required that leadership resided within individuals so that the highest ranking person did not have all the control over all the decisions. Meera, Pathways founder, also pointed out that they had changed the school 'slogan on the insistence of the children from "educating the deprived” to “enabling our future”.

NGO Inspire and Kiran School. The rural NGO, Inspire, is also overseen by a board of Directors: an- all volunteer, highly qualified group of individuals and entrepreneurs. Members of the board also contributed toward the school and the health center and performed other advisory functions. One member donated 65 thousand Rupees to the community to buy cattle from them. The same member donated computers to the school. 
Kiran school handled management functions and processes. At Kiran, I was informed that the teaching materials were developed after years of collaboration and planning meetings with the community members who then became adult students and consequently the teachers of the schools. However, the leadership at Kiran was top-down and hierarchical. The teachers at Kiran performed tasks after taking permission from the NGO founder which required them to have cell phones to call and ask Nargis about planning events and instructional activities.

During observations at the NGO Inspire's head office, I seldom observed that the NGO office was functional and in use. During the pilot study, the office was functional and there was one accountant there. The Director hired a project coordinator as well. The NGO office staff had a high turnover rate. When I went back to conduct this study, both staff members were fired and the allegation was that there were instances of fraud and embezzlement. The school teachers assisted the NGO Director in the office when they visited Lahore for the purposes of teacher training. They also cleaned and cooked in the Director's house and performed other household chores. Since the other NGO personnel were not visible at that time of the visit, Nargis was the entire NGO in herself. And she was using it as a measure to make the entire process or operation cost effective. There was some help available, for instance, the partner NGO members that came on rice festival day or the donor members that sometime visited the school. As a cost reducing element, different positions were not introduced in the NGO office. For example, a website manager, an accountant, a supply provider, a purchase officer, a trainee consultant, a curriculum planner, etc. These positions are not filled to reduce the costs of managing and operating the NGO. However, this produces an enormous burden on the 
one person that is trying to juggle all these different roles. This produces not only an enormous strain on the individual; it questions the very viability of the organization and its sustainability.

Even though Inspire claimed on its website that the school was not funded by money from International Donor support, Nargis had come across the site while she was working on a project for CIDA. Nargis, the NGO founder, made the following claim as I queried her about international donor assistance,

"With CIDA, we completed a project cycle of three years. After that we did not apply for any funds anywhere. The reason for that is usually it is said that if NGOs do not have external funding and if they do not have institutional funding, they will close the experiment over-night. We thought that we will restore sustainability ourselves, with the support of the community, and through fund raising from a local base. So for last three years, we have not done any fundraising (from the international donor agency) but our experiment has been very successful. Even though it requires more hard work and is more challenging.” (Interview with Nargis, 2010).

Nargis further explained the annual expenses incurred in the year 2010 as follows,

"We think that if we have 2.5 million Rupees than we can very easily run the school. We can hire good teachers and offer them pick and drop services. Because of a lack of resources, I have run the school for the whole year in 300,000 Rupees, however, the quality and work suffered a lot as a result of that." (Interview with Nargis, 2010).

When international donor agencies leave people and organizations in the middle of projects that is a real test of community's resourcefulness and resilience. The school and the NGO managed to mobilize the community and to keep the operation functional with their meager resources; however, it poses serious questions about the long-term sustainability of the project. 
The word community is a multi-faceted term, and it is challenging to put boundaries and define the word community in various settings. The community can be defined as individuals that exist within the four walls of the school, the teachers, students, staff and administrators. Within the school community there are people who function mostly outside the four walls of the school, however they interact a lot with the people within the school: for instance, parents, donors, board members, stakeholders etc. The word community took different shapes and forms in the two contexts. It referred to the immediate community that existed within the four walls of the schools and the community that existed outside the boundary walls of the schools. In the rural area, the community outside the school was strongly connected with the day-to-day operations of the school. This was not the case with Sunshine where the individuals living in the neighboring residential area may have little or no connection to the school.

The neighborhood within which the school exists is also a part of the school's community. However, the word community is used in this study to describe the involvement of the individuals that are involved in the functioning of the two schools. No effort was made to study the school's neighborhood in isolation, formal parent interviews were not conducted. However, I spoke with members of the community, such as parents, volunteers, and donors, as they visited the school for events and participated in various school activities. An attempt is made in case descriptions to situate the two cases in their geographical, social and economic context. The word community would take different shapes and forms in the rural and in urban settings. The rural community exists in a completely different setting than the urban community. For example, the individuals that live in the rural areas are indigenous and the communities in the urban areas are mostly 
transplants who have migrated from mostly rural areas or small cities to the area close to the urban school.

The involvement of community from outside the four walls of the school to inside the school was readily visible as a rural phenomenon. The NGO founder, Nargis, developed mutual trust-based relationships with the community. Not only they donated land, they provided support in building construction. The community put up the rice festival with their own meager resources to support her and to make her friends and to make her family proud. At Kiran, the community was initially involved in land donation and construction of the school. The founder identified key change agents within the community and assigned them tasks so that the school could operate in that vicinity. She performed the function of mobilization through community gathering and community activism. Then other individuals from the rural area joined her team and kept helping her and the team. This process created a strong sense of community ownership and support for the project. The project was then not just limited to a school, the project then evolved into a health center as well. Within the school, community support was evident in how the students helped to paint the school, took care of the lawns, fixed the swings, carried water in containers, and cleaned the area where the annual rice festival was held. The community paid for all the expenses that were incurred to conduct the rice festival. In the rural area, the community was initially involved in key decision making within the school. For example, the community demanded that grown-up boys would not study sideby-side with grown-up girls. Hence boys were removed from the school after fourth grade. This practice is enforced based on the gender segregation norms that are widely practiced in Pakistan. Community involvement has faded out in terms of not so much 
involvement in the day-to-day affairs of the school but rather than just gradual and general phasing out. There was definitely a stronger sense of community and self-help within the rural school community,

"For a year and a half, while the health center and school were being constructed, then all the labor, their bedding, their accommodation, and their food which requires millions of Rupees, that everything came from the community. While the school was being constructed than all the teachers donated their one month's salary, even though, they do not make a lot of money and we did not ask them, the initiative came from them." (Interview with Nargis, 2010).

The shortage of the teachers was a common problem at the Kiran school. Once some of the teachers were married, they moved out of the village and in that way the community was deprived of an asset, a trained teacher that they had created with their shared resources. Nargis also had significant concerns and doubts about the involvement of the community in the operations of the school. As I conducted multiple interviews with Nargis over the course of four years (2008, 2009, 2010 and 2011), she had changed her stance about community involvement within the school. She had fired all but one teacher upon my follow-up visit and explained that one of the reasons was the tension caused by community taking too much control over the decision making in the school.

\section{Cross Case Analysis of School Leadership}

Both Inspire and Pathways used the horizontal connections of the NGO leaders successfully to create leverage for the school. Pathways because of its urban placement and community setting; and the personality of its leaders was more successful in making Sunshine more visible and globally connected. While I was in Lahore in 2010, Sunshine was being recognized in the local print and electronic media for creating successful partnerships with an Indian school. A small delegation of teachers and students from India visited Sunshine amidst border tensions and severe difficulties in getting visas 
which created significant amount of coverage in the media. The real strength of Inspire lies in creating community involvement, ownership and mobilization which has enabled it to operate Kiran. However, it is challenging to compare across the two schools within the leadership theme because the two schools are operated by two different NGOs who have completely different techniques and approaches toward curriculum and school management. It could be said that they have some similarities but their approaches toward school management are generally different.

Social class of the leaders. One of the key findings of the study is to situate the participants in the social class to which they belonged. In case of Sunshine and Kiran, the leadership is coming from powerful women who run the NGOs that support the school. The two NGO founders who run these schools, including the urban school principal, are from a different social and economic class then the individuals that they are serving. The women leaders who run the schools belong to a different social class and the teachers belong to the same social class as the children. During the course of data collection, it was important to ask the question of why these women were running these schools? In so doing, the founders tried to change the world of these teachers, and the students. The founders are not from the same social class and act as a medium for leverage and provide advocacy options to these groups who would not have individuals in position of power and with access to resources. For example, Nargis, Inspire’s founder, belonged to the elite class (having received education abroad) then the women that she was working with (rural women). She had more resources, she could advocate for them, and she also had the ability to mobilize them. Money has enabled the two NGOs to secure and perform operations to run a school for children who would otherwise not have access to 
education. It is not clear if the two NGO founders have used the school or the NGOs for their own personal social and economic benefits. By the time they started with the NGOs, they were already rich, and privileged. At the same time, they have personally donated generously and collected funds from their immediate families to support the running and functioning of the school. They have also contributed their personal effort and time, however, it was not clear how much money they earned as a result of their services. The NGOs are represented by the personalities of these two women and they are the driving force behind the two schools and the NGOs. Both the original founders have a vested interest in the success of the school. The two NGO founders have considerable power and control in terms of managing the operations within the two schools. The two schools and the NGOs are acting as small organizations rather businesses that are creating opportunities for jobs in the communities in which they exist. The NGO can be used as the vehicle to control and manage populace left alone by state that is then overtaken by non-state actors. The NGOs set up their own stage and they perform functions that may not necessarily change lives of the individuals for better but they might be getting more and more control of the lives of the people who have no other better recourse.

\section{Access}

Access is defined as the ability to get to a resource and to utilize that opportunity or resource. Some other terms that describe access are to gain admittance or to gain entrance. When one is denied access to resources on the basis of geographical location, ethnicity, gender, social and economic classes this result in inequity. Equity is defined as an ability to receive and utilize equal treatment and opportunities. Inequity is when a certain group is denied access to resources, and social services based on their ethnicity, 
gender, social class, income level and geographical location. In the case of this discussion, access refers to several things which are as follows: access to trained, qualified teachers, resources, and facilities. Moreover, access refers to achieving elementary education for children from low-income background.

Access at Kiran. Access is an important factor in determining whether the children in rural areas are able to reach the school. The existence of the two schools enabled children to access education which would not have been possible in the absence of these schools. I asked teacher Aneela if there was a fee to attend the school, would parents be able to send their children to school,

"Most people cannot afford (to pay). Few people will accept it and no one can pay a fee every month. Here, people get money after several months at harvest time. Here, nobody is willing to buy a uniform for their children, who do you think would pay a fee?” (Interview with Aneela, 2010).

Ahsan, the student of Kiran school, answers questions about his background in the following excerpt:

"Zafreen: What does your father do?

Ahsan: He is a milk man and he sells milk.

Zafreen: Does he work at the farms as well?

Ahsan: Miss, he does a little bit of farm work also.

Zafreen: Do you have cows?

Ahsan: No, we do not.

Zafreen: Do you have goats?

Ahsan: We have two goats.

Zafreen: How many people are in your house?

Ahsan: Dad, mother, and my siblings (four).” (Intreview with Ahsan, 2010). 
It appears through this exchange that Ahsan’s family with their meager resources, selling milk from two goats, cannot afford to pay for his education and would not be able to provide access to education in the absence of a school in the vicinity. Even though a child such as Ahsan, would seem better off than homeless children on the street he is living below the poverty line. Ahsan's access to elementary education is made possible by the presence of the NGO school. His access to education is restricted by his geographical location and his socio-economic background. Access due to setting or geographical location is a fixed construct and cannot be changed. Geographical location either allows or inhibits the school in connecting with available resources. One can increase or add to the flow of resources to the school setting. For example, being connected to a paved road would be a resource that would provide rural children access to books and/or field visits. Without having any access to local stores, modern shops and roads, the children at the rural school were being denied things that their urban counterparts may take for granted. With limited access to paved roads, and vehicles, the shops in the area determined what the individuals were able to buy in terms of books, stationery and other teaching aids on a regular basis. Having access to existing facilities close-by (not more than four to ten miles away) from the rural school further exacerbates the deprivation of social services that this community has faced prior to the work of NGO in their area. I bought toys and books for children in the rural school from Lahore. In that particular instance, I was reminded of the resource poverty of that area. If children have access to resources, trained teachers, money, facilities, and literate adults then they can get an education. Better access to adequate facilities and trained teachers can enable students to learn better. However, the rural school started from nothing and started 
building its resources based on the assets that were available in the community. Once the NGO, Inspire, had access to the communities which it served, change agents were identified within the teaching staff that belonged to the respective community. Using locally available assets resulted in empowerment of the rural community. Some of the assets that were available in the rural community were community mobilization, change agents, leaders, land donation, and labor support.

Access at Sunshine. Sunshine provided access to education for children from low-income backgrounds. A teacher explained why he taught at Sunshine in the following words,

"The main reason of teaching in this school that appeals to me a lot is that the students which are underprivileged and are from underprivileged families and that appeals to me a lot and I am here to serve the people of my community.” (Group Interview with teachers, 2010).

The father of Anisa, a child at Sunshine, earned roughly a $\$ 100-\$ 120$ as the head of the household by working as a motor rickshaw driver. The amount is not even two dollars per day per individual in the household. There are hidden costs associated with getting an education even when schooling is free. For instance, when children have to pay to participate in extra-curricular activities, or to spend money on buying books, the fact that the school is free is only marginally helpful.

"They took money from us as well, Rupees fifty (less than 1 USD) for the trip.......they also took one hundred and fifty Rupees for the files. The files are needed for papers, and then for the crazy chicken dance they made us pay another one hundred and fifty Rupees. This school is for needy people but now they are increasing their requirements. That is not a good thing because this school is for needy people and they send their children here thinking that this will be good for their future." (Interview with Sitara, 2012). 
As Sunshine decided to go from a free school to fee only school, it will pose significant problems for most of its children. Sitara had already dropped out of Sunshine by the time I had conducted the follow-up visit. Over time children and their parents by default were paying more for services at Sunshine. There were costs associated with payment for transportation as well as entrance fee, however, on the follow-up visit Sunshine started to charge a monthly fee from each student which made it very difficult for some of its students to continue studying at the school.

\section{Cross Case Analysis of Access}

The nature, population and location of a certain community determine the access to education that the community will get. For example, the socio-economic level, and the availability of assets within a certain community are important indicators of what kinds of educational experiences the children would have. The rural community is somewhat easily bounded rather than the urban community which is not restricted to a neighborhood or to a given radius mile that can be drawn around the school. In case of Sunshine, the community in which it existed and the community that it served were two different entities. However, in the case of Kiran, the community in which it existed and the community that it served were the same. A similar comparison of community mobilization was not possible at Sunshine. A caveat here is that the urban community is very hard to locate, identify and define as a broadly based homogenous group.

Access is about the ability to get resources (money) or other assets (moveable or fixed) to the school. The available resources could also be organizations ranging from public or private, for-profit groups to other NGOs. Both Inspire and Pathways were tapping onto the right resources quite effectively to increase educational access for 
children. Access points at the ability to be connected to these organizations in ways which would provide leverage to the school and its students. It appears that Pathways had utilized the networking opportunity to connect with organizations that would provide leverage to the school quite effectively. For instance, Sunshine is linked to several organizations that provide support in terms of teacher training and scholarship for students. There are some examples of Kiran using that network as well. For instance, at the rice festival staff members of a supporting NGO were present to support the work of the school. A group from Malaysia arrived at Kiran and conducted workshops on the harmful effects of pesticides.

Both schools also eliminated children to whom they could not provide access. On the day of the rice festival at Kiran, there were children who showed up to take part in the day's festivities that were not enrolled in any school. The children, who did not go to any school, were the ones who found it difficult to pay for any sort of money for textbooks, copies or uniform.

Ultimately quality education depends on funding, the more money one has the better chances there are to provide an education to children. The more resourceful the NGO, the more opportunities it has for leveraging the school and supporting quality education for the children. A steady flow of income and allocation of resources will determine the standard and the quality of education. Money will determine whether the school will be functional or not. However, community based assets, curriculum and leadership will determine the long-term sustainability of the school. 


\section{Gender}

In this study, gender emerged as a theme when the two schools provided education for mainly girls. Sunshine provided education for boys in the evening and Kiran provided education for boys only until middle school.

Gender at Kiran. The reason for pushing boys out of Kiran was that the community raised their voice against sending boys to the rural school with the girls after

they had reached puberty. The rural community did not want boys to be studying side by side with girls in the same school after they had reached middle school. In this case, the community emerged as a powerful influence in making decisions about what happens within the school. Also in the absence of a boys' school in the vicinity the boys may not have an opportunity to go beyond a primary education. With the lack of a presence of the schooling opportunities for boys nearby they could and do end up dropping out permanently.

"Zafreen: Do you walk to school?

Ahsan: Yes, Miss, we do.

Zafreen: Do you come by yourself? Or someone else drops you off here?

Ahsan: All of my siblings we all come together to the school. ...........

Zafreen: Tell me how long are you going to study in this school?

Ahsan: Miss, as long as madam would teach us. When she would say now you have to leave because you are older then we would go to Sialpur.

Zafreen: Okay, is Sialpur far away?

Ahsan: Yes, it is. It takes about an hour and half to get there.” (Interview with Ahsan, 2010). 
Limiting female mobility and gender segregation norms are an impediment for getting a higher education for women in these areas. In a country like Pakistan, which is predominantly patriarchal, the society fails to respond to the needs of the individuals who are historically weak: children, women and individuals in poverty. Girls at Kiran were also aware of their inability to continue their education. The following conversations with two girls from Kiran will help the readers understand their dilemma.

"Zafreen: Okay, how much will you study?

Asma: I want to do sixteen classes or I would do a B.A.

Zafreen: Okay, what would you do then?

Asma: Miss, I would not do anything, then I will be a grown-up and then my father would not let me out of the house.

Zafreen: Okay so when girls grow up, they do not go out of the house?

Asma: Miss, we are Syed, that is why we do not go out of the house.” (Interview with Farzana, 2010).

Asma mentions her perceived higher caste as detrimental to her ability to continue an education. The reasons why she would be barred to step out of the house are, however, not restricted to caste only.

“Zafreen: Do you want to study further?

Hajra: Yes.

Zafreen: Which grades?

Hajra: Miss, I do not know.

Zafreen: How much would you study?

Hajra: Miss, I do not know, my parents would know.

Zafreen: What does your heart desire, how much do you want to study?

Hajra: Miss, whatever my parents can provide for. 
Zafreen: What would you become when you grow up?

Hajra: I do not know.” (Interview with Hajra, 2010).

Hajra’s inability to articulate her future could be amounted to her age, inexperience, or lack of nudging by teachers or adults in that direction. It is important for young girls to have positive female role models, moreover, a continuous change of traditional gender role perceptions would be necessary for girls to continue their education and travel outside the village to receive higher education. Since much of the literature on women's education and literacy is focused on the immediate beneficial outcomes of basic literacy and primary education, long-term education for girls has yet to become a focus and priority for development sector projects.

Gender at Sunshine. There is evidence of gender discrimination where women make less money than their male counterparts in the urban school. The cleaning lady at Sunshine made Rupees 4, 750 (60 USD) whereas a female teacher at the same school made Rupees 6,000 (75 USD) and a male teacher Rupees 11,000. (137 USD) The principal at Sunshine made Rupees 50,000 (625 USD). In a school, it is relatively convenient to account for behavior that is observable, for instance, teaching and learning, whereas it is very difficult to report findings around behavior which is non-observable, discreet and not readily available for outside scrutiny. I made several attempts to view accounting books at Sunshine but I was unsuccessful. Even though an accountant was made available for interview purposes, exact records were not accessible. Therefore, the exact amount of money that each individual at Sunshine made is not known. The finding points at the general bias that exists between male and female salaries in Pakistan and is not unique to the particular school. The difference in salaries could also be amounted to 
the difference in experience between the male and female teachers. More funds are needed to pay teachers equitably but in order to preserve teachers' respect and dignity it would be important to treat them as professionals. Since data was not available on how much income each person earned in the school, it is hard to determine if women made less on average than men in the urban school.

\section{Cross Case Analysis of Gender}

Women at Kiran also made an average of Rupees 3,000 to Rupees 10,000 per month (38 USD to 125 USD). The exact amount of money each of the teachers made is not known. 38 USD is less than what the cleaning lady made at Sunshine. The justification for lower salary structure was explained by the NGO founder as "even that small amount is significant for a rural woman who has no hopes of an employment or opportunities of cash flow within the family.” (Personal Communication with Nargis, 2010).

However, throughout Asia, women earn on average half the income compared to men with the same job positions which represents a striking strategic disadvantage with regard to their access to societal leadership positions where higher education, income and professional leadership experience are highly indispensable passage openers (Ayaz and Fleschenberg, 2009). These are concerns for gender as well as the social class issues. There is a huge disparity between the salaries of the teachers and the Principal. The Principal is not the member of the same social class that the teachers and the students belong to. Pakistan presents a rich diversity of cultures and political, social and economic structures that have features of traditional patriarchal values. A single woman in Pakistan 
does not need money to support a family yet or to raise children so instead of fair and equitable pay structure she might be subjected to exploitation.

The NGOs are run by women who are local nationals of Pakistan. Both Meera and Nargis are born and are raised there and received education through the elite system and have received education abroad. They are run by women who identify themselves primarily as educators. They are providing an education to girls by employing women from the community who they trained to become literate. The rural school creates gender empowerment by providing employment opportunities for the teachers from that community. The NGO uses the local community and the local women in the area and empowers them. It empowers them by providing them with an education and then it further provides employment opportunity to them as they work in the same school and the health center. The teachers are being empowered as they come from the same local community as the students and some of them especially in the rural areas were educated from the school. The fact that women do not drive vehicles and a lack of access to public transport system in the absence of paved roads severely limits their ability to access any services on their own. 


\section{Chapter Six: Discussion}

In the previous sections, an attempt was made to describe how the NGO schools provide education to children in two different communities with different contexts. The three main research questions that guided the inquiry were:

- How does an NGO school provide education to primary school aged children?

- What processes and structures are evident in two NGO schools in providing quality primary education to children in Pakistan?

- What factors and characteristics are evident in two NGO schools that provide opportunities for teaching and learning for primary school aged children in Pakistan?

\section{Processes and Structures in Providing Quality Primary Education}

The thematic analysis about curriculum and school leadership helped the reader understand the processes that impacted the quality education for children in urban school, sun, Sunshine, and the rural school, Kiran: teaching, teacher training, assessment techniques, management, and the hiring and firing of teachers. In the previous sections, the following structures and their descriptions were identified: the NGOs; the schools; the teachers, the administrators; and the boards.

The results of the data analysis questions the viability of the assumption that all schools are fundamentally similar in nature since they are involved in the 
provision of teaching and learning and that in the quantitative data analysis, difference in these areas become irrelevant through the use of larger data set. However, the structures and processes employed in these schools have considerable similarities and differences, which use of critical analysis both reveals and renders significant. The critical analysis is framed by examining the qualitative data of the case study and posing deeper questions that yield analysis about the underlying human interests that are frequently hidden or glossed over. The two schools are similar in that they are operated and managed by NGOs that are supported by wealthy individual donors. The differences in their structures stem from the fact that the two schools are in different settings; they operate in different social, economic, cultural, geographical, and historical settings. During the course of data analysis, I become more and more aware of the tensions and the sometimes conflicting evidence that existed between the various accounts of how the schools and the NGOs conducted their business. In each case, the interrelationships between the school and their sponsoring NGOs developed as an influential structure in how the schools were organized. The overlap of NGOs and schools was not something that I set out to study but that is definitely an emergent finding from qualitative data analysis.

Organizational structures: NGOs and leadership. During the course of data analysis, the relationship between the NGOs and the structure of leadership developed as a significant factor in the way teaching and learning was enacted at each school. The NGOs and trusts are governing bodies that create the frameworks within which activities (educational and otherwise) operate. The NGOs provided funds and leadership that enabled the schools to function in a cost effective manner. The NGO provided a structure for each of the schools to interact with local and international communities, government 
agencies, and private entities in ways that leveraged resources for the benefit of children in the schools (see Figure 10). This collaborating and networking is essential in understanding how the NGO schools provide and enriching experience for its students and teachers, and how they respond to human interests- which is a central component of critical theory examination.

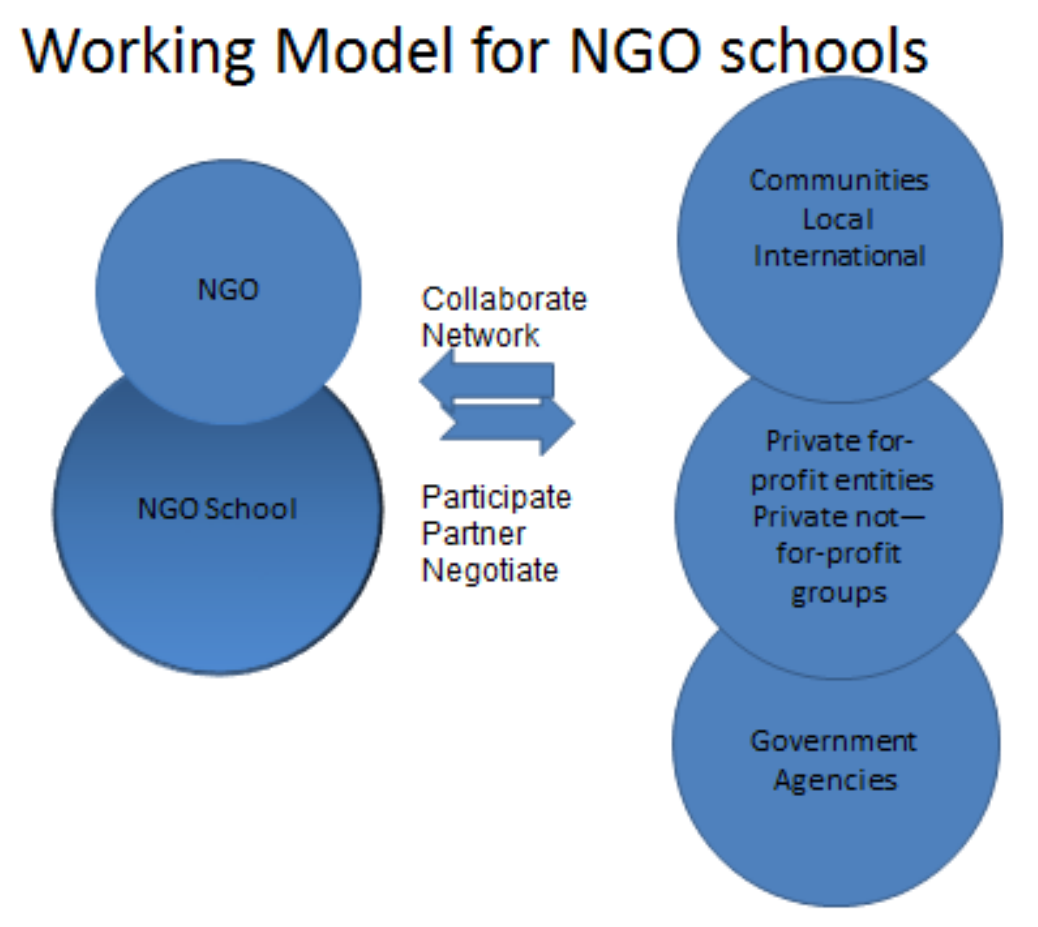

Figure 10: Structures and processes for Kiran and Sunshine schools

I argue that both NGOs are structures that provide opportunities for teaching and learning to occur in the two schools. In each case, the NGOs maintained funding sources that allowed the schools to function. The NGOs provided monitoring and oversight for management functions and operations of the two schools. They created leverage, 
provided support for the day-to-day monitoring and evaluation processes. The networking and connections that the NGOs established for the schools worked effectively. The two NGOs worked in ways that offered vision, leadership, training and guidance to both schools. In each case, these structures assured the long-term sustainability that was necessary to run the schools.

Organizational structures at Kiran School. Whereas the strength of the NGO Inspire is in providing oversight management and training for Kiran School, it was also strong in community mobilization, advocacy and gaining community support. Nargis, the founder of Inspire, recognized internationally as an expert in curriculum development and community mobilization.

The adult literacy technique adopted at Kiran School to train teachers uses original and indigenous materials created by Nargis, and was influenced by Freire’s adult literacy pedagogy. Generative codes, pictures, dialogues, critical and liberating conversations among learners as group participants are some of the key constructs that Nargis incorporated into the adult literacy program. In using Freire’s dialogical approach, each member of the community, i.e., teacher, student, administrator, becomes a coinvestigator and an active agent capable of bringing transformative action (Jiang, as quoted in Goodman \& Carey, 2004). So while the curriculum materials took a liberationist pedagogy approach, the curriculum was enacted in a hierarchical way, using traditional assessment techniques.

One inherent weakness of NGO's structural relationship with Kiran School is that was a single-personality driven operation. The NGO founder managed all of its functions. 
This has enabled them to keep the costs to a minimum, and the funds were channeled to where they were most needed in the absence of a solid support from an international donor agency. Furthermore, a single-personality driven venture stifled the voices of the community. It also reflects some idiosyncratic values that are reflected in the school's management operations. This structural relationship impeded the efforts of the community mobilization and was at odds with the liberationist pedagogy of the adult literacy curriculum. By the end of the research study, the NGO founder had changed her perspective on the value of community mobilization and was shifting to more centralized decision making processes.

To ensure non-discriminatory practices, maximum participation of all community members and fiscal accountability, multiple voices must be involved in the decisionmaking processes at Kiran School. Within the framework of organizational sustainability, it would be important to develop a leadership team to manage the school and interface with the NGO. Moreover, a word of caution would be then to make sure that theer are boundaries of action and participation: that the NGO founders are not doing too much, exhausting themselves rapidly or doing so much on their own so that then no one can follow their footsteps.

Organizational structures at Sunshine School. In case of the, Pathways NGO's structural relationship with Sunshine School in the urban setting, the support came in the form of networking. Sunshine School benefitted from a two-level management structure: one within the school and another outside the school.

Two management and leadership structures existed outside of the school. The Children's Education Trust generated and monitored the primary funds for the school. 
The Pathways NGO provided training, management oversight, leverage and expansion of the Sunshine School model. The two NGOs are powerful as they mobilize resources. The decision to make Sunshine School a fee-based school was a powerful gate keeper in terms of who can access the school. It limited opportunities for those children at Sunshine School whose families were unable to pay the fee. The children most affected were the ones who had one or more siblings at Sunshine. The policy for fee reduction was enacted when there or more children from the same household were attending Sunshine.

When the procedure for receiving and distributing favors, goods and resources to specific individuals remains in the hands of a powerful group, it raises questions about the motivation of that group (Young, 1994). Even though the Pathway NGO was specifically created to "enable the disadvantaged”, it acts as a group or as an institution acting on behalf of the disadvantaged group. Private NGOs such as Pathways, have an inherent interest in the economic sphere in order to sustain their funding stream to accomplish their goal of educating children from poverty. However, achieving that goal was being threatened by switching to a fee-based school. Through continued presence onsite, it was observed that this policy was not created with the input from multiple stakeholders. It was a top-down policy that caused great deal of commotion within the parental community. The goal of expansion was much more important than retaining children from the lowest income bracket at Sunshine. With the process of expansion, it is important to decide how and where to start next. It was not clear how the NGO determined where a school would be built next and how the location is decided. These decisions were part of the human interests that were hidden in the original school's development, and each of the major and the minor decisions involved in determining 
where the school would be located spring from the interests of the founders, and while hidden becomes a barrier to the school's replication. These decisions also become proxies for particular human interests that were involved in making the decision.

The structure of leadership acted in oppressive ways when it determined teachers' compensation scales. Teachers at Kiran make less than minimum wage whereas teachers at Sunshine School barely make the minimum wage. Female teachers at Sunshine make less money than their male counterparts. Women were severely disadvantaged in these settings because there were limited employment opportunities available for them. As teachers in Kiran and Sunshine schools, women were empowered; however the NGO structure maintained the cultural norms of the broader society by paying the women lower salaries, thus creating a financial benefit for the NGOs. The cost of running the schools would increase if teachers' salaries were increased. At the same time, teacher morale, their quality of life and sense of professionalism decreased as they came to understand that they were being undercompensated for their services.

The pervasive discriminatory practices of both NGOs are reflective of a broader patriarchal society. The structural constraints emerge as a result of the dominant culture that informs and maintains traditional school practices. The gross inequities continue to exist because of the cumulative effects of social and cultural factors. Gender biases allow for the vision of women's work, life and education as less than equal and of lesser value than those of men. Women's equal participation with men in social, political and economic sectors remains a question of basic human rights.

Organizational processes. The two schools employed several processes that ensure smooth management of school functions. The structures of leadership would entail 
the processes of hiring, and firing teachers and determining their salary. For the purpose of answering research question 2, two main processes were identified as teaching and curriculum selection. This discussion emerges as a result of data collected through observations and interviews reported in Chapters 4 and 5.

Curriculum. The structure of leadership would help in determining the process of decision making about the curriculum, about the actual teaching process, and the implementation of the chosen curriculum. The process of teaching can be further broken down into the selection of curriculum, making lesson plans, choosing methods of assessment etc. The structure of leadership would also determine whether the process of teaching is control centered. When the top leadership is very control centered and when the top leadership exercises the influence of the decision making powers, teaching consequently is also strictly control oriented and control driven.

Teaching. The structure of teachers and teaching is different in the two schools as the teachers are more educated in Sunshine School than in the Kiran School. The teachers and the administrators were defined by the very nature of the process that they were involved in. Other processes that are evident in providing education in these two schools would the presence of educated and trained teachers to teach the chosen curriculum.

The similarity in teaching at both schools stems from the fact that the teachers employ an eclectic approach toward teaching with influences from the more traditional forms of learning. In the traditional forms of learning the stress is on memorization; however, the teachers in the two schools expressed a clear disdain for memorization that does not involve clear understanding. They also employ methods and approaches which allow them to use puppetry or role-playing to convey a message. For example, role- 
playing centered on challenging the status quo in the rural school, and in the urban school puppetry was focused around fostering healthy relationships with bordering countries. This approach is significantly different from the traditional approach. The public school curriculum has historically been used to create strong feelings of animosity toward the neighboring country of India. In the rural school, the stress was also on connecting the learner's content to their real life; for example, the lessons about habitat and the use of pesticides is a case in point. In the rural school, the children did not know the names of the Governor of Punjab or the Prime Minister. Many of them had also not visited Lahore. The official dignitaries sitting in remote centralized locations had no bearing and connection to their immediate lives; however, that is knowledge that would eventually help them to connect with their urban counterparts.

\section{Factors and Characteristics that contribute to Teaching and Learning}

There were numerous characteristics that supported teaching and learning in the two schools. The factors that provide opportunities for teaching are teachers’ qualification, teacher training, a curriculum, teaching methodology and teacher motivation. Each of these also reflects human interests from a critical theory analysis. There are factors and characteristics that inhibit teaching and learning. A high turn-over rate for the staff could inhibit opportunities for student learning. A restriction for upward mobility and promotions for teachers could inhibit opportunities for teaching. The school environment is a factor that provides opportunity for learning in several directions (for different audiences, such as in-service teachers, parental education, community development etc.). In both schools, there were aspects of learning environment which restricted students' learning, for example free play. Data indicated that children had 
complained about a lack of play in their lives, opportunities to go on the swings and facilitated play time. In both schools, children were being given physical punishment which put a strain on them, and raises critical questions about the interests of those involved in the educational processes.

Monitoring and evaluation. For the rural school Kiran, the availability of trained, literate female teachers was one of the most important factors that allowed for students to learn. Regular monitoring visits helped to strengthen the performance of the school staff. Nargis, the NGO founder for rural school, also received monthly test scores and daily reports from teachers about students’ performance. She travelled extensively to the school to monitor the daily activities and students’ learning.

"There are several ways in which evaluation is designed for this school. Regular monitoring visits are conducted where performance is evaluated. Assessment is based on whether a student has achieved desired competencies and outcomes for each subject. Self-assessment is also encouraged.” (Interview with Nargis, 2010).

During the early years of the school, staff was hired from Lahore who coordinated regular monitoring visits.

"She (the coordinator) would check children's homework and would see how the children were working. And whenever there was a problem, she would explain it to the children and I.” (Interview with Saima, 2010).

The monitoring and training visits by the NGO founder, Nargis, and the coordinator, Saima, helped in improving the quality of teaching.

Community mobilization and support for the school. The process of community mobilization involves building coalitions and bringing people together to give them a voice. The NGO founder, Nargis, spent 10 years in the rural community creating trust-based, mutually beneficial relationships. The community was able to provide land 
for school construction. By partnering with the residents of the community to provide social services (such as education and health services that were needed in the area) a deeper sense of responsibility and ownership for the schools was created. Local community involvement took different forms, from donating land to recruiting teachers to designing curricula and discussing pedagogy.

The rural community had bought in to the philosophy of the NGO Inspire and they were willing to invest and support their children's education was a factor that enhanced teaching and learning in the school. However, the presence of trained teachers was more important than the presence of other structures such as building and resources that supported instruction. Learning could be further improved by the presence of more classrooms since some classes were still held outside in the hallways where students were exposed to vagaries of extreme weather. Two new classrooms were constructed and were being in use when I visited the school in Fall of 2011. Newly hired staff from Lahore was also added to improve learning within the school.

At Kiran, there was a culture of self-help and community participation. Students had a strong sense of community, belonging and shared space within the school. There were several instances where students were involved in taking care of the gardens, weeding and painting the entire school building which demonstrated their sense of belonging to the school and commitment to improving their learning environment. The senior school students were instructed to paint the school walls with the paint that the NGO administrator had brought with her. She and I also helped the teachers and the students paint the school. By the time of the annual rice festival was held at the school, the entire school was painted by grade ninth and tenth students. 
Staffing problems. There were several factors that inhibited teaching and learning within the Kiran school. Those factors involved: lack of firing policies and procedures; marriage of trained female teachers so that they were either not allowed to teach or migrated out of the village; high-crime rate reputation of the area that resulted in teachers from Lahore or nearby town reluctant to teach in the schools; and lack of paved roads and transportation facilities.

Kiran had a high staff loss rate and the primary cause of local teachers leaving the school was marriage. Either it increased their responsibilities to an extent that they could not afford the time away from home or they migrated to other villages or Lahore to be with their husbands. Teachers were also hired from Lahore periodically to teach science and math to the senior classes. These teachers also left after some time because either the commute was a great burden on them (every day or even sometimes a week) even when the NGO paid for it or the NGO ran out of resources to pay for their daily travels. The reputation of the area as a place with high crime rate did not help with staffing problems either. The NGO administrator had interviewed teachers for senior classes who were residents of Lahore. She later informed me that it was too expensive to pay for the daily travels of these teachers and hence they were not hired. However, she had hired new staff from Lahore upon the follow-up visit in 2011.

Two of the teachers were fired by the NGO administrator before the research was concluded on the basis of failing to come to the regular training meetings held in Lahore and not following the protocol to report absence from such training. However, it is my understanding that such firing of local teachers has happened before and after some negotiations the fired teachers in the past were re-hired. 
There are serious difficulties in providing an education when the adult population in the vicinity is not literate. Furthermore, problems arose as the women who were literate got married and moved out of the villages. The rural teachers also did not have a higher education to be able to teach Sciences and Math to the best of their ability and there were no options for them available either to further enhance their education. When teachers tried to appear for the twelfth grade exam on their own, they were fired for asking for a two month leave to prepare for the exam. Children from the rural school would continue to face barriers in obtaining an education. The lack of separate school for boys, the distance required to travel to a boys' school, and the shortage of teachers are some of factors that are detrimental for rural children in achieving an education.

The use of IB curriculum. At Sunshine, the presence of the IB curriculum helped to improve students' learning. It also allowed teachers to unlearn the ways in which they were taught at public schools. Small group work and seating arrangement also helped to improve the sense of community within the learners and fostered an environment of healthy competition. The IB curriculum promotes environmental consciousness and students were working on projects that centered around ideas such as sharing the planet.

Teacher training. At Sunshine, teacher training was highlighted as a factor that promoted teachers’ professional development which in turned fostered student learning. According to teacher Ameera,

“ There is professional opportunity for the teachers...we have so many new things and ideas for teaching Math, Biology and handling of modern technology.....and teachers are getting more exposure and international exposure like teachers can go outside of the country for training.” (Group interview with teachers, 2010). 
Teacher Sobia further added,

"I am here because we have good freedom and we have opportunity to learn so many things through workshops....” (Group interview with teachers, 2010).

\section{Ethics and Reciprocity}

In the course of data-analysis, I have grappled with two questions: is it acceptable to identify learning in the two schools as influenced by the constructivist and behaviorist paradigms? Is it ethical to attribute names to the learning approaches in these two schools that emerge out of Western views on the learning process? After extensive fieldwork in the two schools, these observations and naming were the direct result of the data collected. The theory and the paradigm according to which the instruction happens are not identified by any one person in these schools. I describe the theoretical paradigm that guides teaching, learning and curriculum with the help of the teaching methods, activities and way of assessment that are being used in the classrooms. I asked teachers to describe what they teach and how do they teach it. I also asked learners to describe what they learned in schools and how they learned it. The resulting discussion or the narrative is a construction of the main theories that guide and instruct teachers' teaching and their thinking about their teaching. The main theories that guide the curriculum are also portrayed with the help of the mission statement of these two schools. A discussion with the two NGO founders helped in identifying their stance on teaching and learning that occur in these two schools. The synthesis from these aforementioned data sets has resulted in a summary of approaches at work in these two schools. 
In order to be ethically responsible, I have written a full description of who am I and how I am approaching my research participants. A vast social class difference existed between myself and some of the participants of the study; namely the teachers and the students. However, the disparity was ten times multiplied when a comparison is made between the researcher and the researched in the rural setting.

The firing of two teachers from Kiran school was an ethical conundrum as I felt responsible for it in some way. The outside observation might have had put pressure on the teachers to perform and they were being punished for not being up to the task. I also felt that this process was quite political and it was also a way of showing everyone who was the real boss. It was a cause of concern that the NGO administrator did not use any proper protocol in firing teachers. She informed the teachers on last pay day that they were fired. Teacher Aneela who was the de-facto Principal conveyed this information to the fired teachers. In that case, Teacher Aneela had to risk her reputation in the small, tightly-knit community as the carrier of bad news. Few people viewed her as merely a messenger and failed to perceive that she may not have been an accomplice in the firing. I also found the firing as a threat to the research process because that made me question the credibility of numerous hours of data that I had collected through interviewing and observing the fired teachers. I decided that as an outside observer it was not my job to respond to the incident so I did not intervene. The school faced a potential scarcity of teachers at that time. In retrospect, I wish that I had something about the quality of their teaching which I thought was quite remarkable. However, I constantly inquired from the other teachers if the fired teachers were re-hired. I saw them at the rice festival and was relieved to see that they were so involved. They were sisters and getting fired from the 
school meant not only loss of income but also loss of face in the community. The NGO founder explained that they were poorly performing. She further explained that their brother was also involved in a police case where he had fired at the doctor at the health center a year ago.

Through a sustained presence in the field as researchers, there is a constant feedback loop, there is pinpointing of the deficiencies and there is a constant effort to improve them. For reciprocity, I agreed to translate the teachers' manual from Urdu to English for the Kiran school. I bought books and toys for the school children. I raised funds and asked my parents to contribute toward the health center and made a small contribution toward the school. I tried unsuccessfully to find a doctor for the school. I helped to make a budget for a teacher training center for the adult literacy training center. For Sunshine, I helped with creating assessment schedules, and creating rubrics for assessment. I helped the urban school coordinator in designing curriculum based on the IB framework. Reciprocal relationships work both ways as I helped Teacher Sabira understand the terms such as creating rubric, reflection, and collective decision making, she enabled me to understand the framework for the IB curriculum.

\section{Beyond Data Collection: Epilogue}

The work of qualitative researchers is complex. The story continues once they have left the field, the work still goes on. The organizations and people that they study are living entities, while researchers have been studying these organizations they have been looking at the data that is being collected in a certain point of time. However, the organizations that they study are in constant flux. The organizations are dynamic and vibrant. Two teachers who were fired, were hired back and fired again. The de-facto 
principal of the rural school, Aneela, resigned and moved to Lahore. The school was closed down for a month. The newly hired teachers refused to continue working after getting familiar with the high crime rate reputation of the area. At Sunshine, the institution of a fee based policy for all children, except a few exceptional cases of extreme hardship, caused a lot of consternation amongst parents.

\section{Analysis through the lens of Critical Theory}

Critical research is one form of an empirical project that is associated with critical discourse, a form in which a researcher utilizes field methods that place the researcher on site to re-present the lived experience of people living in asymmetrical power relationships. For research to be considered critical it should participate in a larger critical dialogue rather than follow any particular set of methods or research techniques (Le Compte, Millory \& Presissle, 1992). For this purpose, I analyze the power and privilege relationships between the NGOs and the clientele they serve through the lens of critical theory.

The NGOs advocate for communities who do not have access to resources or access to powerful gate-keepers such as, individuals from affluent backgrounds who could improve their situation. The NGOs are significant as they advocate and implement projects to provide educational access for children from poverty. However, the support that comes in the form of resource generation and resource allocation is quite powerful. It grants hidden and invisible powers to the NGOs. This is more of a hidden or a covert process where the NGO has some invisible powers in holding the purse strings of whatever resource is allocated to the school. The NGOs also provide employment opportunities for teachers from those communities. However, by employing less 
democratic, insufficiently transparent and more centralized processes the NGOs run the risk of having too much control over the lives of the communities that they claim to serve; namely teachers and students. With the use of autocratic processes the existing power structures are kept intact. There has to be an ethical relationship between a resource-rich institution and its poor clientele (Karim, 2008). In the absence of an ethical relationship, the NGO could be used as the vehicle to control and manage school-age populations left alone by the state. The NGOs perform functions that may not necessarily change lives of the individuals for better but they might be getting more and more control of the lives of the people who have no other better recourse.

NGOs, founding members and powerful trusts have to reassess and reevaluate the power and control they exercise over the lives of the individuals that they claim to serve. Equitable treatment of teachers is important in raising teachers' self-worth as professionals. Equity is equal access without any forms of discrimination on the basis of race, gender, ethnicity and socio-economic status. Language and socially dominant discourse entail social power and access to economic success (Delpit, 2000). Students and teachers who are not a part of mainstream discourse can learn the dominant discourse and utilize it to gain access. However, the role of the NGOs is to facilitate the process of access and not to prevent teachers and students from utilizing opportunities. By firing teachers who are seeking to enhance their academic development, the NGO attains coercive powers over the lives of these teachers through the use of sanctions. The powerful groups have used sanctions to keep the subordinate populations alienated and subjugated (Carspecken \& Apple, 1992). In this way, the NGOs consciously or 
unconsciously perpetrate construction and maintenance of social domination and subordination rather than disrupting it.

The hierarchies of class and gender limit opportunities available for teachers and students of the two schools. In a class-based society such as Pakistan, gender, caste and social class are important factors that contribute toward the choices available for teachers, students and parents from low-income backgrounds. Female teachers and students have limited opportunities for employment and further education due to social taboos in a male dominated society. Furthermore, the exclusion of boys from the rural school results in their further alienation from getting access to schooling beyond primary grades. The absence of a boys school in the vicinity is troubling because it ceases all opportunities for them.

The blatant inequalities in the instructional content, medium of instruction, teacher salaries, and facilities in the two schools are a serious concern for social justice and equity. The relative silence of mainstream researchers over such obvious discriminatory schooling practices for children and teachers from low-income backgrounds is appalling and unacceptable.

\section{Synthesis}

Overall, the study developed a further understanding and appreciation of the social forces that shape the schools. The social forces were influenced by the following: the geographical location, access to resources, and the community in which each school exists. However, a different data set is needed to answer the question of the impact of the school on the community which it serves. The work is important because it contributes to the understanding of social sector development projects, such as education, which enable 
the poor to get access in Pakistan. By teasing out the similarities and differences between the two NGOs and the two schools, this work gives us a small snapshot of how education is being provided to children from low socio-economic backgrounds. The narrative also helps the reader to deconstruct key terms such as NGOs, schools, children from lowincome backgrounds, curriculum and access. The descriptions help to develop the understanding that the terms NGOs, NGO schools, and teachers are not homogenous and monolithic. Furthermore, it helps to frame and explore some of the contributing factors that affect schooling choices and experiences for teachers and students such as geographical setting and gender.

The changing nature of the NGO schools in areas of curriculum policy, funding arrangements, and teacher recruitment and training can be identified as a major barrier to effective use of the NGO school models within the public sector. However, the flexibility, modification and constant introspection of the curriculum is also the strength of these schools. Public schools are more static and hence restrained in their ability to respond to the needs of an ever-increasing primary school population in a rapidly globalizing world. 


\section{Chapter Seven: Recommendations and Implications}

In conclusion, we have seen that there are two different NGO school models that can be used to educate children from poverty. This research contributes to the literature on the work of NGO schools in Pakistan. By describing the interaction of the schools and the NGOs the research findings reveal a complex set of structures and factors that influence the instructional practices used in each school. The findings suggest that NGOs have an important role to play in education of children from low socio-economic backgrounds. In its contributions regarding a case study methodology, this study provides evidence that the use of case study is a viable method to research the role of NGO schools in education in Pakistan.

It is exceedingly difficult and challenging to provide education for children from low socio-economic backgrounds in the developing world. Moreover, I would argue that it is an extremely complex endeavor to study education of children of poverty and to make sense of the findings amidst the chaos, violence and political turmoil. Owing to this particular context, I contend that making sense of and describing how two NGOs and the schools they support provide education to primary-aged children is critical to Pakistan's goal of achieving universal primary education. This, I believe, is the most important contribution of this research.

There are few studies that look at the nature and the use of instructional strategies to teach children from low-income backgrounds in Pakistan (Warwick and Reimers, 1995). Even when such studies analyze the nature of classroom instruction, attempts are not made to link them to an overarching curriculum philosophy that drives the instruction and the methods that is used to teach the academic content on which the students are 
tested. Historically testing has been the only measure of determining how schools are performing. This research contributes to the knowledge base that serve as a foundation for a broader dialogue about who are the teachers and students in low-income schools and how should their needs be addressed? How do teachers teach: How do they learn to teach? How are they trained to teach? Who are the students and how do they create their worlds and what can be learned from them? What do students have to say about their learning and assessment? What do children have to say about their schools and their life within the school? For future research, it would be critical to examine how extra-curricular activities and play is viewed within the school curriculum.

Further research might show that NGO schools have streamlined their learning approaches, instructional and assessment strategies. For instance, on the follow-up site visit to Sunshine School, they had stopped receiving the government grant that required teachers to test students on the public school's curriculum. Student assessment for subjects such as Science, English and Social Studies, was beginning to reflect the instructional strategies that were being used in classes. Students were being graded on project work that required teachers to use rubrics for continuous assessment. A similar discussion on learning approaches and their connection to student assessment is not currently present in the literature. It is my hope that this work would open doors for further exploration in this regard.

The medium of instruction is an issue which could be informed by further research: what are the appropriate languages of instruction? Instruction in English language requires an advanced level of understanding of the language and the course content on the part of the teachers. Teachers at Sunshine, even though educated at 
government schools, have made significant progress in developing their English language skills through continued learning opportunities and training. However, at Kiran, teachers who are proficient in basic English literacy skills would find it challenging to teach children English or teach content knowledge in English.

It is quite challenging for a student graduating from the rural school to enter professional schools and colleges for Engineering and Medicine. There is already a significant body of research from Pakistan that children and their parents favor learning in English whether the parents are literate or not and whether all of their children attend a free school, a private school or a religious school as the mastery of English language promises upward social and economic mobility (Mansoor, Azam, Zafar \& Tatari, 2007). Therefore the urban children are in a better position to move forward and progress to institutions that require them to study engineering or medicine in English later. The rural children would have trouble with this upward progression. Further longitudinal research can help to understand how children progress beyond these schools.

Another area of study I intend to pursue in the future is the role of extra-curricular activities and play within the school curriculum. Further exploration in this regard could answer the following questions: Is play an important part of the curriculum? How is play defined in school settings? How physical play is different from other physical activities such as singing, dancing, performing role plays as well as performance in the puppet theater and the performance in festivals? How is the perception of the students about their play different from the perception of how teachers perceive child's play? 


\section{Recommendations}

Within the framework of the discussion, six broad policy recommendations and action steps arose from this research.

1. Teachers needed to be treated as professionals worthy of taking independent action to further enhance their professional and academic development. Many action steps need to be taken in this regard. For example, hiring, firing, salary determination and promotion policies at the two schools need to be made specific and transparent. Teachers must not be fired on a whim or for idiosyncratic reasons. It is not clear how the teachers' salaries rates are decided and determined (at Kiran and Sunshine), what policies are used for the selection of teachers for their training abroad (at Sunshine), and how promotion and rank is determined for a teacher (at Kiran and Sunshine). Teachers, both male and female, need to make at least the minimum wage (Rupees 8,000. USD 100 per month) to be considered as valued employees of the organizations.

2. The decision making for school management has to become more collaborative, participatory and democratic. Various stakeholders need to be informed of the processes involved in making key decisions. For instance, when Sunshine went from a free school to a fee-only school model, there was a lot of resistance that had to be faced by the community of parents. In the findings, there are no clear indications of how parents are involved in the day-to-day management and functioning of the two schools.

3. Other school policies that require more attention is the discipline of children through punishment and beatings. I observed instances of corporal punishment at 
both Kiran and Sunshine schools. It is critical for developing children's selfesteem and self-worth that they be treated with love, care and respect in a safe, non-violent environment. Teachers need to follow a method of teaching which enables children to learn with joy and respect so that they are motivated to continue learning. Corporal punishment needs to stop.

4. The funding processes and structures of NGOs that support NGO schools have to be made more transparent. There must be a protocol or set of policies to ensure that due process has been handled and that fiscal management must be transparent, streamlined, and easily accessible from outside. More information is needed to factor the funding structure at both schools. It is not clear how much money each of the contributing partners (private for-profit groups, international donor agencies) has donated to the NGOs. Pathways lists contributions and donors on its website. Inspire lists on its websites various linkages it had with multiple organizations but the role of each of the organizations in providing monetary assistance is not clear. The in-kind support from these groups, such as, volunteer assistance is also not discussed clearly at the respective websites of the NGOs. There should be ways in which the community receives information about how the funds that sustain their school are raised and managed. The websites must be updated to an extent that they list how money was being spent. It would not only raise the profiles of the NGOs it would also increase the value of the work that they are doing.

5. Teaching in students' first language (Punjabi) is critical. Even though no instruction took place in Punjabi at Sunshine, the school had developed a method 
for honoring Punjabi by using it for extra-curricular activities such as puppet plays and theatre productions. At Kiran, ways must be developed where children and teachers could use Punjabi for self-expression.

6. The two NGOs partnered with other NGOs for fund raising and other projects. However, the linkages between NGOs that provided development assistance could be strengthened further. There are tremendous opportunities for growth for the NGO sector in Pakistan and each of these organizations can learn significantly from best practices and lessons they have learned as they serve children from lowincome backgrounds. For instance, the teacher literacy and training manual for adults could be a great resource for other NGOs working with illiterate adults in rural areas particularly women. There is a dire need for a platform where NGOs can share their success stories and identify pitfalls so that these organizations can benefit from collective wisdom.

\section{Implications for further research}

The difficulties that are faced by Kiran's community are unique to their setting. They are located in a place where the modern facilities are not too far away. Individuals with resources, often choose to leave their villages for the urban area, Teacher Aneela at Kiran, for instance, migrated to Lahore. Even though rural to urban migration is a trend that is widely seen in research literature (Ali \& Rieker, 2008) coming out of South Asia, it was not the focus of this study. Perhaps more people from the rural area are migrating to urban centers, especially when Lahore, the second largest city of Pakistan, is close to these villages. Urban migration is a phenomenon which is not usually feasible for everyone in the rural community. 
The availability of a support structure and opportunity for jobs can be factors that would contribute toward rapid urban migration, but that is a trend that needs to be further explored. The small rural community that exists in the state of Punjab is considered to be one of the richer, most populous, more resourceful states in Pakistan. Therefore, this research is not reflective of remote areas in the Northwestern part of Pakistan where access to social services can be extremely challenging for the community. Moreover access could be complex for any researcher, especially a female researcher in remote, rural areas. Further research with NGO schools in other parts of Pakistan could help to add to the existing research knowledge base.

I was not able to step out of the school into the community so much that I could discern and quantify the real impact of the NGO schools in their respective rural and urban communities. I limited my interviews with individuals who were present inside the school. I did not collect data on individuals who lived in the neighborhood in the two communities. An urban suburb in a sprawling city like Lahore is a very complex entity which makes it challenging to figure out who is present and available in a community and how the work of the NGO school is changing and perhaps shaping the lives of the individuals for better or for worse. Exploring the communities would then be a question for future research.

The United Nations Educational, Scientific, and Cultural Organization (UNESCO) launched the 2006 Global Report on Education for All (EFA) initiative with the goal to report findings and recommendations by the year 2015. The Report identifies literacy as crucial for economic, social and political participation and development, especially in today’s knowledge-driven society (The United Nations, 2005). It further 
stated that literacy is the key to enhancing human capabilities with wide-ranging benefits, including critical thinking, improved health and family planning benefits. Literacy, the ability to read and write, is a fundamental right of all human beings. According to Stuckey (1991), "the key to achievement is education, and we believe the heart of education is literacy (p.vii).” Alkema (2003) has stated in a study of literacy in New Zealand schools that the most important characteristic to help a child reach functional literacy skills at an appropriate grade level is the quality of interaction between the student and teacher. Teacher competence is in turn influenced by the quality of governance, management and leadership within the school.

At Kiran, the rural school, significant efforts were made to improve the functional literacy skills of children and women. The possibility for future research could examine how increased literacy impacted the overall well-being of rural women who had benefitted from the program run by the NGO Inspire and the learners who studied at Kiran. The rural children at Kiran are learning a curriculum which is well-rounded with diverse subjects. However, significant improvements would have to be made in their overall educational experience if their learning levels were to be compared with children from Sunshine or other urban communities. Moreover, there are serious questions about equity if the rural children were to learn a curriculum that is not equivalent to what their urban counterparts are learning.

Even though these two schools are reaching out to children from low-income backgrounds, children in the lowest levels of poverty do not have access to education: homeless children, slum dwellers and child laborers such as urban trash collectors. The 
children who attend the NGO schools in this study are children who live at home with their parents or extended family members.

It is also crucial to ensure that children have access to education beyond the primary grades. For future research, it will be critical to examine how the approaches described in this research could be expanded to reach out to more students. Private institutions, such as NGOs in Pakistan, are small scale in their impact and their effort is limited. They do not have the ability to provide to the many millions that are in need of a primary education. While many are in agreement that it is the responsibility of the State to provide for the education of many million children that are out of school, this is not yet happening in Pakistan. However, it is the civic responsibility of privileged and educated individuals with resources to not just wait for the state to intervene. The state may not intervene because of over-spending on defense budget, budgetary deficits, economic, and political instability and social crisis. In that case, in an environment of unrest and political instability, it is the responsibility of the informed citizenry to provide for those who do not have access to basic facilities. It would not be possible for private entities to provide education free of cost if their goal is expansion. It is not the goal of private institutions to provide quality primary education to all children in Pakistan. In order to provide elementary education to all Pakistan's children, all stakeholders would have to be invested.

The challenge for the provision of Universal Primary Education will only be addressed if private, non-profit institutes collaborate with government institutions. Collaboration is already functioning through school adoption scheme. Private, non-profit organizations have adopted government schools and they are working within the 
framework of public-private partnerships (Creeden, 2011). Both of the founders of the schools in this study are also involved in numerous other projects related to education; both have tried to adopt government schools but were not successful. What could these NGOs accomplish by collaborating with government schools in the region and implement their unique instructional approaches and methodologies? What if NGO government school collaboration could successfully expand the free primary school model?

In conclusion, I reiterate that the provision of a high quality primary education to all Pakistan's children is the responsibility of the state. The state's inability to do so has resulted in the intervention by international donor agencies and local, privately owned for-profit and nonprofit organizations. They are critical stakeholders in collaborating to provide for education to all Pakistan's children. As more and more forces enter the market to provide education for children from families in low-income brackets, the gap between what actually happens in the school and the goal of universal primary education may widen.

Pakistan's current population is approximately 175 million people and the population will predictably increase at even a faster pace in the next decade (Bloom \& Rosenberg, 2011). A significant number of the individuals in Pakistan are below the age of 15 (World Bank, 2012). If a large number of Pakistani children do not have access to education, they would fail to find meaningful employment and would be unable to lead productive lives in the future. It is critical to Pakistan's political, economic and social stability to find a way to educate children.

Pakistan lacks a coherent, long term policy for increasing access to quality primary education. Serious gender inequities and imbalances between rural and urban 
communities persist in both the availability and quality of education facilities. According to Fowler (2004), during a policy analysis it is vital to understand who will gain power as result of a policy and who will lose power because of the policy. If the universal primary education policy is put into action, not only it will threaten the existing status quo, clearly the marginalized groups will gain power with a just and equitable educational system. A lack of universal access to education strengthens and reinforces the existing status quo. To translate the policy into action it should be ensured that children, both males and females, living in poverty, the ones in labor market, and the ones living in rural areas will have equal access to quality education.

Educators need to be at the forefront to create an awareness of and raising consciousness about equal access to primary education. Educators must be equipped with skills necessary to demand that social justice issues, such as the basic human right to get a quality education, be at the forefront of educational policy creation. 


\section{References}

Aftab, T. (1994). Fighting illiteracy: What works and what does not: A case study of female illiteracy in Pakistan. Convergence. 27(4). 1-8.

Ali, K., \& Rieker, M. (2008). Introduction: Urban Margins. (Cover story). Social Text, 26(2), 1-12.

Aikman, S. \& Unterhalter, E. (Eds.). (2005). Beyond Access: Transforming policy and practice for gender equality in Education. Oxford: Oxfam Publishing.

Akmal, H. (2003). Pakistan national human development report 2003. Poverty, growth and governance. Karachi: Oxford University Press.

Alderman, H. Orazem, P.F. \& Paterno, E.M. (2001). School Quality, school cost and the public/private school choices of low-income households in Pakistan. Journal of Human Resources 36(2), 304-326.

Anderson, S. (2000). Views from the South. The effects of Globalization and the WTO on third world countries. CT: Food first books and The International Forum on Globalization.

Andrabi, T. Das, J. Khwaja, A.I. (2006). A dime a day. The possibilities and limits of Private schooling in Pakistan. World Bank Policy Research Paper 4066. (WPS4066). Retrieved December 7, 2006 from http:// econ.worldbank. org

Anzar, U. (2002, March). The NGO sector in Pakistan: Past, present and future. Paper presented at the Annual Meeting if the Comparative and International Education Society. $46^{\text {th }}$ Orlando, Florida.

Anzar, U. (1999). Education Reforms in Balochistan, 1990-1998: A case study in improving management and gender equity in primary education. (Report No. ED 453 988). Washington DC: World Bank.

Ayaz, A. \& Fleschenberg, A. ( 2009). The gender face of Asian politics. Oxford: OxfordUniversity Press.

Bello, W. (2000). Building an iron cage: Bretton woods institutions, the WTO, and the South. In Anderson, S (Ed.), Views from the South. The effects of globalization and the WTO on third world countries. (pp. 54-90). Canada: Food First Books.

Birdsall, N. Levine, R. \& Ibrahim, A. (2005). Toward universal primary education: investments, incentives, and institutions. London. Earthscan.

Bloom, D.E. Rosenberg, L. (2011). The future of South Asia: Population dynamics, economic prospects, and regional coherence. Retrieved from Harvard University, 
Center for Population Studies and Development Studies, Program on the Global Demography of Aging Institute http://www.hsph.harvard.edu/pgda/working.htm

BRAC. (2009). Core Programmes at BRAC. Education. Retrieved from http://www.brac.net/index.php?nid=120

Brookfield, S. (2005). The power of critical theory: Liberating adult learning and teaching. San Francisco: Jossey Bass.

Brooks, J.G., \& Brooks, M.G. (1993). The case for constructivist classroom. San Francisco: Jossey Bass.

Boukary, H.D. (2004). The village schools of Save The Children/USA in Mali. A case study of state-NGO relations in the provision of basic education. In Sutton and Arnove (Ed.), Civil society or shadow state? State/NGO relations in education (pp. 71-109). Connecticut: Information Age Publishing.

Burnett, N. (2005). The EFA Global Monitoring Team Report. Education for All. Literacy for life. (2005). Paris: UNESCO Publishing

Carspecken, P. F. \& Apple, M. (1992). Critical qualitative research: Theory, methodology and practice. In LeCompte, M.D. Millory, W.L. Preissle, J. (Eds.), The handbook of qualitative research in education. (pp. 507-551). San Diego: Academic Press, Inc.

Chang, H.J. \& Grabel, I. (2004). Reclaiming development. An alternative economic policy manual. Canada: Fernwood Publishing Limited.

Cummings, W.K. \& Williams, J.H. (2008). (Eds.) Policy-making for education reform in developing countries. Policy options and strategies. Lanham, MD: Rowman \& Littlefield Education.

Curtis, L.A. (2007). U.S. aid to Pakistan: Countering extremism through education reform. In Heritage lectures. The Heritage Foundation. ( May, 2007). No. 1029. Retrieved from. http://oversight.house.gov/documents/20070509164319.pdf

Creeden, J. (2011). The Rise of Public Private School Partnerships. Independent School, 70(3), 22-26.

Das, J. Pandey, P. \& Zajonc, T. (2006). Learning levels and gaps in Pakistan. World Bank Policy Research Working Paper 4067. Retrieved December 7, 2006, from http://econ.worldbank.org

Delamont, S. (2004). Ethical issues. In Seale, C. Gobo, G. Gubrium, J.F. \& Silverman, D. (Eds.), Qualitative Research Practice. (pp. 2217-229). Thousand Oaks, California: Sage publications. 
Delpit, L.D. (2000). Acquisition of literate discourse. Bowing before the master? In Gallego, M.A. Hollingsworth, S (Eds.) What counts as literacy. Challenging the school standard. (pp. 65-85). New York: Teachers College Press.

Denzin, N.K., \& Lincoln, Y.S. (3 rd Eds.). (2000). The sage handbook of qualitative research. California: Sage Publications.

Denzin, N.K., \& Lincoln, Y.S. (Eds.). (2005). The sage handbook of qualitative research. California: Sage Publications.

Denzin , N.K. and Lincoln, Y.S.(Eds.). (2008). In introduction. The discipline and practice of qualitative research. In Denzin, N.K., \& Lincoln, Y.S. (3rd Eds.), The sage handbook of qualitative research (pp. 1-32). California: Sage Publications.

Dewey, J. (1938). Experience and education. New York: Touchstone.

Dryfoos, J.G. (2003). A community school in action. Reclaiming Children and Youth. 11(4). 203-205.

Eder. D. \& Fingerson, L. (2002). Interviewing children and adolescents. In Gubrium, G.F. \& Hosletin, J.A. (Eds.), Handbook of interview research: Context and method (pp. 181-201). Thousand Oaks, CA: Sage Publications.

Edwards, D. \& Hulme, D. (Eds.). (2002). Non-Governmental organizations. Performance and accountability. Beyond the magic bullet. UK: Earthscan Publication Limited.

Ernest, P. (1994). Varieties of constructivism: Their metaphors, epistemologies and pedagogical implications. Hiroshima Journal of Math ematics Education. 2. 1-14.

Freire, P. (1970). Pedagogy of the oppressed. San Francisco: Jossey-Bass.

Foley,D. \& Valenzuela, A. (2008). Critical ethnography. The politics of collaboration. In Denzin, N.K., \& Lincoln, Y.S. (3rd Eds.), The sage handbook of qualitative research (pp.217-234). CA: Sage Publications.

Fosnot, C.T. (1996). Constructivism: theory, perspectives and practice. New York: Teachers College Press.

Fowler, F.C. (2004). Policy studies for educational leaders: An introduction. New Jersey: Merril Prentice Hall.

Ghaus-Pasha, A. \& Iqbal, M.A. (2003). Defining the Nonprofit sector: Pakistan. Working papers of The Johns Hopkins Comparative Nonprofit Sector Project No. 42. Baltimore: The Johns Hopkins Center for Civil Society Studies.

Giroux, H.A. (2009). Youth in a suspect society: democracy or disposability? New York: Palgrave Macmillan. 
Grbich,C. (2007). Qualitative data analysis: An introduction. Thousand Oaks, CA: Sage Publications.

Grown, C. Gupta, G.R. \& Kes, A. (2005). Taking action: Achieving gender equality and empowering women. London: Earthscan.

Haq, M. \& Haq, K. (1998).Human development in South Asia. United Nations Human Development Program's Human Development Report. Karachi: Oxford University Press.

Hoodhbhoy, P. (Ed.) (1998). Education and the state: fifty years of Pakistan. Karachi: Oxford University Press.

Huberman,A.M. and Miles, M.B. (1994). Data management and analysis methods. In Denzin, N.K., \& Lincoln, Y.S. (3rd Eds.), The sage handbook of qualitative research (pp. 1-32). California: Sage Publications.

Internet Wing Ministry of Information, Government of Pakistan. (2004). Pakistan basic facts. Available online at: http: // www.pak.gov.pk/public/govt/basicfacts.html

Janesick, V.J. (2000). The dance of qualitative research design: Metaphor, methodolatry, and meaning. In Denzin, N.K., \& Lincoln, Y.S. (Eds.), The sage handbook of qualitative research (pp.209-219). California: Sage Publications.

Jiang,B.B. (2004). Problem posing. Freire's transformational method in ESL. In Goodman. and Carey. (Eds.), Critical and multicultural conversations. New Jersey: Hampton Press Inc.

Karim, L. (2008). Demystifying Micro-credit: The Grameen Bank, NGOs, and Neoliberalism in Bangladesh. Cultural Dynamics. 20 (1). 5-29.

Khan, F. (2007). School management councils: A lever for mobilizing social capital in rural Punjab, Pakistan? Prospects. XXXVII (1). 57-79.

Khan, S.R. (2005). Basic education in rural Pakistan: A comparative institutional analysis of government, private and NGO schools. Karachi: Oxford University Press.

Khan, S.R. (2003). Participation via collective action in government and NGO schools in Pakistan. Development in Practice. 13(1)361-376.

Kincheloe, J.K. (2008). Knowledge and critical pedagogy: An introduction. Albany, NY: Springer.

Kincehloe, J.L. \& Mclaren, P. (2008). Rethinking theory and research. In Denzin, N.K., \& Lincoln, Y.S. (3rd Eds.), The sage handbook of qualitative research (pp. 303342). CA: Sage Publications. 
Korten, D.C. (1995). When corporations rule the world. San Francisco, CA: Korten Kumarian Press/ Berret-Koehler Publishers.

Krathwohl, D.R. (1997). Methods of educational and social Science research. An integrated approach. NY: Longman.

Kronstadt, K.A. (2004, December). Education reform in Pakistan. Report No.RS 22009. CRS Report for Congress. Retrieved from CRS Web.

Kvale, S. (1996). InterViews: An introduction to qualitative research interviewing. Thousand Oaks, CA: Sage Publications.

Lather, P. (1988). Feminist perspectives on empowering the research methodologies. Women's Studies International Forum. 11(5). 69-81.

Lecompte, M.D. Millroy, W.L. Preissle, J. (Eds.) (1992). The handbook of qualitative research in education. London: Academic Press.

Maletta, H. (2008). Gender and employment in rural Afghanistan [Electronic version]. Journal of Asian and African Studies. 43 (2). 173- 196.

Mansoor, S. Azam, S.I. Zafar, M. Tatari, S.K. (2007). Gender and language in higher education. In Qureshi and Rarieya (Eds.), Gender and education in Pakistan. (pp. 147-170).

Mansuri, G. (2006). Migration, school attainment and child labor: Evidence from rural Pakistan. World Bank Policy Research Working Paper . Retrieved from http://www.worldbank.org.pk/WBSITE/EXTERNAL/COUNTRIES/SOUTHASI AEXT/PAKISTANEXTN/0,,contentMDK:20131452 menuPK:293078 pagePK: 1497618 piPK:217854 theSitePK:293052,00.html

Mclaren, P.L. \& Giarelli, J.M. (1995). Critical theory and educational research. New York: State University of New York Press.

MercyCorps. (2007, December). Sustainability field study. Understanding what promotes lasting change at the community level. Retrieved from http://www.mercycorps.org/publications/11935

Milam, W.B. (2009). Bangladesh and Pakistan flirting with failure in South Asia. New York: Columbia University Press.

Miller- Granvaux, Y. Welmond, M. \& Wolf, J. (2002). Evolving partnerships: The role of NGOs in basic education in Africa.

Nath, S. R. (2002). The transition from non-formal to formal education: The case of BRAC Bangladesh. International Review of Education. 48 (6). 517-524. 
Okwany, A. (2004). Entering the quagmire. Examining State-NGO interaction in the provision of education for street girls in Kenya. In Sutton and Arnove (Eds.), Civil society or shadow state? State/NGO relations in education (pp. 177-202). Connecticut: Information Age Publishing.

Phillips, D.C. (1995). The good, the bad, and the ugly: The many faces of constructivism. Educational Researcher. 24(7). 5-12.

Philips, D.C. \& Soltis, J.F. (1998). Perspectives on learning ( $3^{\text {rd }}$ ed.). New York: Teachers College Press.

Petrovich, J., \& Wells, A. S. (2005). Bringing equity back: Research for a new era in Americaneducational policy. New York: Teachers College Press.

Rehman,T. (2005). The Muslim response to English in South Asia: With special reference to inequality, intolerance and militancy in Pakistan. Journal of Language, Identity and Education. 4(2). 119-135.

Ryen, A. (2004). Ethical issues. In Seale, C. Gobo, G. Gubrium, J.F. \& Silverman, D. (Eds.), Qualitative Research Practice. (pp. 230-247). Thousand Oaks, California: Sage publications.

Samant, U. (2005, March). The role of women's groups in the development of community education. Paper presented at WE LEARN conference, Retrieved from http:// litwomen.org/conferences/presentations/samant_paper.rtf

Sathar,Z.,A., Lloyd, C.,B., \& Haque, M. (2000). Investments in children's education and family-building behavior in Pakistan: Findings from rural NWFP and Punjab. Report funded by the Rockfeller Foundation New York.

Seale, C. Gobo, G. Gubrium, J.F. \& Silverman, D. (Eds.). (2004). Qualitative Research Practice. Thousand Oaks, California: Sage publications.

Shah, G.H. Bari, F. and Ejaz, N. (2005). The role of NGOs in basic and primary education in Pakistan. NGO Pulse report. Lahore: Lahore University of Management and Sciences.

Silverman, D. (2000). Doing qualitative research. A practical handbook. London: Sage Publications.

Skinner, B.F. (1978). Reflections on behaviorism and society. New Jersey: Prentice Hall.

Stacki, S. L. (2004). Building a partnership for teacher empowerment in India. Trusting teachers strengthens process and program. In Sutton and Arnove (Eds.), Civil society or shadow state? State/NGO relations in education (pp. 203-225). Connecticut: Information Age Publishing. 
Stake, R.E. (2008). Qualitative case studies in sage. 443-466. In Denzin, N.K., \& Lincoln, Y.S. (3rd Eds.), The sage handbook of qualitative research (pp. 443466). California: Sage Publications.

Stuckey, J. E. (1991). The Violence of literacy. Portsmouth, NH: Boynton Cook.

Sutton, M. \& Arnove, R.F. (Eds.). (2004). Civil society or shadow state? State/NGO relations in education. Connecticut: Information Age Publishing.

Warwick, D. P. \& Reimers, F. (1995). Hope or despair? Learning in Pakistan's Primary Schools. Connecticut: Praeger.

Weiss, A. (2002). Walls within walls: life histories of working women in the old city of Lahore. New York: Oxford University Press.

Willetts, P. (2002). What is a Non-Governmental Organization. In UNESCO Encyclopaedia of Life Support Systems . Section 1 Institutional and Infrastructure Resource Issues. Report No. (1.44.3.7). Retrieved from http://www.staff.city.ac.uk/p.willetts/CS-NTWKS/NGO-ART.HTM

Williams, J.K. \& Cummings, W.K. (2005). Policy-making for education reform in developing countries: Contexts and processes, Volume 1. Lanham: Rowman and Littlefield Education.

The United Nations. (2005). The Millennium Development Goals Report. New York.

The World Bank. (2006). Pakistan Gender Assessment Report. The World Bank. Washington D.C.

The World Bank. (2008). Ten things worth knowing about The World Bank in Pakistan. Retrieved from http:// worldbank.org.pk/WBSITE/EXTERNAL/COUNTRIES

The World Bank. (2012). Pakistan: The Untold Story. Retrieved from http://web.worldbank.org/WBSITE/EXTERNAL/COUNTRIES/SOUTHASIAEX T/0,,contentMDK:23180514 menuPK:158937 pagePK:2865106 piPK:2865128 theSitePK:223547,00.html

Thorne, S. (1998). Ethical and representational issues in qualitative secondary analysis. Qualitative Health Research. 8(4). 547-554.

Yin, R.K. (2009). Case study research: design and methods. Applied social science research methods series. Los Angeles: Sage Publications.

Young, P. (1994). Equity in theory and practice. Princeton: Princeton University Press.

Zaidi, S.A. (1999). The new development paradigm: Papers on Institutions, NGOs, and local government. Karachi: Oxford University Press. 


\section{Appendix A--- Informed Consent for the NGO Administrator/Principal}

You are invited to participate in a research study conducted by Zafreen Jaffery from the Department of Curriculum and Instruction in the Portland State University, Graduate School of Education. As a result of the study, the researcher expects to learn about the working of NGO schools in Pakistan. You are being selected as a participant in this study because you work at an NGO school.

If you decide to participate, you will be interviewed and the responses from the interview will be analyzed for inclusion in the study. Though you will not receive any direct or monetary benefit from taking part in this study, your participation in the study will increase what is known about the functioning of an NGO school.

To maintain confidentiality for the interview process, your responses for the interviews will be coded so that others will not be able to identify you based on your responses during the interview. Only the researcher will have access to the code list. The data will be kept secure in the researcher's office.

Your participation is voluntary. You do not have to take part in this study, and it will not affect your relationship with the researcher, Zafreen Jaffery. You may withdraw from this study at any time without affecting your relationship with the researcher.

If you have concerns or problems about your participation in this study or your rights as a research participant, please contact the Human Subjects Research Review Committee, Office of Research and Sponsored Projects, Portland State University, PO Box 751, Portland, OR 97207, 503-725-4288. If you have questions about the study, please contact the researcher, Zafreen Jaffery (503-725-8576) at Portland State University, Graduate School of Education, PO Box 751, Portland, OR 97207.

Your signature indicates that you have read and understand the above information and agree to take part in this study. Please understand that you may withdraw your consent at any time without penalty, and that, by signing, you are not waiving any legal claims, rights or remedies. The researcher will provide you with a copy of this form for your own records. 
- I give permission to record the interview on an audio recorder. Yes/No

- I give permission to use my real name in the presentation and publication of this study. Yes/No

- I give permission to take pictures during the interview. Yes/No

Signature

Date 


\section{Appendix B--- Informed Consent for the Students}

You are invited to participate in a research study conducted by Zafreen Jaffery from the Department of Curriculum and Instruction in the Portland State University, Graduate School of Education. As a result of the study, the researcher expects to learn about the working of NGO schools in Pakistan. You are being selected as a participant in this study because you work at an NGO ___ school.

If you decide to participate, you will be interviewed and the responses from the interview will be analyzed for inclusion in the study. Your name will be kept confidential and responses will be recorded anonymously. Your name will not be mentioned anywhere in the publication or presentation of this research. When information from this study is shared in articles or presentations, your name will be altered or deleted, to protect your identity. Though you will not receive any direct or monetary benefit from taking part in this study, your participation in the study will increase what is known about the functioning of an NGO school.

Information that is obtained in connection with this study and that can be linked to you or your identity will be kept confidential. To maintain confidentiality, your responses for the interviews will be coded so that others will not be able to identify you based on your responses during the interviews. Only the researcher will have access to the code list. The data will be kept secure in the researcher's office.

Your participation is voluntary. You do not have to take part in this study, and it will not affect your relationship with the researcher, Zafreen Jaffery. You may withdraw from this study at any time without affecting your relationship with the researcher.

If you have concerns or problems about your participation in this study or your rights as a research participant, please contact the Human Subjects Research Review Committee, Office of Research and Sponsored Projects, Portland State University, PO Box 751, Portland, OR 97207, 503-725-4288. If you have questions about the study, please contact the researcher, Zafreen Jaffery (503-725-8576) at Portland State University, Graduate School of Education, PO Box 751, Portland, OR 97207. 
Your signature indicates that you have read and understand the above information and agree to take part in this study. Please understand that you may withdraw your consent at any time without penalty, and that, by signing, you are not waiving any legal claims, rights or remedies. The researcher will provide you with a copy of this form for your own records.

- I give permission to record the interview on an audio recorder. Yes/No

- I give permission to take pictures during the interview. Yes/No

Signature

Date 


\section{Appendix C--- Informed Consent for the Students’ Parent/Guardian}

Your child is invited to participate in a research study conducted by Zafreen Jaffery from the Department of Curriculum and Instruction in the Portland State University, Graduate School of Education. As a result of the study, the researcher expects to learn about the working of NGO schools in Pakistan. Your child is being selected as a participant in this study because he/she studies at an NGO __ school.

If you allowed for your child to participate in the study, your child will be interviewed and the responses from the interview will be analyzed for inclusion in the study. Your child's name will be kept confidential and responses will be recorded anonymously. Your child's name will not be mentioned anywhere in the publication or presentation of this research. When information from this study is shared in articles or presentations, your child's name will be altered or deleted, to protect your identity. Though your child will not receive any direct or monetary benefit from taking part in this study, your child's participation in the study will increase what is known about the functioning of an NGO school.

Information that is obtained in connection with this study and that can be linked to your child's identity will be kept confidential. To maintain confidentiality, your child's responses for the interviews will be coded so. That no one will be able to identify your child based on their responses during the interview. Only the researcher will have access to the code list. The data will be kept secure in the researcher's office.

Your child's participation is voluntary. Your child does not have to take part in this study, and it will not affect your or his or her relationship with the researcher Zafreen Jaffery. Your child may withdraw from this study at any time without affecting your or his or her relationship with the researcher.

If you have concerns or problems about your participation in this study or your rights as a research participant, please contact the Human Subjects Research Review Committee, Office of Research and Sponsored Projects, Portland State University, PO Box 751, Portland, OR 97207, 503-725-4288. If you have questions about the study, please contact the researcher, Zafreen Jaffery (503-725-8576) at Portland State University, Graduate School of Education, PO Box 751, Portland, OR 97207. 
Your signature indicates that you have read and understand the above information and agree to take part in this study. Please understand that you may withdraw your consent at any time without penalty, and that, by signing, you are not waiving any legal claims, rights or remedies. The researcher will provide you with a copy of this form for your own records.

- I give permission to record the interview on an audio recorder. Yes/No

- I give permission to take pictures during the interview. Yes/No

Signature

Date 


\section{Appendix D--- Informed Consent for the Teachers}

You are invited to participate in a research study conducted by Zafreen Jaffery from the Department of Curriculum and Instruction in the Portland State University, Graduate School of Education. As a result of the study, the researcher expects to learn about the working of NGO schools in Pakistan. You are being selected as a participant in this study because you work at an NGO __ school.

If you decide to participate, you will be interviewed and the responses from the interview will be analyzed for inclusion in the study. Your class may be observed by the principal investigator for the sole purpose of taking record of current teaching methodologies employed and practices used for the teaching and learning of functional literacy skills. Your name will be kept confidential and responses will be recorded anonymously. Your name will not be mentioned anywhere in the publication or presentation of this research. When information from this study is shared in articles or presentations, your name will be altered or deleted, to protect your identity. Though you will not receive any direct or monetary benefit from taking part in this study, your participation in the study will increase what is known about the functioning of an NGO school.

Information that is obtained in connection with this study and that can be linked to you or your identity will be kept confidential. To maintain confidentiality, your responses for the interviews will be coded so that others will not be able to identify you based on your responses during the interview. Only the researcher will have access to the code list. The data will be kept secure in the researcher's office.

Your participation is voluntary. You do not have to take part in this study, and it will not affect your relationship with the researcher, Zafreen Jaffery. You may withdraw from this study at any time without affecting your relationship with the researcher.

If you have concerns or problems about your participation in this study or your rights as a research participant, please contact the Human Subjects Research Review Committee, Office of Research and Sponsored Projects, Portland State University, PO Box 751, Portland, OR 97207, 503-725-4288. If you have questions about the study, please contact the researcher, Zafreen Jaffery (503-725-8576) at Portland State University, Graduate School of Education, PO Box 751, Portland, OR 97207. 
Your signature indicates that you have read and understand the above information and agree to take part in this study. Please understand that you may withdraw your consent at any time without penalty, and that, by signing, you are not waiving any legal claims, rights or remedies. The researcher will provide you with a copy of this form for your own records.

- I give permission to record the interview on an audio recorder. Yes/No

- I give permission to take pictures during the interview. Yes/No

Signature

Date 


\section{Appendix E: Interview Protocol \#1: Individual Interview Questions for the NGO Administrators/ Principal}

\section{Getting Started}

1. Tell me about what inspired you to start the school?

2. Did you come across any barriers in getting the first school started? If yes, what were the barriers in getting the first school started?

3. What were the barriers in terms of cost and finances?

4. When the school first started, who were the key stakeholders?

5. Was any needs analysis conducted during the planning stages of the school? Who was involved in the planning stages for opening the school?

\section{The community}

1. What kinds of population/community does the school serve?

2. How involved is the community in the management and functioning of schools?

3. How did you get the support of the community to start the schools?

4. How is the community mobilized to support the school? Are there any Parent teacher associations? If yes, how often do they meet and how are they selected?

5. What if any role does the school play in community development?

\section{The need for NGO schools}

1. What is important about the work that you are doing? Is there a demand for NGO schools at the local level?

\section{Student Population:}

1. What is the school's population? How many girls and boys are enrolled? Is there a record for this kind of data?

2. What is the enrollment and retention rate?

3. What is the student repetition rate?

4. What has the school done to bridge the gender gap in enrollment?

5. Does your school provide education for both girls and boys? If it is coeducational has that been a cause of any conflicts with the community?

\section{Teaching and Learning:}

1. Who decides the curriculum? What kind of curriculum is being offered at the school? Is the focus of the curriculum teacher centered or student centered? How are the students evaluated?

2. Who are the teachers in your school? How are teachers hired? 
3. Who trains the teachers? Are there any in-service or pre-service training opportunities for the teachers?

4. What is being taught? What is the medium of instruction? How is the medium of instruction decided?

\section{Funding and Cost:}

1. How is the school funded? Where did the original monetary support come from?

2. How are the funds raised in the community?

3. Are you planning on opening more schools?

4. Who does the school partners with?

5. Is the school funded by any grants?

6. How is the school staffed and what amount of budget is spent on teachers and on administration?

Motivation

7. Are there any fee for services provided to the students?

\section{Evaluation}

1. Tell me about what keeps you motivated to do the kind of work that you are doing?

2. How do you evaluate the working of the school?

3. How is the information about school success and failure conveyed to the stakeholders?

4. Are there any third, party external evaluators of the school's functioning?

5. How do you ensure fiscal responsibility and accountability?

6. Is your successful in providing for the needs of its teachers and its students? 


\section{Appendix F: Interview Protocol \# 2: =Group Interview Questions from the Teachers}

1. Tell me about what inspired you to join an NGO school?

2. What kinds of population/community does the school serve?

3. Who decides the curriculum?

4. What kind of curriculum is being offered at the school? Is the focus of the curriculum teacher-centered or student-centered?

5. How are the students evaluated?

6. How were your hired to teach in the school?

7. How were you trained for teaching? Are there any in-service or preservice training opportunities for the teachers?

8. Is your school successful in providing for the needs of its teachers and its students?

9. What is the medium of instruction at the school? How is the medium of instruction decided?

10. How involved is the community in school management?

11. How involved is the NGO in operating and management of the school? 


\section{Appendix G: Interview Protocol \# 3: Individual Interview Questions for the Teachers}

1. How does an NGO school provide education to primary aged school children?

2. What processes and structures are evident in two NGO schools in providing elementary education to children in Pakistan?

3. What factors and characteristics are evident in two NGO schools that provide opportunities for teaching and learning?

\begin{tabular}{|c|c|}
\hline QUESTIONS & FOCUS OF ANALYSIS \\
\hline $\begin{array}{l}\text { - Tell me about your background: } \\
\text { education, age, primary language, } \\
\text { marital status etc. }\end{array}$ & - $\quad$ RQ \#2 Teacher profile \\
\hline $\begin{array}{l}\text { Do you live in a cemented house? } \\
\text { Do you have electricity, t.v. and } \\
\text { running water in your house? }\end{array}$ & - RQ \# 2 Teacher profile \\
\hline $\begin{array}{l}\text { - Tell me why do you teach at an } \\
\text { NGO school and what motivates } \\
\text { you to do teaching? }\end{array}$ & - RQ \# 2: Teaching processes \\
\hline $\begin{array}{l}\text { - How would you describe the role } \\
\text { of teachers in this school in } \\
\text { selecting the curriculum and } \\
\text { textbooks? What is your role in } \\
\text { developing and designing } \\
\text { teaching materials for your class? }\end{array}$ & $\begin{array}{ll}\text { - } & \text { RQ \# 2: Teaching processes } \\
\text { - } & \text { RQ \# 3: Opportunities for } \\
\text { teaching } & \end{array}$ \\
\hline $\begin{array}{l}\text { - How would you describe yourself } \\
\text { as a teacher? What is your } \\
\text { teaching methodology? }\end{array}$ & $\begin{array}{l}\text { - RQ \# 2: Teacher Profile and } \\
\text { processes }\end{array}$ \\
\hline $\begin{array}{l}\text { - Is your teaching style traditional } \\
\text { based with emphasis on rote } \\
\text { memorization or the emphasis is } \\
\text { on problem solving? }\end{array}$ & $\begin{array}{ll}\text { - } & \text { RQ \# 2: Teacher processes } \\
\text { - } & \text { RQ \# 3: Opportunities for } \\
\text { teaching } & \end{array}$ \\
\hline $\begin{array}{l}\text { - What methods of assessment do } \\
\text { you use to assess your students? }\end{array}$ & - RQ \# 2: Process of assessment \\
\hline $\begin{array}{l}\text { - Are you satisfied by the } \\
\text { performance of your students in } \\
\text { class and on tests? }\end{array}$ & - RQ \# 2: Process of learning \\
\hline $\begin{array}{l}\text { - Are you satisfied by your } \\
\text { teaching performance? What can } \\
\text { you improve? }\end{array}$ & - RQ \# 2: Process of teaching \\
\hline - Would you like to study further? & Opportunities \\
\hline
\end{tabular}




\begin{tabular}{|l|l|l|}
\hline & \multicolumn{2}{|l|}{ teacher's learning } \\
\hline$\bullet \begin{array}{l}\text { Would you want to receive more } \\
\text { in-service training? }\end{array}$ & $\begin{array}{l}\text { RQ \# 3: Opportunities for } \\
\text { teacher's learning }\end{array}$ \\
\hline$\bullet \quad \begin{array}{l}\text { Do students pay any fee to attend } \\
\text { this school? Do students get free } \\
\text { textbooks? }\end{array}$ & $\bullet$ RQ \# 2: Budget structures \\
\hline - RQ \# 2: profile of students \\
$\begin{array}{l}\text { How involved are the parents in } \\
\text { their children's education? }\end{array}$ & $\bullet$ RQ \# 2: Management structures \\
\hline How involved is the NGO staff in \\
$\begin{array}{l}\text { school management and teacher } \\
\text { training? }\end{array}$
\end{tabular}




\section{Appendix H: Interview Protocol \#4: Group Interview Questions for the Students}

1. Tell me about your background: education, age, primary language, etc.

2. Describe your school for me. What is it like? Do you like your school? What are your favorite subjects?

3. What do you not like about your school?

4. How do you learn in this school? What do you do all day?

5. What are the hours of the school? How many days of a week you come to school and is the school open all year around?

6. What do you study in this school? What does your teacher teach?

7. Do you study in English or do you study in Urdu? Which language do you prefer?

8. Would you like to study further? Is it important to study further?

9. What would you like to become when you grow up?

10. Do your parents come to your school? What do they do when they come to your school? Do they help you in homework? Do they ask you to study?

11. Do you pay a fee to come to this school? What else do you need in this school? 


\section{Appendix I: Interview Protocol \# 5: Individual Interview Questions for the Students}

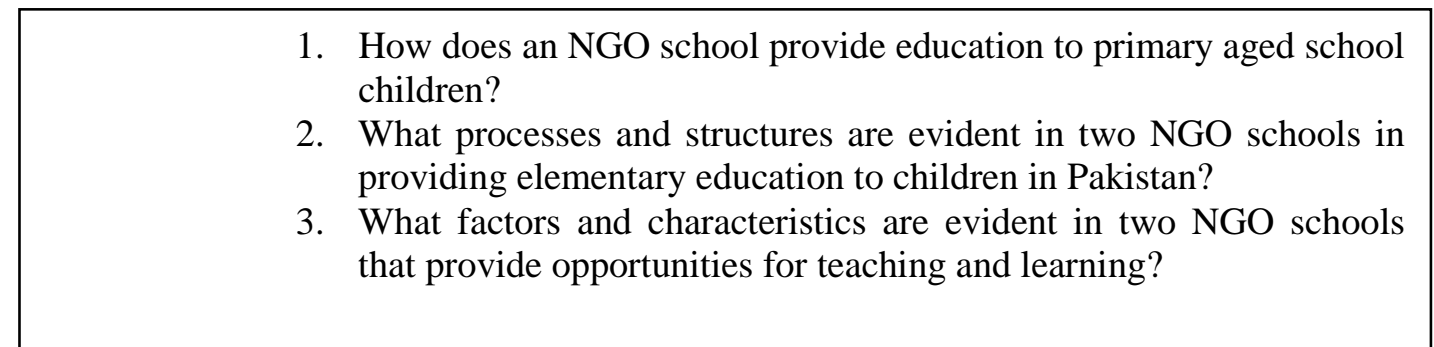

\begin{tabular}{|c|c|}
\hline QUESTIONS & FOCUS OF ANALYSIS \\
\hline 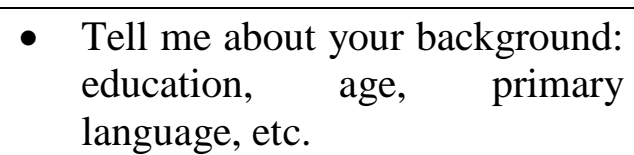 & • $\quad$ RQ \#2 Student profile \\
\hline $\begin{array}{l}\text { Do you live in a cemented } \\
\text { house? Do you have electricity, } \\
\text { t.v. and running water in your } \\
\text { house? }\end{array}$ & - RQ \# 2 Student profile \\
\hline - Do you like your school? & $\begin{array}{llll}\text { - } & \text { RQ \# 3: Opportunities for } \\
& \text { learning }\end{array}$ \\
\hline $\begin{array}{l}\text { - What do you like or dislike } \\
\text { about your school? }\end{array}$ & $\begin{array}{llll}\text { - } & \text { RQ \# 3: Opportunities for } \\
& \text { learning }\end{array}$ \\
\hline $\begin{array}{l}\text { - What are your favorite subjects? } \\
\text { Why? }\end{array}$ & $\begin{array}{llll}\text { RQ \# 3: Opportunities for } \\
\text { learning }\end{array}$ \\
\hline $\begin{array}{l}\text { - What are your least favorite } \\
\text { subjects? Why? }\end{array}$ & $\begin{array}{ll}\text { - } & \text { RQ \# 3: Opportunities for } \\
\text { learning } & \end{array}$ \\
\hline $\begin{array}{l}\text { - Do your parents pay a fee to this } \\
\text { school? }\end{array}$ & • $\quad$ RQ \# 2: Budget structures \\
\hline $\begin{array}{l}\text { - Do you get free textbooks or } \\
\text { other material at the school? }\end{array}$ & $\begin{array}{ll}\text { - } & \text { RQ \# 3: Opportunities for } \\
& \text { learning } \\
\text { - } & \text { RQ \#2: Management processes }\end{array}$ \\
\hline $\begin{array}{l}\text { - Who is your favorite teacher } \\
\text { and why? }\end{array}$ & $\begin{array}{ll}\text { - } & \text { RQ \# 3: Opportunities for } \\
\text { learning }\end{array}$ \\
\hline $\begin{array}{l}\text { - What would you like to do after } \\
\text { finishing fifth grade? Would } \\
\text { you want to study further? }\end{array}$ & $\begin{array}{ll}\text { - } & \text { RQ \# 3: Opportunities for } \\
\text { learning } & \end{array}$ \\
\hline $\begin{array}{l}\text { What would you want to } \\
\text { become after you finish school? }\end{array}$ & $\begin{array}{lll}\text { - } & \text { RQ \# 3: Opportunities for } \\
& \text { learning }\end{array}$ \\
\hline $\begin{array}{l}\text { - Do you need anything in this } \\
\text { school? Do you need teachers, } \\
\text { books, resources, other things? }\end{array}$ & 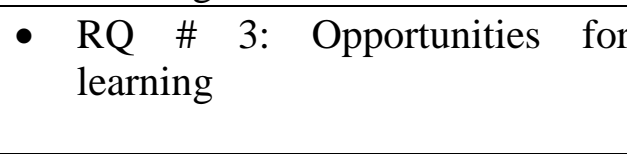 \\
\hline $\begin{array}{l}\text { - What would you do to improve } \\
\text { things in your school? }\end{array}$ & $\begin{array}{ll}\text { RQ \# 3: Opportunities for } \\
\text { learning }\end{array}$ \\
\hline
\end{tabular}




\begin{tabular}{|c|c|}
\hline $\begin{array}{l}\text { - Tell me about tests in your } \\
\text { school? Do you like tests? Do } \\
\text { you do well on tests? Do you } \\
\text { have to memorize for tests in } \\
\text { school? }\end{array}$ & 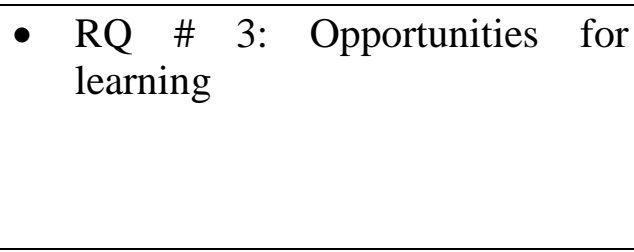 \\
\hline $\begin{array}{l}\text { - Are you satisfied with your } \\
\text { performance in school? }\end{array}$ & $\begin{array}{ll}\text { - } & \text { RQ \# 3: Opportunities for } \\
& \text { learning }\end{array}$ \\
\hline $\begin{array}{l}\text { Do you like to talk, or to do role } \\
\text { play in class? }\end{array}$ & $\begin{array}{ll}\text { - } & \text { RQ \# 3: Opportunities for } \\
& \text { learning }\end{array}$ \\
\hline $\begin{array}{l}\text { - Do your parents come to } \\
\text { school? What do they do when } \\
\text { they come to school? }\end{array}$ & - RQ \# 2: Management structures \\
\hline
\end{tabular}




\section{Appendix J: Classroom Observation Protocol}

\section{Date:}

Time:

School/Class:

Classroom Teacher:

\begin{tabular}{|c|c|c|c|}
\hline $\begin{array}{l}\text { Describe: What did I } \\
\text { see? Sights, scenes }\end{array}$ & $\begin{array}{l}\text { Describe: What did I } \\
\text { hear? Sounds }\end{array}$ & $\begin{array}{l}\text { Comments/ } \\
\text { Reflections }\end{array}$ & Interpretations \\
\hline $\begin{array}{ll}\text { - } & \text { Instructor } \\
& \text { Activities } \\
\text { - } & \text { Instructor } \\
& \text { materials } \\
\text { - } & \text { Classroom } \\
& \text { environment } \\
\text { - } & \text { Content of } \\
& \text { instruction }\end{array}$ & $\begin{array}{ll}\text { - } & \text { Instructor's } \\
\text { Speech: } \\
\text { questions, } \\
\text { directions } \\
\text { - Students' } \\
\text { Speech: } \\
\text { questions, } \\
\text { clarifications } \\
\text { - Student- } \\
\text { Instructor } \\
\text { Interactions } \\
\text { - } \text { Content of } \\
\text { Instruction }\end{array}$ & & \\
\hline
\end{tabular}




\section{Appendix K: Research Log Protocol}

Memo before the visit/observation

- Fifteen minutes of free-write

- Ideas, Impressions, thoughts, pre-conceived notions

Memo after the visit/observation

- Fifteen minutes of free-write

- Focused free write following the format below

Date

Time

School

Office

Place of Observation

Observer

Length of Observation

\begin{tabular}{|l|l|l|l|}
\hline $\begin{array}{l}\text { Describe: } \\
\text { What did I } \\
\text { see? Sights, } \\
\text { scenes }\end{array}$ & $\begin{array}{l}\text { Describe: What did I } \\
\text { hear? Sounds }\end{array}$ & $\begin{array}{l}\text { Comments/ } \\
\text { Reflections }\end{array}$ & Interpretations \\
\hline$\bullet$ & $\bullet$ & & \\
& & & \\
& & & \\
& & & \\
\end{tabular}




\section{Critical Incident Memo}

\begin{tabular}{|l|l|l|l|l|}
\hline $\begin{array}{l}\text { Describe: } \\
\text { What did I } \\
\text { see? Sights, } \\
\text { scenes }\end{array}$ & $\begin{array}{l}\text { Describe: What did } \\
\text { I hear? Sounds }\end{array}$ & $\begin{array}{l}\text { Reponses of } \\
\text { individuals } \\
\text { involved }\end{array}$ & $\begin{array}{l}\text { My } \\
\text { response, } \\
\text { reactions, } \\
\text { feelings }\end{array}$ & $\begin{array}{l}\text { Interpret } \\
\text { ations/ } \\
\text { Analysis }\end{array}$ \\
\hline & & & & \\
& & & & \\
\end{tabular}

